\title{
Reenactment as Event in Contemporary Cinema
}

by

Sylvie Jasen

A thesis submitted to the Faculty of Graduate and Postdoctoral Affairs in partial fulfillment of the requirements for the degree of

Doctor of Philosophy

In

Cultural Mediations

Carleton University

Ottawa, Canada

(C) 2011, Sylvie Jasen 
Library and Archives Canada

Published Heritage

Branch

395 Wellington Street

Ottawa ON K1A ON4

Canada
Bibliothèque et

Archives Canada

Direction du

Patrimoine de l'édition

395 , rue Wellington

Ottawa ON K1A ON4

Canada
Your file Votre référence
ISBN: $978-0-494-83233-2$
Our file Notre référence
ISBN: $978-0-494-83233-2$
NOTICE:

The author has granted a nonexclusive license allowing Library and Archives Canada to reproduce, publish, archive, preserve, conserve, communicate to the public by telecommunication or on the Internet, loan, distribute and sell theses worldwide, for commercial or noncommercial purposes, in microform, paper, electronic and/or any other formats.

The author retains copyright ownership and moral rights in this thesis. Neither the thesis nor substantial extracts from it may be printed or otherwise reproduced without the author's permission.
AVIS:

L'auteur a accordé une licence non exclusive permettant à la Bibliothèque et Archives Canada de reproduire, publier, archiver, sauvegarder, conserver, transmettre au public par télécommunication ou par l'Internet, prêter, distribuer et vendre des thèses partout dans le monde, à des fins commerciales ou autres, sur support microforme, papier, électronique et/ou autres formats.

L'auteur conserve la propriété du droit d'auteur et des droits moraux qui protège cette thèse. $\mathrm{Ni}$ la thèse ni des extraits substantiels de celle-ci ne doivent être imprimés ou autrement reproduits sans son autorisation.
In compliance with the Canadian Privacy Act some supporting forms may have been removed from this thesis.

While these forms may be included in the document page count, their removal does not represent any loss of content from the thesis.
Conformément à la loi canadienne sur la protection de la vie privée, quelques formulaires secondaires ont été enlevés de cette thèse.

Bien que ces formulaires aient inclus dans la pagination, il n'y aura aucun contenu manquant.

\section{Canadä}




\begin{abstract}
This dissertation investigates the use of reenactment in contemporary documentary and narrative films. It is specifically concerned with the meanings and repercussions of reenactment for non-professional performers whose memories, emotions, and subjectivities both inform the film's depiction and are deeply affected by its making. The study argues that reenactment is both an imitative and formative activity that not only takes place on the screen but encompasses the entire filmmaking process. It therefore expands what is understood as reenactment in film beyond the frame to address the ethical and political implications of film production. This is what I call reenactment as an event, a concept developed here through four case studies: Michael Winterbottom's In This World(2002), Peter Watkins' La Commune (Paris 1871) (2000), Igloolik Isuma Productions' The Journals of Knud Rasmussen (2006), and Roger Spottiswoode's Shake Hands with the Devil (2007). Indeed, the reenactment as event is less interested in replicating or even representing the past than in evoking its current traces and ongoing impact. The presence of the past is specifically marked in the body and the performance of the non-professional actors. The amateur is thus a key site of the blurring of temporalities (past and present) and of filmic categories (documentary and fiction). This project therefore shifts away from the original-copy relationship that has preoccupied much of the theorizing of reenactment in cinema. Whereas the original-copy comparison implies a relationship between two separate and complete entities, this study argues that neither the reenactment nor the referent constitutes a clearly defined and delimited object.
\end{abstract}


Both are instead characterized by fluidity and lack of boundaries; just as the past persists in the current memories and gestures of the performers, the reenactment extends beyond the screen and continues after the film's production. Moreover, an examination of reenactment as an event centers on the singularity of the performance as a dynamic process that simultaneously attests to and generates a continuity of tradition in contemporary conditions. 


\section{Acknowledgements}

I am grateful to many people for their support throughout the research and writing of this dissertation. Chris Faulkner has been a patient and committed advisor whose guidance over the years has been invaluable. My committee members, Franny Nudelman and Mark Salber Phillips, also read early drafts of several chapters and contributed suggestions. Their criticisms provided me with direction through the course of writing and helped strengthen the project. I am immensely fortunate for having a committee with insights from a diverse range of expertise.

Thanks are also due to my friends and colleagues in the Film Studies department at Carleton University. Many discussions with Marc Furstenau and Mitsuyo WadaMarciano yielded valuable advice that was greatly appreciated. I especially want to thank Zuzana Pick for her friendship and encouragement over many years and for introducing me to one of the core films in this study, The Courage of the People.

I am also indebted to my friends and family who provided much needed emotional support throughout the process. Without their encouragement this dissertation would not have been completed. My husband Paul has played many critical roles. Paul's unwavering confidence in my work, along with his intellectual acumen, have been constant sources of inspiration. I cannot thank my mom and step-dad enough for their incredible patience and their consistent championship of my scholarly pursuits, which has convinced me to persevere on numerous occasions. Additionally, the weekly meetings of the "thesis group" have been a necessary motivational force on the road to completion. 
Thank you to the group members, Alex Wetmore, Heather McAlpine, Robert Evans, and Janne Cleveland, for our stimulating discussions and for sharing their own challenges and experiences in the journey of writing a dissertation.

Finally, this study was made possible by grants from a number of institutions. The Social Sciences Research Council provided financial assistance for several years, in addition to the Ontario Graduate Scholarship. Equally significant is the funding I received from Carleton University, particularly with the Edward Bower Carty Award. 


\section{Table of Contents}

$\begin{array}{ll}\text { Abstract } & \text { ii }\end{array}$

Acknowledgements $\quad$ iv

Table of Contents $\quad$ vi

Introduction 11

\section{Chapter One}

$\begin{array}{ll}\text { Reenactment as Event } & 28\end{array}$

\section{Chapter Two}

In This World: Fiction as Document and Intervention

\section{Chapter Three}

The Amateur in Reenactment: Experience, Identity, and the Personal in La Commune (Paris 1871)

\section{Chapter Four}

Performing Knowledge: The Making of The Journals of Knud Rasmussen

\section{Chapter Five}

Ethical Imperatives: Reenacting Trauma in Shake Hands with the Devil

Conclusion

Filmography

Bibliography 


\section{INTRODUCTION}

The terms "recreation" and "reenactment" are often used interchangeably to describe cinematic depictions of historical events. While both terms suggest a mimetic performance modeled on a previous moment or situation their conflation obscures a crucial point of divergence. In contrast to the circumscribing notion of a past re-created, reenactment is more open-ended. While recreation implies an ideal of absolute fidelity with the past (or, more accurately, a dominant narrative of the past), reenactment speaks to something processual and contingent, premised on a continuity between the contemporary staging of a cinematic production and the living history it engages, however distant or recent. To understand reenactment in this way is to acknowledge the production process as a formative experience, one underscored by the ethically and politically charged relations of filmmaking. This dynamic is what I term reenactment as an event.

This dissertation is specifically interested in contemporary films that acknowledge their own artifice and construction. If reenactment ordinarily posits an iconic performance that refers to a prior occurrence in place of the indexical immediacy of the event itself, the notion of reenactment as an event proposed here insists instead on the immediacy of the performance. Emphasis is placed less on the signifying operation of reenactment than on the activity of staging as a material and experiential process that generates particular affects, effects, meanings, and consequences for the participants involved. Thus films that signal their own making demonstrate three central features of 
reenactment as an event: (1) the practice is identified as itself historically situated; (2) it is located in and comprises the entire production; and (3) it constitutes an affective engagement with the past for the performers.

The first of these features is demonstrated by films which point to their own temporal duality, that is, their effort to refer to the past while, at the same time, drawing attention to the situatedness of the production in the present. In the documentary Little Dieter Needs to Fly (1998) Werner Herzog returns Vietnam War veteran Dieter Dengler to the exact site in the Laotian jungle where he had been held captive thirty years earlier, asking him to describe the dehumanizing conditions of his ordeal and to reenact his escape. With the assistance of local men who pose as his captors, Dengler demonstrates how he was bound and abused, how he slept, and how he eventually managed to free himself. During the reenactment he remains dressed in contemporary clothing and describes the events in past tense to the camera. Hence, while a performance may imitate actions or follow the trajectory of a prior event, it does not necessarily portray a historical period or replicate the referent with detailed accuracy. In this way, the film's emphasis is not simply on the object of representation but also on the process of representation. This last point is well illustrated by Peter Watkins' La Commune (Paris 1871) (2000), in which the Paris Commune is reenacted with actors in period costume yet in an intentionally artificial-looking setting. The Communards also speak to a camera crew, watch events unfold on television sets, and step out of character to discuss the film's production and the relevance of the Commune to current events and contemporary conditions. Like Little Dieter, then, La Commune avoids the pretense of transporting the 
viewer to the past, as if the prior events could be recreated in the way they originally occurred. Instead, the viewer remains constantly aware of the actors as actors and of the reenactment as a mediating and interpretive activity.

The "eventness" of the reenactment also extends beyond the screen. Not limited to that which takes place in front of the camera, it encompasses the entire filmmaking process (including such things as travel, rehearsal, research, various sorts of training, set construction, costume design, the joys and ordeals of production, and so on). Michael Winterbottom's In This World (2002) illustrates this well. Production of the film, which depicts the journey of two Afghan refugees attempting to reach London, involved traveling the same route commonly taken by asylum seekers in the hands of human smugglers. Although the filmmakers, the crew, and the non-professional actors do not experience the kinds of difficulties and dangers typically faced by the refugees who make this risky trip, the filming process nevertheless follows the typical trajectory, taking place in actual locations, navigating difficult border crossings, and employing local means of transport along the way. In some cases, the off-screen dimension of reenactment can also include the preparatory work of a cast or crew, such as the construction of material culture (costumes, sets, etc.) or an actor's preparation for his or her role, as activities that are modeled on previous occurrences and documented material. While Oliver Stone's Platoon (1986) is a fictional narrative about the Vietnam War, rather than a reenactment, the actors prepared for their roles in an imitation of the physical conditions faced by American soldiers in Vietnam. Tom Berenger explains that Stone put "the actors through an intensive session in the Philippine jungle where [Platoon] was shot, forcing them to 
haul sixty-pound packs and eat [army field rations]." Whereas this "behind the scenes" reenactment is in the service of creating an authentic depiction and adding to the film's realism ${ }^{2}$, in other cases the practice can have a different meaning and purpose. For example, through the reconstruction of artefacts and clothing by indigenous communities for ethnographic representations of a traditional way of life, the reenactment can work to reinforce community ties and local histories that have been ruptured by decades of colonialism. In this context, the film and what takes place on camera become one fragment of a much larger instrumental project. It would, therefore, be a mistake to privilege the film text as a site of meaning; rather, the entire production of the film has significance and consequences for the participants involved. Indeed, it is precisely by attending to reenactment in the present and in the production process that the films examined in this study prioritize the meaning of the reenactment for the performers.

Performance is therefore the third central feature of reenactment as an event. Whereas the terms "recreation" or "reconstruction" can imply a certain immutability the stasis of a museum display, a narrative orthodoxy - the element of performance in reenactment is understood here as a formative operation involving collective subjectivities and historical continuities. This study specifically concentrates on the performances of non-professional actors, as both protagonists in the films and collaborators in their production. Having ordinary people involved in the reenactment of historical events, either as extras or as protagonists, is a common practice and one that can provoke strong emotions on the part of the performers, especially when these actors

\footnotetext{
${ }^{1}$ Tom Berenger quoted in Marita Sturken, Tangled Memories: The Vietnam War, the AIDS epidemic, and the Politics of Remembering (Berkeley: University of California Press, 1997), 97.

${ }^{2}$ See Sturken, Tangled Memories, 97
} 
have a personal connection to the events being depicted. Consider the Russian workers storming the Winter Palace in October (Sergei Eisenstein, 1928); the National Liberation Front members who play themselves in The Battle of Algiers (Gillo Pontecorvo, 1966); the air traffic controllers of United 93 (Paul Greengrass, 2006), at work, made to watch the 9/11 attacks all over again; or the Derry community members in Bloody Sunday (Paul Greengrass, 2002) who reenact the massacre of Irish protestors by British paratroopers. The following chapters examine a broad range of performers' investments in the referent - as witnesses to the actual events, survivors of the depicted trauma, descendants of the historical figures, or representative individuals whose life circumstances are shared with their characters. Here, the role of the amateur is crucial. It points us toward the ethical and political stakes of reenactment, particularly the ways in which performers' emotions, memories, attitudes, and lives inform filmic representations and are, in turn, deeply affected by their involvement in the production.

All three facets of the reenactment as event are evident in John Walker's film Passage (2008). As a documentary on the mapping of the North West Passage, it includes a historical dramatization and demonstrates the process and effects of staging the past. Initially written as a historical narrative feature, Passage transformed into a documentary that combines segments of the original period drama with documentation of its making, including preparations, rehearsals, and discussions among actors and consultants. In this way, the film very effectively illustrates the distinction between reenactment as a dimension of the production process and a staging in the present, on the one hand, and period drama as a narrative depiction of the past, on the other. Moreover, 
by documenting preparation for the dramatizations, Passage both represents historical events and indicates how the past is constructed, contested, and interpreted. Specifically, the film's making initiates cross-cultural encounters that interrogate the ways in which historical truths are constructed by explicitly addressing the power relationships entailed in historical representations, the struggles over the meaning of the past, and their potentially damaging consequences. At the same time, however, the film identifies the conditions of production as potential sites of cultural exchange and dialogue. Cases such as this therefore have significant implications for the study of historical representations in film, revealing reenactment as a distinct pedagogical and ethical practice that involves learning from others and from history.

Passage investigates the controversial circumstances surrounding the disappearance of two British Navy ships, led by Sir John Franklin, on an expedition to locate the North West Passage in 1845 . The film focuses on Dr. John Rae, who was commissioned by the British Navy to continue the search and determine what happened to Franklin's ships and crew after they had been missing in the Arctic for three years. Rae's search was conducted on land with the assistance of a small group of Inuit whose skills for survival in the Northern climate were invaluable to his success at completely mapping the North West Passage (13,000 miles) on foot. From testimonies by local Inuit, Rae learned that the crew from the earlier expedition had been encountered, that they appeared to have gone mad from cold and starvation, and that their recovered corpses showed evidence of cannibalism. Upon his return to Britain, Rae's information about Franklin and his men was rejected by both the Navy and Franklin's widow who, with the help of Charles 
Dickens, launched a campaign against Rae and the Inuit by accusing Rae's Inuit informants of cannibalizing the British Navy's crew. Passage combines a variety of formal strategies, to weave together a web of intersecting storylines, in different locations and periods. The historical material is presented with expositional voice-over narration, along with maps, drawings, photographs, and journal entries that explain the trajectory and details of both voyages, and scripted sequences that dramatize the events with Lady Franklin and Naval officers in nineteenth century Britain. This is juxtaposed with vérité footage that documents the cast in rehearsals, Walker in discussions with the art director on reconstructing the settings, and the actor who plays Rae, Rick Roberts, preparing for his role.

Roberts' preparation comprises much of the first half of the film and it is precisely the actor's own journey, which is modeled on Rae's, rather than his scripted performance in the role of Rae, that constitutes a reenactment. Roberts traces Rae's voyage from his home in the Orkney Islands to the Canadian Arctic and visits the exact locations where Rae was known to have camped during his quest. Like Rae, Roberts composed his own journal entries, which are relayed through voice-over; he also wore a skin parka while traveling through the Arctic, participated in traditional Inuit dances and songs, and learned the skills needed to live off the land, such as building an igloo or identifying edible berries. The scenes in the Orkney Islands and the Arctic are separate from the dramatizations. Instead of representing the past the scenes document Roberts' preparatory research through physical immersion in Rae's environments and activities. This includes the actor being taught to shoot a rifle, but the contrast between his own 
difficulties with the weapon and Rae's skills as a marksman prevents a collapsing of the two men's experiences, or any assumption of equivalence between historical periods. Thus, Roberts' journey is neither an attempt to replicate nor represent Rae's journey. Rather, it acknowledges Rae's voyage as its model while maintaining its own historical specificity in the present. This means that the past exists as a resource from which Roberts can learn, but over which the reenactment can never have mastery. So we see Roberts, in the Arctic, making mistakes as part of this learning process; the Inuit guides poke fun at his lack of survival skills and his poor decision-making. However, the point is not merely to document Roberts' own inexperience, but, more significantly, to make the connection to Rae, the conditions he encountered and his reliance on the Inuit guides for his survival and success.

By including the contemporary context of its historical representation, Passage exhibits what the period dramatizations alone cannot, namely the continuity of the past in the present and the ongoing impact of historical events on contemporary lives. This is poignantly demonstrated through the case of Taqak Curley, a descendant of the Inuit who helped Rae and an advisor on the film's production. Although the Rae/Roberts narrative is the main thread throughout the film, in the second half it is juxtaposed with yet another journey, one taken by Curley on a reverse trajectory from Canada to London, England. In London, Curley observes with amazement the statues built in honour of Franklin and his crew's "discovery" of the North West Passage. He also visits the exact room where a committee of the British Navy planned the 1845 expedition and where he meets Ernest Coleman, a retired naval officer and historian. Undeterred by Curley's challenges, 
Coleman firmly defends what became the official version of the events - that Franklin and his crew discovered the North West Passage and were attacked and "mutilated" by "Natives." When Curley requests an apology for the "shameful and arrogant [labeling]" of his ancestors, Coleman refuses. This heated debate between Coleman and Curley is less a matter of determining the ultimate Truth about the past than it is about redressing a persistent and damaging mischaracterization of the Inuit people. Thus, the film indicates how the construction of official historical truths (or the perpetuation of falsehoods as truths) is implicated in what E. Ann Kaplan refers to as "transgenerational trauma" as it applies to "traumatic contact and residues of past colonial encounters." That the nineteenth century campaign marking the Inuit as savages and cannibals (which included Dickens' advocacy of genocide) has caused enduring emotional harm is made apparent in a speech delivered by Curley at the end of the documentary. During a rehearsal for the dramatization, Curley introduces himself to the entire cast and other participants as one of the "savages" identified by Lady Franklin and Dickens, whose campaign "set out to destroy the reputation of the Inuit race." He refers to their efforts as a "character assassination" that "still impacts my people since no one takes ownership to establish reconciliation." Curley's speech is the most moving moment in the film because it demonstrates the continued relevance and damaging effects of what might otherwise be seen as a temporally remote and insignificant controversy.

The journeys undertaken by Curley and Roberts - the investigations, reconstructions, and confrontations that each entailed - can be understood as

\footnotetext{
${ }^{3}$ E. Ann Kaplan, Trauma Culture: The Politics of Terror and Loss in Media and Literature (New Brunswick, New Jersey, and London: Rutgers University Press, 2005), 115.
} 
interventions in the present through the engendering of "contact zones," or meeting spaces for cross-cultural sharing, learning, and negotiation. ${ }^{4}$ Although Curley's meeting with Coleman does not reenact a previous occurrence, it is predicated on historical events and their depiction. Moreover, it reveals the continuity between those events and the reenactment via the effort to intervene in the continued perpetuation of fallacies about the Inuit (discourses which are put into question through Roberts' reenactment in the Arctic). Both events confront divisions of power with different results; while the confrontation with Coleman reflects existing power relations, Roberts' learning from the Inuit destabilizes them. A third point of contact occurs in the film between Curley and Dickens' great-great grandson, who is present at the rehearsal when Curley gives his speech and offers an apology on behalf of his family. While the film concludes with a teary-eyed embrace between the two men and reciprocal invitations to each other's homes, the apology fails to provide closure, remove wounds or forgive past mistakes. Instead, the historical material presented through the dramatizations and Curley's painfilled speech continue to resonate beyond the apology and haunt the somewhat awkward encounter with Gerald Dickens. Nevertheless, this ending establishes a point of departure by opening the potential for exchange and understanding across cultural boundaries. It is precisely this potential that Rae's experience in the Arctic contained and which Roberts' reenactment of it evokes without actually representing the past or assuming an exact correlation with it. The reenactment, then, does not provide either Roberts or viewers with a comprehensive knowledge of the past, whereby history becomes an object of

\footnotetext{
${ }^{4}$ See Mary Louise Pratt, Imperial Eyes: Travel Writing and Transculturation (London and New York: Routledge, 1992).
} 
knowledge to learn about, but rather presents the historical event as a lesson, or a model, to learn from.

By reenacting a journey across national borders, concentrating on a white Western protagonist who navigates a foreign land, attending to traditional Inuit knowledge, and alternating between the past and the present, Passage contains elements from each of the following case studies: In This World, La Commune, The Journals of Knud Rasmussen (Zacharias Kunuk and Norman Cohn, 2006), and Shake Hands with the Devil (Roger Spottiswoode, 2007). Each of these films is representative of a certain tradition or "type" of reenactment in cinema. As an example of a reenactment of a journey, In This World traces the typical route taken by contemporary asylum seekers through a human smuggling network. La Commune belongs to a militant tradition of using historical reenactment which concentrates on a specific historical event and period to commemorate the political action of marginalized communities. The Journals of Knud Rasmussen both belongs to and is a response to the history of reenactment in ethnographic filmmaking, in which indigenous subjects reenact traditional activities of a particular place and period. And Shake Hands with the Devil provides an example of reenactment in a more conventional docudrama that employs survivors of a recent national trauma to depict the Rwandan genocide. As films that highlight reenactment as an event, these case studies demonstrate certain common features across ethnographic films and mainstream docudramas, representations of the historical and of the topical. However, the specificities of each project provide distinct sites for investigating the divergent uses of reenactment in film, whether as a document (In This World), as a tool 
for activism (La Commune), as a method of knowledge making and cultural renewal (Journals), or as a means of working through personal and collective trauma (Shake Hands).

What is significant to all of the films and especially illuminating for an understanding of reenactment as an event is the way in which the production process is either made visible in the films themselves or made public by documenting the filmmaking through additional material, such as making-of-documentaries, published production diaries, and websites for the films. Each case study is therefore examined in the context of the information made available on the film's production, the genre or tradition to which the film belongs, and other cultural work to which the film is closely related, whether that be the literature on which it is based or the body of work of each of the filmmakers. Rather than regarding the film as an isolated text, such a reading locates the film's making within a larger, ongoing project. The production material in particular indicates the way reenactment possesses an instrumental priority and purpose, as a transformative experience for the amateur performers who belong to the marginalized communities that are represented, including Afghan refugees, Inuit subjects, the Parisian working class, and Rwandan victims of genocide. These subjects' involvement in these films establishes each production as an ethically, politically, and emotionally charged activity that foregrounds the actors' agency and the stakes involved in the representation of their own cultural or national history.

As films that enlist popular participation in the staging of a collective past, examples of reenactment in cinema belong to and share certain features with other 
practices of public history. If historical reenactment can take many forms (including living history museums, pageants, and military training), the term most often evokes images of performers in full period regalia involved in the recreation of specific battles from the Civil War, Vietnam War, First World War, and many others, which may or may not take place for an audience of spectators. Typically, historical reenactments are committed to commemorating defining moments of national histories. Alan Filewood explains that this commemorative function informs the ways in which reenactors seek to recreate the past in its material and visceral immediacy: "Reenactors typically resist the notion of acting, preferring instead to speak of creating 'impressions' that commemorate historical actuality through the production of authenticity, in body, in location, in material culture and in the sensation of experience." Filewood's remark indicates the objective of physical immersion in an environment that reproduces the material conditions of a historical period with respect to clothing, food, accommodations, and paraphernalia. Although historians often express skepticism about the priority given to a sensory experience of the past, historical reenactment is typically regarded as concerned with "history from below," with its attention to the ordinary and everyday lives of historical agents. $^{6}$

In cinema, reenactment is equally used to produce commemorative records of national historic events, such as the Bolshevik Revolution in October, the struggle for independence in The Battle of Algiers, the Northern Ireland Civil Rights Association (NICRA) march in Bloody Sunday, and the Siglo XX miners' strike in Bolivia in The

\footnotetext{
${ }^{5}$ Alan Filewood, "People's Theatre, People's Army: Masculinism, Agitprop, Reenactment," XCP: Crosscultural Poetics 13 (2003): 15.

${ }^{6}$ See Vanessa Agnew, "Introduction: What is Reenactment?" Criticism 46.3 (2004): 327-39.
} 
Courage of the People (Jorge Sanjinés, 1971). These films present a "history from below" less by focusing on quotidian details (although this is the case in In This World, La Commune, and The Journals of Knud Rasmussen) than by employing and depicting ordinary people as a collective hero in the staging of popular uprisings against oppressive governments. Moreover, in many cases a "history from below" can have a deliberate political intent by positing the memories and perspectives of marginalized groups as a counter-document to official accounts of an event, its misrepresentation or its suppression. This is demonstrated in The Battle of Orgreave (Mike Figgis, 2001), which documents the reenactment of a British miners' strike in 1984 that turned violent when police attacked the striking workers. Figgis' documentary examines the way the media reports at the time supported the Thatcher government, especially in an instance where television footage was edited in reverse order to appear as if the miners provoked a cavalry charge by the riot police. Robert Blackson explains how the reenactment, which was organized by the performance artist Jeremy Deller and performed by many ex-miners from Orgreave, sought to counter the media's misrepresentations by privileging the miners' perspective:

Significant to the reenactment is the fact that Deller, in large, relied on memories from both miners and police officers to re-create the battle scene, rather than the copious quantities of biased newspaper articles that initially reported the story. By allowing personal memory to direct the course of the reenactment, rather than the newspaper accounts, Deller's work, The Battle of Orgreave, and the Mike Figgis film that documented the performance were effectively righting old wrongs. ${ }^{7}$

\footnotetext{
${ }^{7}$ Robert Blackson, "Once more...With Feeling: Reenactment in Contemporary Art and Culture," Art Journal 66.1 (2007): 32.
} 
Blackson argues that by employing ex-miners (alongside professional reenactors) The Battle of Orgreave exemplifies how reenactment can provide a means of reclaiming the past and a sense of agency on the part of marginalized communities.

A dependence on personal or collective memories as the foundation for a performance is distinguished from more conventional examples of historical reenactment that maintain an unwavering commitment to authenticity in order to, in Blackson's words, "better reflect an impersonal history." 8 Historical reenactments are usually concerned with reconstructing a historical period with detailed accuracy in both the environment (setting, costumes, props) and the performance (language, social conventions, trajectory of action). Anachronisms are carefully avoided in an effort to establish a complete illusion of inhabiting the past without contamination by the present. Many filmed and televised reenactments similarly aspire to an authentic depiction by filming at the location where the represented event occurred and by reconstructing a mise-en-scène that accurately reproduces the original setting. Some films ensure a fidelity to the original by strictly relying on existing documents, previously recorded footage, or written transcripts. By contrast, alternative approaches like Little Dieter and La Commune embrace anachronisms to invite confusion of temporalities and to explore the relationships between past and present. Both films are more concerned with exhibiting the memories and interpretations of the performers than an adherence to "getting it right". And since both the performances and the filming are improvised in the moment rather than predetermined by a script, the films register a dynamic and

\footnotetext{
${ }^{8}$ Ibid.
} 
contingent engagement between the camera and the performers as opposed to providing an illustration of documented facts.

As film reenactment intersects with historical reenactment in various ways, the practice also has its own specificity within the history of cinema. Contemporary examples are situated within traditions of reenactment in ethnographic films, historical films, docudramas, and documentaries. Across these generic contexts, and regardless of the historical period, reenactment in cinema blurs the boundaries between the categories of documentary and fiction, which has often provoked discomfort and anxiety. From reenactments in early cinema to documentaries and docudramas, hybrid films have been charged with intentionally deceiving audiences, with confusing fact with fiction, with attempting to disguise fiction as fact, or with distorting history. Although examples of deliberate deception by filmmakers using reenactment are rare, reenactment's status as a performance exists in a tension with its potential function as a record or a document. If reenactments that insist on a fidelity to authoritative sources seek to mitigate this tension, those based on the memories of the participants preserve it by identifying the amateur performer as a site of reenactment's duality as artifice and as evidence. On the one hand, the performer partakes in a constructed staging of a referent that is mediated by his or her memory. On the other hand, the memory of the performer testifies to a truth of the historical event that is grounded in personal experience. Thus, the evidentiary authority of the reenactment is here located less in the authenticity of its representation, as in the case of fact-based reconstructions, than in the past's manifestation in and its effect upon the present. 
Although the use of reenactment in film is as old as the medium itself, it has attracted surprisingly little interest from cinema scholars. This neglect has begun to be addressed and corrected with the emergence of a small but growing body of literature, along with conference panels in the last few years and the first issue of a film journal devoted to the topic. ${ }^{9}$ Following theorizations of reenactment in historiography, art history, and theatre studies, the recent impetus for the study of reenactment in film is in part a response to a reemergence of the practice in contemporary cinema, especially documentary. Another contributing factor is the intersection of reenactment with questions of trauma, historical representation, cultural memory, performance, and early (or proto-) cinema, as current areas of interdisciplinary academic research. The existing literature establishes a valuable groundwork for exploring a rich, diverse, and undertheorized area of cinema; but as articles or chapters in larger projects such studies are limited in their attention to individual films, individual filmmakers, or a single generic category. As the first full-length investigation of reenactment, this dissertation addresses a wider range of films across generic boundaries and converges with three broad discursive areas: documentary, docudrama, and representations of history, memory, and trauma.

Perhaps because reenactment has been a standard practice in documentary filmmaking since the production of early newsreels, it has primarily been mentioned in passing within histories of the genre, theories of ethnographic cinema, and discussions of specific films. It is only recently that documentary reenactments have begun to be

\footnotetext{
9 Jonathan Kahana, ed. "Dossier: Reenactment in Contemporary Documentary Film, Video, and Performance," Framework 50.1/2 (2009).
} 
analyzed in some detail with foundational essays by Brian Winston and Bill Nichols. ${ }^{10}$ While Winston concentrates on the use of reenactment during the classical period of documentary and Nichols examines a self-reflexive function in more contemporary films, both authors outline a spectrum of types of reenactment and explore its particular value as a representational technique. Both essays also discuss reenactment as a form of fiction in documentary that poses a potential threat to documentary proper. As a representation of the historical world that constructs rather than captures the profilmic event, reenactment weakens documentary's traditional claims and assumptions of objectivity and authenticity. Attention is therefore placed here on reenactment's meaning for and within the documentary genre. This dissertation includes analyses of a number of documentary films but is not limited in its focus to a single generic category. Instead, it seeks to demonstrate how reenactment as an event operates within a diversity of genres and formal approaches, with similar tendencies and features found in both documentary and narrative films. I specifically consider how questions of intervention, self-reflexivity, process, and the ethics of filmmaking, which typically belong to the sphere of documentary practice, are equally relevant to the staging of prior occurrences in the production of narrative features.

Indeed, the case studies here largely belong to the genre of docudrama either by depicting historical events in a narrative form or by combining the conventions of documentary and fiction. In the literature on docudrama, comprehensive studies of the genre in both British and American contexts posit critical perspectives on the ways in

\footnotetext{
${ }^{10}$ Bill Nichols, "Documentary Reenactment and the Fantasmatic Subject," Critical Inquiry 35 (2008): 72 89, and Brian Winston, "'Honest Straightforward Re-Enactment': The Staging of Reality," in Joris Ivens and the Documentary Context, ed. Kees Bakker (Amsterdam: Amsterdam University Press, 1999), 161-70.
} 
which mainstream traditions in television and cinema appropriate documentary truth claims and authenticate their fictionalized depictions of historical events. ${ }^{11}$ By contrast, a more recent turn to the broader field of hybridity (which includes mockumentaries) has shifted towards a consideration of the potential of generic blurring to challenge the assumptions underlying documentary's privileged access to the historical world. ${ }^{12}$ However, both approaches in the scholarship on cross-generic mixing are characterized by a common focus on films' rhetorical structures and formal conventions. The emphasis on textual strategies is reflected in the development of rigorous terminology to describe the multiplicity of ways the aesthetics, forms, and rhetorical strategies of documentary and fiction are combined: drama-documentary, documentary-drama, docudrama, dramadoc, faction, and mock-documentary. ${ }^{13}$ Within this theoretical lens, and given that docudramas generally involve the staging of the profilmic event, there is little discussion of reenactment as a particular practice in the genre. Nevertheless, a study on reenactment shares concerns with theorizations of docudrama, such as the use of non-professional performers, the ethical implications of a representation, and the privileging of personal experience in the depiction of historical events. However, these concerns are reframed in the context of reenactment from a focus on narrative structures and viewer engagement to the meaning and function of the performance for the participants.

\footnotetext{
${ }^{11}$ Derek Paget, True Stories? Documentary Drama on Radio, Screen, and Stage (Manchester and New York: Manchester University Press, 1990) and Steven N. Lipkin, Real Emotional Logic: Film and Television Docudrama as Persuasive Practice (Carbondale and Edwardsville: Southern Illinois University Press, 2002).

${ }^{12}$ Gary D. Rhodes, and John Parris Springer, eds. Docufictions: Essays on the Intersection of Documentary and Fictional Filmmaking. Jefferson, North Carolina and London: McFarland \& Company, Inc, 2006.

${ }^{13}$ Steven N. Lipkin, Derek Paget, and Jane Roscoe, "Docudrama and Mock-Documentary: Defining Terms, Proposing Canons," in Docufictions: Essays on the Intersection of Documentary and Fictional Filmmaking, eds. Gary D Rhodes, and John Parris Springer (Jefferson, North Carolina, and London: McFarland \& Company, Inc, 2005), 11-26.
} 
While an attention to reenactment is absent in docudrama theory, analyses of its specific function and meaning in narrative cinema have taken place in studies on cultural memory, historical representation, and realist films. Essays by Marita Sturken on Oliver Stone's docudramas, ${ }^{14}$ Aileen Blaney on Bloody Sunday, ${ }^{15}$ and Ivone Margulies on realist practices, ${ }^{16}$ investigate the role of reenactment in the representation of historical, national, or personal trauma. All three authors identify reenactment as a potential means of catharsis, or a working through of trauma by offering interpretations of the original event and reworking previous representations. This function of reenactment is primarily applied to the context of spectatorship with respect to the meanings it generates for viewers. Sturken, who examines reenactment in terms of the repetition and imitation of documentary images, distinguishes the practice in cinema from historical reenactment when she notes that "personal participation in reenactments carries different cultural implications than those moments when national stories are reenacted through Hollywood docudramas." 17 Certainly the viewing of a reenactment is not the same as performing in one, but such "personal participation" is nonetheless significant in films that employ nonprofessional actors in depictions of their own national or cultural histories and has an impact on the meanings of the films for both viewers and performers. How cultural memories and historical traumas are then engaged not only at the level of exhibition but

\footnotetext{
${ }^{14}$ Marita Sturken, "Reenactment, Fantasy, and the Paranoia of History: Oliver Stone's Docudramas," History and Theory 36.4 (1997): 64-79, and "Personal Stories and National Meanings: Memory, Reenactment, and the Image," in The Seductions of Biography, eds. Mary Rhiel, and David Suchoff (New York and London: Routledge, 1996), 31-41.

${ }^{15}$ Aileen Blaney, "Remembering Historical Trauma in Paul Greengrass's Bloody Sunday," History \& Memory 19.2 (2007): 113-38.

${ }^{16}$ Ivone Margulies, "Exemplary Bodies: Reenactment in Love in the City, Sons, and Close-Up," in Rites of Realism: Essays on Corporeal Cinema, ed. Ivone Margulies (Durham: Duke University Press, 2003), 21744.

${ }^{17}$ Sturken, "Reenactment, Fantasy, and the Paranoia of History," 74.
} 
also in production, along with the function of the reenactment for the participants, is in need of consideration.

The discursive contexts and distinct ways in which reenactment in cinema has been discussed are elaborated upon in chapter one. That chapter's review of the existing literature provides an overview of the historical shifts in the uses of reenactment and the range of types of reenactment in film, from examples in early cinema and classical documentary to the spectrum of contemporary uses in both documentary and narrative films. The history of reenactment and the theorizations of the practice are organized according to three recurring and overriding themes: authenticity, self-reflexivity, and interpretation. Each thematic frame investigates a particular relationship that the reenactment establishes with the original event on which it is modeled and to which it refers. Although questions of authenticity, self-reflexivity, and interpretation are relevant to the films in the current study, chapter one demonstrates how a view of reenactment as an event challenges the original-copy comparison that underpins previous analyses of reenactment. The original-copy framework implies a comparison between two separate, static, and distant entities by means of which the reenactment constitutes a discrete object - the complete representation on screen - and the referent is usually a single identifiable event in the past. Emphasis is typically placed on the difference and the distance between the original and the copy, the reenactment and its referent, the past and the present. By contrast, the reenactment as an event is marked by a closeness with the referent such that the past is not so much represented as it is conjured in its current affects and resonances. It is therefore distinguished from a reenactment of an event, which seeks to replicate the 
past, by foregrounding the way in which the physical actions and bodily gestures of the performers make the past present.

Chapter two expands on the definition of reenactment as a formative activity as opposed to a facsimile. It specifically concentrates on how the production process is made visible on-screen and constitutes an intervention in the historical world. Intervention here refers less to the filmmaker's construction or staging of the profilmic event, which applies to all documentary reenactments, than to the repercussions that the process of the reenactment and the film's entire production can have for the participants involved. The consequences of the reenactment can range from the unscripted emotional responses that a performance provokes, or the acquisition of new knowledge by imitating an activity, to the transformation of a performer's life circumstances. This chapter draws on Fredric Jameson's notion of production as an event in documentaries that belong to a postmodern period of cinema. In these documentaries the film's making is actively involved in the film's object, which is both captured by the camera and purposely transformed through the process of filming. The camera is therefore acknowledged as a participant in the events that unfold on-screen. This is also the case in a reenactment as an event, which is characterized by a dynamic, contingent, and intersubjective encounter between the camera and the performers. As an example, I concentrate on Michael Winterbottom's In This World, a fiction film that employs documentary aesthetics and methods in a reenactment of transnational migration. The film's similarity with documentary, however, cannot be reduced to its form or conventions alone but more significantly applies to the production as an intervention in the world by making apparent 
the camera's presence and the way the filming has a transformative impact on the life circumstances of the Afghan refugee actor.

Since the effects and affects of the film's making on the performer are a defining feature of reenactment in this study, chapter three investigates the implications of using amateur actors. It specifically argues against reading the use of amateurs as merely a device to authenticate the narrative by highlighting the individual and collective stakes of the performers in the representation, the production, the historical events and their legacy. The reenactment of the Paris Commune in La Commune (Paris 1871) provides a central example, as a production that involved 220 residents of Paris whose social position as workers, immigrants, or activists corresponded to the characters they play. Rather than extras, these amateur actors were hired as collaborative participants and their improvised performances collectively author the film. The project was conceived by Peter Watkins, whose career-long commitment to engaging ordinary people in media production and the representation of their own history offers valuable insights into the meaning of the amateur in reenactments that have application well beyond Watkins' own work. As an improvised and actor-driven performance, the reenactment in La Commune is identified as a personal and experiential engagement with the past and its representation for the performers. Many conventional docudramas and historical films are critiqued for their reduction of the political to personal experience by individualizing historical events through character driven narratives that encourage viewers' emotional identification with the characters over critical perspectives. The personal and experiential dimensions of reenactment, however, apply not to the narrative structure but to the amateur actors' 
engagement with the historical material, as their own emotions, attitudes, and convictions inform the performance, which in La Commune takes on a political meaning.

While both In This World and La Commune reveal the act of filming and the performances as interrelated and reciprocal processes, chapter three examines the broader sphere of filmmaking by attending to what takes place off-screen, prior to the filming, as equally a site of reenactment. It therefore broadens the scope of what is considered reenactment in film to include the making of material culture in the construction of the mise-en-scène, the costumes, sets, and props. This is illustrated with the production of The Journals of Knud Rasmussen (Zacharias Kunuk and Norman Cohn, 2006), a narrative feature that recounts the Danish explorer's meeting with an Igloolik shaman while on an expedition in the Arctic during a period of transition in Inuit communities from Shamanism to Christianity. Journals was made in Igloolik, Nunavut, with the participation of local Inuit residents as actors and crew, for whom the project of reenacting a traditional way of life in and for the film served a pedagogical function. The documentation of the film's production available on the production company's website indicates how a variety of activities involved in the making of the film constitute a reenactment, activities that perform traditional skills based on models, including artefacts, ethnographic photographs, and oral history. By borrowing the definition of performance from performance studies theory, this chapter posits reenactment as a way of knowing and transmitting knowledge, which here applies to the production of Journals as a project committed to passing on traditional Inuit skills from community elders to the younger generations. This use of reenactment to establish continuity between past and 
present is at once situated within and distinguished from a tradition of the practice in ethnographic cinema.

All of the films in these chapters concern the ethics of filmmaking with amateur performers, are made in cross-cultural production contexts, and involve the reenactment of traumatic events. Chapter five therefore explicitly investigates the intersection of these elements in the narrative feature Shake Hands with the Devil (Roger Spottiswoode, 2007), a film that recounts Lieutenant General Roméo Dallaire's experiences as the head of the United Nations peacekeeping mission in Rwanda during the country's 1994 genocide. The Canadian production was filmed in Rwanda and employed Rwandan locals as actors to perform in the roles of militia killers and genocide victims. Thus, the production of Shake Hands raises questions about the ethics of reenactment with respect to the representation of another's national history and the use of genocide survivors to reenact the performers' traumatic past. By concentrating on the film's making and on the documentation of its production process, this chapter shifts the concern with ethics in docudrama from a focus on a film's responsibility towards the viewer to the filmmaker's responsibility towards the performers. An attention to reenactment as an intervention, the meaning of the performance for the amateur, and the entire sphere of filmmaking, inform the analysis of Shake Hands as a production that becomes a site of emotional pain and a reliving of the past for the Rwandan actors.

Taken together, these chapters examine the implications of reenactment as a formative performance within the process of a film's making. The cases collected here are drawn from widely differing cultural contexts and conditions of production, yet they 
share with each other what could be called a generative ethic. That is, in each case, the reenactment is meant to contribute to the perpetuation or activation of that which is reenacted. The documentary filmmaker Joris Ivens points to this generative potential of reenactment in a discussion of his 1933 film Borinage, in which a reenactment of a miners' protest that took place several weeks prior transformed into an actual protest:

While they marched up the steep village street with some comrades behind them, the people came out of their homes and they, the miners of Wasmes, their women and children, without even noticing the camera, spontaneously took part in the demonstration a second time and followed behind the portrait of Marx leading the way...The scene which had been especially repeated just for the film, developed into a real scene, a real demonstration, because of the pre-existing tense political situation in Borinage. ${ }^{18}$

Thus, the imitation of a prior event gives way to the creation of a new event initiated by the film's production. As a combination of reenactment and spontaneous creation, the filmed demonstration does not repeat the initial demonstration but in fact builds on the earlier experience in new conditions, with its own specificity. In this way, the performance renews the values, the ideological convictions, and the sense of collective agency that gave rise to the original. Sven Lütticken has noted a similar ethic behind the reenactments of the storming of the Winter Palace. Beginning almost immediately after the first occurred, they were intended as a means of continuing the revolution during the Civil War that followed by "activating the masses and giving history a forward impulse." ${ }^{19}$ This dissertation concerns the ways in which reenactments generate a futuredriven momentum. As such, it seeks to demonstrate how reenactment in film is not only

\footnotetext{
18 Joris Ivens, "Repeated and Organized Scenes in Documentary Film (1953)," in Joris Ivens and the Documentary Context, ed. Kees Bakker (Amsterdam: Amsterdam University Press, 1999), 263.

${ }^{19}$ Sven Lütticken, "An Arena in Which to Reenact," in Life, Once More: Forms of Reenactment in Contemporary Art, ed. Sven Lütticken (Rotterdam: Witte de With, Centre for Contemporary Art, 2005 ), 55.
} 
a means of representing events in the historical world; it is also, and more significantly, an event that intervenes in the historical world. 


\section{CHAPTER ONE}

\section{Reenactment as Event}

In his introduction to a dossier on reenactment in a recent issue of Framework Jonathan Kahana speaks of a renewal of reenactment in cinema, which is "confirmed when one considers the ubiquity and variety of reenactment, in the broadest sense of the term, in moving-image work made and shown on television, in theaters, and in galleries today." 20 Kahana's observation of a resurgence not only suggests that the practice is currently common and widespread but it also implies a history in which contemporary uses are situated and which they recall. Reenactment has been a part of filmmaking since the birth of the medium. It initially comprised a distinct and popular genre in early cinema that reconstructed familiar news stories, then diversified as a method for representing contemporary and historical events across generic categories within both documentary and fiction films. Reenactment has been and continues to be employed for a range of purposes, including as an illustrative, self-reflexive, pedagogical or historiographical strategy within a diversity of formal contexts. In their multiplicity, current practices belong to traditions that they borrow from, respond to, and dialogue with.

Whereas the practice is not new to cinema, it is a rather recent object of study, with scholarly interest gradually emerging on the heels of reenactment's revival. Although the existing literature, which consists of individual essays or chapters in broader studies, is grounded in different fields of inquiry and generic contexts (such as documentary,

\footnotetext{
${ }^{20}$ Jonathan Kahana, "Introduction: What Now? Presenting Reenactment," Framework 50.1/2 (2009): 47.
} 
docudrama, realist film, early cinema, and historical representation), it exhibits shared theoretical concerns. This chapter discusses three prevalent themes in the study of reenactment: questions of authenticity, fidelity and truth; self-reflexive and anti-realist uses; and the function of reenactment in repeating traumatic pasts. The first encompasses the anxiety surrounding reenactments within newsreels and documentaries along with the arguments that have responded to charges of reenactment's deception and its threat to documentary proper. The second shifts to the view of this threat as a positive and productive challenge to documentary realism within documentary filmmaking and in other contemporary forms of hybrid cinema that combine documentary and fiction conventions. The third frame concentrates less on the troubling relationship of reenactment to the documentary genre than on examples within narrative cinema, including realist films and docudramas, with a particular focus on the reenactment of personal and national traumas. Emphasis is placed on how the repetition of a traumatic past initiates mourning or provides moral lessons for viewers by reworking and assigning meaning to the original event.

This dissertation is also concerned with the ways in which reenactments in cinema engage contemporary and historical traumas, though with a focus on films that prioritize the meaning and function of the reenactment for the performers, whose identities, memories, and collective histories inform the representations. Although the primary case studies are relatively recent films, they are defined not only by their contemporaneity or similar subject matter but also, and more importantly, by their employment of ordinary people in the production and their attention to the filmmaking process as a dynamic and 
contingent engagement between the performer, the filmmaker/camera, and the referent. This chapter therefore proposes a conceptualization of reenactment as an event, which points to the limits of understanding cinematic reenactment as a mere facsimile by placing emphasis on the formative dimension of the performance. By attending to the conditions of production and its ramifications for the participants, the notion of reenactment as an event reframes questions of authenticity, self-reflexivity, and function from the viewers' reading of a film to the performers' affective investment in a film's making. The primary examples in this chapter are two films completely different from one another in terms of form and genre: The Courage of the People (Jorge Sanjinés, 1971), which is a narrative that incorporates documentary elements, and Shoah (Claude Lanzmann, 1985), an interview-based documentary. Yet, as politically driven projects that identify the memories and histories of the participants as essential to reenactment's formative potential and commemorative purpose, both belong to the body of work examined in the following chapters. The centrality of performance and process in both also indicates the way in which reenactment, specifically understood as an event, is not tied to a particular form or genre but operates across a diverse body of films, including documentaries and docudramas.

\section{The Question of Authenticity}

The dramatization and staging of events from the historical world typically inspire questions regarding a representation's authenticity, which has historically been an aspiration (and claim) of such films, a source of their appeal for audiences, and a point of 
controversy for critics. When viewing a docudrama, for instance, one is almost instinctively compelled to ask "how accurate is this portrayal?" or "is it true?" The question is one of fidelity of the depiction to the events it depicts. Jerry Keuhl, a staunch critic of the docudrama, argues that the films can never accurately reproduce the actions and dialogue as they actually occurred and therefore always constitute "lies about real people." ${ }^{21}$ With respect to the documentary reenactment, the primary criticism has been focused less on the issue of accuracy than on its legitimacy as a documentary practice. ${ }^{22}$ Documentary reenactments have been open to charges of deception, fraud, and manipulation, as trying to pass off a depiction as an objective and valid record when it is not. Regardless of how common a practice reenactment is within the documentary genre, it has continually generated anxiety among producers, disturbed critics, and raised skepticism among viewers. ${ }^{23}$ Scholarly work has in turn addressed how such films authenticate their representations in order to make truth claims, generate belief, or confirm a place within the documentary genre.

Studies on reenactment in early cinema have noted the objective of realism in many staged actualities and newsreels, whether through location shooting, special effects, or subdued performances. ${ }^{24}$ These films, although occasionally depicting historical

\footnotetext{
${ }^{21}$ Jerry Keuhl, "Lies About Real People," in Why Docudrama? Fact-Fiction on Film and Televison, ed. Alan Rosenthal (Carbondale and Edwardsville: Southern Illinois University Press, 1999), 119-124.

${ }^{22}$ In his seminal study of the documentary genre and its distinction from fiction film, Representing Reality, Bill Nichols writes that because "the special indexical bond between the image and historical referent is ruptured" the use of reenactment in documentary "run[s] some risk of credibility". Bill Nichols, Representing Reality: Issues and Concepts in Documentary (Bloomington: Indiana University Press, 1991), 21.

${ }^{23}$ Brian Winston discusses some recent controversies regarding the use of reenactment in documentary in his book Lies, Damn Lies and Documentaries (London: BFI Publishing, 2000).

${ }^{24}$ See in particular Charles Musser, Before the Nickelodeon: Edwin S. Porter and the Edison Manufacturing Company (Berkeley: University of California Press, 1991) and Charles Musser, "The Early
} 
material, are largely characterized by their reconstruction of topical events, often based on newspaper reports, especially battles from current wars (Spanish-American War and Boer War), executions, natural disasters, the apprehension of criminals, and prizefights. David Levy identifies the earliest surviving example as an Edison studio production of 1897 that depicts an ambulance rushing to save a victim of a train accident. By 1903, what Levy calls the "reconstituted newsreel" was an established practice in the United States, in which all the major American production companies participated. ${ }^{25}$ In his analysis of battle reenactments, Levy examines the genre's appropriation of newsreel aesthetics, specifically pointing to the use of location shooting, spatial depth, and movement towards the camera as strategies by which producers sought to make their "fake" newsreels appear as authentic as possible. It is precisely this imitation of the newsreel aesthetic itself that Raymond Fielding sees as an intended deceit on the part of reenacted news films. In his study of the American newsreel, Fielding devotes a chapter to reconstructions (titled "Faking the Early News Film") where he distinguishes between four general types of "fake news films": ${ }^{26}$ theatrically staged famous events, realistically staged events, rough recreations of actual events, and the manufacture of unverifiable events. According to Fielding, only the first category is not intended for deception since

Cinema of Edwin Porter" in Cinema 1900/1906: An Analytical Study, ed. Roger Holman (Brussels: Fédèration Internationale des Archives du Film, 1982), 261-280.

${ }^{25}$ Reenacted newsreels were not limited to the United States, with European and British companies and filmmakers also producing such films. In Britain the films were identified as "dramatic representations of actual events". David Levy, "Re-constituted Newsreels, Re-enactments and the American Narrative Film." In Cinema 1900/1906: An Analytical Study, ed. Roger Holman. (Brussels: Fédèration Internationale des Archives du Film, 1982), 243-260.

${ }^{26}$ Raymond Fielding, The American Newsreel: A Complete History, 1911-1967, $2^{\text {nd }}$ Ed. (Jefferson, North Carolina and London: McFarland \& Company Inc., 2006), 5. 
it is the most theatrical, while the other three were meant to pass as news films and therefore constitute a form of fiction in the guise of documentary and journalism.

There is little evidence, however, to suggest that either producers or audiences were concerned with such distinctions between categories and practices or that deception adequately describes the intention and reception of these films. As Miriam Hansen writes,

Imposing the later distinction between documentary and fictional genres upon primitive diversity...is problematic in several respects. Many actualities involved reconstructions - such as the notorious examples of Spanish-American War films shot on a New York rooftop or bathtub recreations of naval battles - yet not necessarily with the intent to deceive; as a subgenre, dramatic reenactments of current events were considered legitimate. Though occasional complaints were heard early on, the standard of authenticity by which all such films would be rejected as "fake pictures" evolved with the classical paradigm and became one of the war cries in the campaign against primitive modes. ${ }^{27}$

Rather than deceiving audiences, reenacted actualities were situated within a broader culture of similar popular entertainments, including panoramas, ${ }^{28}$ wax museums,${ }^{29}$ and live reenactments, ${ }^{30}$ which viewers were already familiar with and from which the films' conventions were borrowed. Kristen Whissel, for example, demonstrates how battle reenactments in early cinema were influenced by "Buffalo Bill's Wild West" show, a traveling live reenactment from 1883 to 1913 that dramatized scenes of the western frontier, including a reenactment of Custer's Last Stand. Whissel argues that "the live re-enactment prepared consumers of urban commercialized leisure for their encounter

\footnotetext{
${ }^{27}$ Miriam Hansen, Babel and Babylon: Spectatorship in American Silent Film (Cambridge, Mass. and London: Harvard University Press, 1991), 31.

${ }^{28}$ Allison Griffiths, "'Shivers down your spine': panoramas and the origins of the cinematic reenactment," Screen 44.1 (2003): 1-37.

${ }^{29}$ Vanessa Toulmin, "An early crime film rediscovered: Mitchell and Kenyon's Arrest of Goudie (1901)," Film History 16 (2004): 37-53.

${ }^{30}$ Live reenactments included Passion Plays, pageants, and exhibitions at World's Fairs that recreated natural disasters.
} 
with re-enactment films and established this early film genre's peculiar authenticity."31 The "reality-effects" produced by the battle reenactments, and borrowed from the "Wild West" tour, involved placing the spectator in the position of a soldier on the battlefield, with enemy forces often rushing towards the camera or firing at the audience. Not only were film reenactments often marked as such, but the fact that this camera perspective and the clarity with which the battles were rendered were both impossible to achieve on an actual battlefield made the film's status as a reenactment apparent. Like its predecessors, ${ }^{32}$ the films sought not to fool viewers but rather to impress them with the effectiveness of the illusion, such that "the pleasures provided by the battle re-enactment lay precisely in its artificiality.",33

Early cinema reenactments, in turn, influenced the aesthetic conventions of both actualities and fiction films. Whissel posits that war actualities, rather than inspiring the battle reenactment, instead aspired to the ideals of battle filming and the standards of realism that the reenactment established. Similarly, as Levy demonstrates, many of the aesthetic features of early narrative films (including editing, multiple angles, depth composition, and camera movement) were initially developed in the reenacted newsreel. Levy adds that while the production of reconstructed newsreels virtually ended in $1907,{ }^{34}$

\footnotetext{
${ }^{31}$ Kristen Whissel, "Placing the Spectator on the Scene of History: the battle re-enactment at the turn of the century, from Buffalo Bill's Wild West to the Early Cinema," Historical Journal of Film, Radio and Television 22.3 (2002): 226.

${ }^{32}$ Allison Griffiths makes a similar point in her analysis of panorama reenactments. See Griffiths, "“Shivers down your spine"”.

${ }^{33}$ Whissel, "Placing the Spectator on the Scene of History," 239.

${ }^{34}$ Two major changes contributed to the demise of the reenacted actuality: longer story films quickly replaced actualities as the dominant form of cinema entertainment and lighter cameras extended filmmakers' mobility and flexibility for recording news events.
} 
the practice did not disappear but "was absorbed into... longer story films". ${ }^{35}$ Hence, a number of the early story films often cited as foundational in the development of narrative cinema and its conventions, such as D.W. Griffith's The Lonely Villa (1909) and Edwin S. Porter's The Great Train Robbery (1903) and Life of an American Fireman (1902), have been identified by scholars as reenactments or docudramas. ${ }^{36}$

Reenactment also continued to be used occasionally in the production of newsreels ${ }^{37}$ and was a standard practice during the early period of documentary, though not as a subgenre defined by topical subject matter but as a conventional method of filmmaking, employed for representing the personal, historical, and typical. From the 1920 s to 1950 s, the staging of activities and events was not only a common practice but also a necessary one as a result of technological constraints; since large and heavy equipment that required lengthy preparation (especially for synchronized sound) prevented capturing events as they happened and filming in certain locations, filmmakers frequently asked subjects to repeat actions or perform typical activities. ${ }^{38}$ In addition,

\footnotetext{
${ }^{35}$ Levy, "Re-constituted Newsreels," 255.

${ }^{36}$ Charles Musser notes that The Great Train Robbery was advertised as a reenactment since it is based on stories of actual hold-ups, though not necessarily a single event. And, like Levy, Musser argues that with the film, along with Life of an American Fireman, Porter extended the realist techniques from his earlier reenacted news films, Execution of Czolgosz with Panorama of Auburn Prison (1901) and Capture of the Biddle Brothers (1902), by combining exterior scenes with studio drama, presenting a detailed "step-bystep" account of events, and filming on-location material as if it was "a news event over which he had no control." Charles Musser, Before the Nickelodeon, 259. John Parris Springer also discusses both of Porter's story films as representative of the hybrid foundation of narrative cinema. See John Parris Springer, "The Newspaper Meets The Dime Novel: Docudrama in Early Cinema" in Docufictions: Essay on the Intersection of Documentary and Fictional Filmmaking, ed. Gary D. Rhodes and John Parris Springer (Jefferson, North Carolina, and London: McFarland \& Company Inc., 2005), 27-42. ${ }^{37}$ Fielding notes for example that a great deal of WWI footage involved reenactment. See The American Newsreel.

${ }^{38}$ In the GPO unit film Night Mail (Basil Wright and Harry Watt, 1936), for example, certain scenes taking place on the train were filmed in a studio with British postal workers performing everyday tasks. These scenes also included synchronized sound, which, as Brian Winston explains, demanded extensive preparation and therefore reenactment: "Although silent footage could be shot on smaller cameras, feature film sound equipment cemented, as it were, feature film techniques in place for the documentary.
} 
filmmakers and subjects reconstructed events that occurred weeks or months previously, such as a protest by miners in Joris Ivens' Borinage (1933), or they used reenactment to depict a more distant past, as in Robert Flaherty's Nanook of the North (1922). Along with staging scenes and constructing action to fit a predetermined storyline, Flaherty had his Inuit actors perform traditional activities using methods no longer practiced. In his films Moana (1926) and Man of Aran (1934) he continued to revive traditional practices long abandoned by the communities he filmed (tattooing in Samoa and shark hunting in the Aran Islands, respectively), which became an established approach in ethnographic cinema. Literature on the history of non-fiction film lists numerous other examples that employ full or partial reenactments to represent a general past or specific historical events during the early history of the genre. ${ }^{39}$ This period of documentary, then, is as fundamentally hybrid as early narrative film.

The rise of Direct Cinema and other observational approaches in the 1960s, however, along with the cultural and technological changes of which they were a part, not only reduced the necessity of reenactment in documentary but also questioned its acceptability as a representational method. New lightweight cameras and portable sound equipment eliminated the need for staging as filmmakers could record spontaneous action and sound without lengthy preparation. These technological shifts were accompanied by a prescriptive and anti-authoritarian rhetoric on the part of Direct Cinema filmmakers,

Documentary synch sound scenes required scripts, rehearsals, multiple takes - just as their fictional equivalents did." Brian Winston, "'Honest, Straightforward Re-enactment': The Staging of Reality," in Joris Ivens and the Documentary Context, ed. Kees Bakker (Amsterdam: Amsterdam University Press, 1999), 165.

${ }^{39}$ See Richard Meran Barsam, Nonfiction Film: A Critical History (Bloomington: Indiana University Press, 1992). 
whose call for an "uncontrolled cinema" of non-intervention rejected previous documentary techniques and conventions in favour of capturing "life as it happens." 40 Truth was to be located in spontaneous and candid moments rather than staged actions. Previously common techniques such as voice-over and reenactment were therefore deemed highly manipulative and authoritative. While many of the methods Direct Cinema repudiated are once again standard documentary practice, reenactment still remains a highly contentious and questionable method. ${ }^{41}$

In his essay "Repeated and Organized Scenes in Documentary" Joris Ivens discusses the use of reenactment in his own films, Borinage and The Spanish Earth (1937), to challenge the assumption that non-staged documentaries are more authentic. He points out the regularity with which documentary filmmakers have their subjects perform or reenact specific actions for the camera:

If persons opposed to re-enacted scenes consider the fact truthfully that everything must be filmed just as it is, just as it happens, then our films would show people constantly staring into the camera, because that is what really happens when you photograph people and that would be the truth, at least according to our opponents. So can we say that re-enactment starts with the interference of the director or cameraman into the 'natural' behaviour of people by insisting that they 'do not look into the camera'. [sic] But it is well known that in most documentary films the director goes further than this basic intrusion, he insists that actions be repeated, he organizes new circumstances or situations, especially in films where the personal element is an important aspect of the film. ${ }^{42}$

Ivens further provides various reasons for reenactment in documentary filmmaking: "the original action was stiffly or incorrectly executed, or the cameraman for some technical

\footnotetext{
${ }^{40}$ For a discussion of Direct Cinema's rhetoric see Paul Arthur, "Jargons of Authenticity (Three American Moments)," in Theorizing Documentary, ed. Michael Renov (New York: Routledge, 1993), 108-134.

${ }^{41}$ See Winston, Lies, Damn Lies, and Documentaries.

${ }^{42}$ Joris Ivens, "Repeated and Organized Scenes in Documentary (1953)"in Joris Ivens and the

Documentary Context, ed. Kees Bakker (Amsterdam: Amsterdam University Press, 1999), 265.
} 
reason did not capture the action the first time, or the light was unfavourable, or an additional close-up had to be shot, etc., etc." ${ }^{43}$ These statements indicate that all documentary production involves some level of intervention on the part of the filmmaker in the profilmic event, including the use of staging and reenactment, which should be regarded as part of the normal procedures of documentary filmmaking rather than its anomalies. Hence, as Brian Winston has pointed out, with the influence of Direct Cinema these techniques were not so much eliminated as concealed. ${ }^{44}$

A critic of Direct Cinema and its legacy, Winston is the first documentary theorist to address reenactment in some detail and defend its use. In his essay, "'Honest, Straightforward Re-enactment': The Staging of Reality," Winston considers "reconstruction as a documentary technique" and argues that although reenactment is a fictionalization it does not deprive a film of documentary value. ${ }^{45}$ While the title of the essay refers to a quote by Ivens about Borinage, Winston discusses Humphrey Jennings' Fires Were Started (1943), a fully reenacted film about the volunteer-based fire brigade's response to the London Blitz. Jennings' film belongs to what Winston calls "the classical period of re-enactment, the first decades of sound documentary from the mid-1930s to the late 1950s." It was during this period that "reconstruction became embedded in documentary practice. ${ }^{, 46}$ He identifies different types of reenactment along a continuum of filmmaking from non-intervention to full intervention in the profilmic event - a range that begins with Direct Cinema's ideal and ends with fiction film. Within this spectrum

\footnotetext{
${ }^{43}$ Ibid., 263.

${ }^{44}$ Winston, "“Honest, Straightforward Re-enactment': The Staging of Reality," 161.

${ }^{45}$ Ibid., 163.

${ }^{46}$ Ibid, 164.
} 
there are levels of reconstruction, including reenactments of witnessed events, of history, of the typical, and of the possible, with the latter approaching complete fiction. Winston locates examples of the typical and the possible in Jennings' film, which, although using actual fire brigade members, constructs fictional characters, includes events that could have taken place but did not, and uses inexact locations: "The creative treatment of actuality on display here is so overwhelmingly creative that it would be easy to dismiss any lingering actuality as being of no significance whatever. But that is exactly what I do not want to do."47

Instead, Winston compares Fires Were Started with a fiction film on the same topic and made in the same year, The Bells Go Down, in order to determine what makes Jennings' version a documentary and not a docudrama like the latter. Despite the fictionalizations within Fires Were Started, Winston identifies significant differences: Jennings' film contains a single plot line, lacks narrative complexity and attention to characters" internal lives and personal histories, and attends instead to the "trivial facts" of firefighting, such as equipment and specialized terminology. The singular and simplified storyline refers to the typical structure of documentaries while the attention to details and interactions indicates the strengths of documentary modes of representation compared to fiction films. Thus, while Jennings reenacts the typical and the possible his film does not fall into a completely fictional mode but maintains documentary structure and conventions. Winston locates the "documentary essence" of Fires in its "detail, public sphere interaction of subjects, and plot simplicity, as much as [in] the authenticity

\footnotetext{
${ }^{47}$ Ibid, 166.
} 
of the documentary actor, his or her actions, and the locations." ${ }^{, 48}$ On the distinction of

the film from its fictional counterpart, then, he writes:

My point here is that the differences between actors and firemen, studio sets and real locations alone are not enough to distinguish the documentary element. It is the context of authenticity, if you will, provided by Jennings at the level of language and in the picture of a complex organization which finally makes the difference. $^{49}$

Documentary and documentary reenactment are therefore defined, and differentiated from fiction, less by how a film is made - whether it uses scripts, sets, actors or not than by how the material is represented.

Indeed, docudramas often use actual locations and ordinary people in their productions, but they are typically characterized by the presentation of historical events within established formal and generic conventions of narrative cinema or television drama. In his study of the documentary drama tradition in Britain, ${ }^{50}$ Derek Paget demonstrates how, despite the genre's often controversial mixing of documentary and fiction aesthetics, it has ultimately depended upon social realist conventions that limit and contain potential meanings. He argues that the social realist approach tends to reduce

\footnotetext{
${ }^{48}$ Ibid, 169.

${ }^{49} \mathrm{Ibid}$

${ }^{50}$ The terms documentary drama and docudrama are used to identify distinct British and American traditions and formal approaches. In contrast to American docudramas, which are usually indistinguishable from fiction films and have a commercial entertainment purpose, the British documentary drama (or dramadoc) has historically combined fiction with documentary conventions and aesthetics and has employed a journalistic approach associated with the public service tradition of British television. In recent decades, however, the British genre has increasingly come to resemble the American version, whether because of a growing number of co-productions or a desire to reduce the controversy and censorship of films that supposedly results from their generic hybridity. For further description of the generic distinctions between the American and British docudrama traditions see Derek Paget, True Stories? Documentary Drama on Radio, Screen, and Stage (Manchester and New York: Manchester University Press, 1990) and Richard Kilborn, “"Drama over Lockerbie' A New Look at Television DramaDocumentaries," Historical Journal of Film, Radio, and Television 14.1 (1994): 59-77. For a discussion of the controversies generated by the British documentary drama's mixing of documentary and fiction conventions see Julian Petley, "Fact Plus Fiction Equals Friction," Media, Culture, and Society 18.11
} (1996): 11-25. 
historical events to personalized stories, thereby preventing a conceptualization of political problems beyond individual experience. ${ }^{51}$ While Paget does point to some alternative traditions, particularly in theatre with Brechtian and Piscatorian influences, his analysis concentrates on the ways in which potentially challenging and problematic material is tamed through conventional representational structures. Similarly, Steven Lipkin's major study of the American docudrama examines how the genre employs standard conventions to give all "true stories" similar meanings within the form of melodrama. ${ }^{52}$ Lipkin thus focuses on structure and how documentary material, stories about real people and events, are shaped by familiar narrative formats established by classical Hollywood cinema. Such shaping by commercial television and by dominant narrative conventions has been a central critique of docudrama and its distortion of history. $^{53}$

According to Lipkin, the potential for controversy and charges of distortion can be minimized depending on how effectively a docudrama warrants its depiction and thereby convinces viewers of the worth of the film and its fidelity to the original events. He identifies three types of warrants: modeling characters and locations on the original, sequencing actual footage with constructed material to make the latter blend with the former, and interaction of fictional constructions with actual people and places. ${ }^{54}$ These warrants seek to establish a film's authenticity, the resemblance of actors and settings to

\footnotetext{
${ }^{51}$ Paget, True Stories?

${ }^{52}$ Steven Lipkin, Real Emotional Logic: Film and Television Docudrama as Persuasive Practice (Carbondale and Edwardsville: Southern Illinois University Press, 2002).

53 See Eric Breitmart, "From the Panorama to the Docudrama: Notes on the Visualization of History" Radical History Review 25 (1981): 115-25. Lipkin, however, argues against this kind of criticism.

${ }^{54}$ Lipkin, Real Emotional Logic, 23-26.
} 
the people and places they represent, and the overall accuracy with which the events are reconstructed. Like Lipkin, Paget also mentions the incorporation of documents, the use of ordinary people, and references to the experience of the actors and filmmakers as means by which docudramas are often authenticated. ${ }^{55}$ Both authors identify these as strategies by which docudrama films and filmmakers make claims to the authenticity, the truth, or the fidelity of their representations. They particularly include the use of documents, actual locations, and ordinary people as the most common tactics employed in the largely mainstream film and television work under analysis. By examining these elements in Jorge Sanjinés' The Courage of the People, a Third Cinema film produced under clandestine circumstances, I suggest that what are typically seen as authenticating devices can take on a political and ethical meaning.

The Courage of the People presents a reenactment of the massacre of miners by the Bolivian Army that took place on June 24, 1964, in the largely indigenous mining community of Siglo XX. The attack was to prevent a meeting of the national miners union, which was increasingly supportive of the guerilla movement led by Che Guevera. The film is composed of several episodes that depict a series of events leading up to the climactic scene of the attack - the government's withholding of supplies to the community, miners' wives organizing a hunger strike in protest, a miner being tortured, and students joining the workers' struggle - in which many of the actors play themselves. Documentary segments divide the episodes by introducing a participant who relays his or her personal story through voice-over, grounding the dramatizations in lived experience and collective memory. A roaming, handheld camera records both the documentary and

${ }^{55}$ Paget, True Stories? 
the acted scenes not as an objective gaze but as a participant, establishing the film's point of view as that of the miners. Additional documentary material is included at the beginning of the film with a sequence of photographs of previous attacks on miners and their aftermath in various other communities. Titles identify the place, the number of wounded and dead, and the names of high-ranking officials responsible, along with their photos. These photographs do not simply authenticate the acted scenes but rather provide a context for decades of conflict and oppression and expose those who are to blame.

Like the photographic documents, the dramatizations have an equally evidentiary role, as performances based on the memories of the actors and the testimonies of the residents of Siglo XX who witnessed the event a few years previously. By involving witnesses and survivors of the massacre, the reenactment places personal experience and memory in opposition to the official record:

Faced with the wave of dictatorships that overtook Bolivia and other Latin American countries in the 1960s and '70s, and the ensuing clamp-down in the mainstream media, Sanjinés came to envision the cinema as the last repository of memory, charged with the crucial mission of refuting official truths and breaking the silence that has enabled dominant groups to (re)write history in order to further their own interests.... Sanjinés approached Courage of the People as both a historical reconstruction and a testimonial to popular resilience; the film was shot in the actual places where the events of 1967 occurred and the dialogs were drawn from the protagonists' memories or were based on their personal reflections. ${ }^{56}$

Although, as Winston argues, the use of actual locations and ordinary people does not in itself provide a reenactment with documentary value, in Courage it is the filming in Siglo $\mathrm{XX}$ with the local indigenous residents that nevertheless serves a documenting function. During the film's closing sequence, in which the people and camera wander among the

\footnotetext{
${ }^{56}$ Gerard Dapena, "The politics of popular memory: Jorge Sanjinés' The Courage of the People," CiberLetras 13 (2005), accessed November 7, 2010, http://www.lehman.cuny.edu/ciberletras/v13/dapena.htm
} 
gravestones of the murdered miners, a voice-over announces: "The bloodstains on the houses are wiped out. The crosses along the roads are taken away. The orphans of the dead were scattered all over the country so that everyone should forget this great genocide. But the events of the Night of San Juan still live in the minds of the survivors." As witnesses and survivors, whose memories inform the performances, the actors and their performances testify to a historical reality in the face of its erasure by the Bolivian government. The film's use of miners and residents, however, is more than an authenticating device; rather, it has a commemorative function with a political resonance by allowing a marginalized people to express their own memories in their own language.

The accuracy of the representation, the degree to which it approximates its referent, the original event, is less significant than the performance itself as an expression of a community and its collective memory. That the reenactment was filmed in the actual location, performed by the residents, and based on their experiences certainly establishes the film's authenticity. This authenticity, however, is not only a matter of aesthetics, of "getting it right" for the cameras, but also of ethics, of telling the story from the community's perspective. Sanjinés asserts that the participation of the people of Siglo $\mathrm{XX}$ was a crucial part of the film's production since the performers' own history and future are at stake: "By eliminating the hierarchical structure of a priori filmmaking, where everything is planned by the filmmakers in advance, we took steps toward permitting genuine popular participation in the creative process of a film dealing with the 
history and destiny of the miners with whom we were working." ${ }^{257}$ It is precisely as the community's collective voice that the film asserts a truth, which is grounded in the site and subjects of a reenactment that serves as testimony to an event against the suppression of its history and memory by authorities.

\section{Reenactment as a Self-reflexive Strategy}

Some more recent studies on generic hybridity in both documentary and docudrama have shifted away from examining how films persuade viewers of the truth of a depiction to how filmmakers instead draw attention to a film's textuality, as opposed to its authenticity. The threat that reenactment then poses to a documentary's claim to representing reality is here not challenged (as in Winston's argument) but rather attributed with a positive value, as a deliberate strategy used to question whether documentaries can provide objective records of events by highlighting the fundamentally constructed nature of documentary representations. These types of practices especially are situated within contemporary contexts, that of the return of reenactment to documentary and the postmodern turn to generic mixing. Although reenactments are often labeled as such and have a history of drawing attention to their own artifice, it is only recently, and in response to the influence of observational approaches like Direct Cinema, that reenactment has been taken up with the intent to undermine documentary realism.

\footnotetext{
${ }^{57}$ Jorge Sanjinés, "Revolutionary Cinema: The Bolivian Experience" in Cinema and Social Change in Latin America: Conversations with Filmmakers, ed. Julianne Burton (Austin: University of Texas Press, 1986), 42.
} 
Currently, reenactment is a common and widespread practice in both cinema and television, found in a variety of media contexts, including news reports, current affairs programming, reality television, commercials, docudramas and documentaries. In most cases, especially on television, reenactments - often labeled as dramatizations - are partial segments combined with interviews and documentary footage in order to illustrate information provided orally. This illustrative function is used in Touching the Void (Kevin MacDonald, 2003), a documentary that alternates between talking head interviews and reenactments to recount an almost fatal climb up the Siula Grande Mountain in Peru. In other documentaries, however, such reenactments have a deliberately self-reflexive intention, as in the work of Errol Morris and Jill Godmilow. In The Thin Blue Line (1988) Morris reconstructs the shooting of a police officer multiple times according to different accounts provided by interviewees; each depiction of the event is attached to conflicting claims about what happened by different witnesses and reports, with none being privileged as the ultimate truth. Such reconstructions are one of a number of techniques Morris uses to draw awareness to his own presence as author and the film as construct. That documentaries are authored texts is also made explicit in Far From Poland (1984), a documentary about the Polish Solidarity Movement that Godmilow made in New York since she was denied a visa to film in Poland. The film combines archival, television and second-hand footage of the event, along with reenactments of interviews from published transcripts performed by local stage actors, to emphasize the difficulty of understanding world events at a distance and the layers of mediation involved in their representation. As a self-reflexive device in both films, reenactments 
are used to exploit the limits of documentary representation by drawing attention to the films' inability to capture events in their making.

By attending to the reemergence of reenactment in documentary films, Bill Nichols moves beyond questions of authenticity and truth to discuss the ways in which reenactments affirm the constructedness of documentary representations. Within his psychoanalytic approach to the theorization of reenactment, Nichols defines this representational method as constituting a "fantasmatic" dimension in documentaries that expresses desire for, loss of, and distance from the original. As "clearly $a$ view rather than the view from which the past yields up its truth....[r]eenactments belong to a situated fantasmatic that nullifies the status of that other fantasmatic of objectivity, omniscience, and finality that haunts the documentary film and its kindred discourses of sobriety." $" 58$ Whereas the indexical relation between the image and its object underpins claims to documentary objectivity, the distance between a reenactment and its referent makes apparent the speaking subject: "The indexical bond, which can guarantee evidentiary status...no longer joins the reenactment to that for which it stands...It is, in fact, not historical evidence but an artistic interpretation, always offered from a distinct perspective and carrying, embedded within it, further evidence of the voice of the fillmmaker." ${ }^{59}$ Nichols also identifies two ways in which reenactment's affective engagement is heightened to persuade viewers of the film's evidentiary status, realist dramatizations and typifications, with early documentary reenactments being representative of the latter category. These types are then distinguished from three more

\footnotetext{
${ }^{58}$ Bill Nichols, "Documentary Reenactment and the Fantasmatic Subject" in Critical Inquiry 35 (2008): 80.

${ }^{59}$ lbid., 88.
} 
self-reflexive (and contemporary) uses that, by contrast, highlight their textual status:

Brechtian distanciation (e.g. Far From Poland), stylization (e.g. The Thin Blue Line), and parody/irony.

The rise of such self-reflexive, parodic, and critical modes of generic hybridity is addressed in Docufictions: Essays on the Intersection of Documentary and Fictional Filmmaking. The editors of the collection note that although the mixing of documentary and fiction is certainly not new but a part of cinema's foundation, it is particularly pervasive in the current "postmodern" moment, during which audiences have become quite familiar with such hybridization.

[G]iven the prevalence of such hybrid forms in contemporary media culture - the increasing tendency to foreground such syntheses as a self-conscious aesthetic strategy - we are proposing a new term, docufictions, as a way of naming an insufficiently analyzed tendency in film practice that has produced an increasingly large and varied canon of texts. ${ }^{60}$

The new term includes docudramas along with mockumentaries; while the latter are more "subversive" in their particular combination of documentary and fiction, both types of films raise formal concerns surrounding the very nature of media representations of historical and contemporary events. ${ }^{61}$ The essays in Docufictions demonstrate a shift in the study of docudrama from critiques of the genre's dominant conventions and interests to a consideration of the potential of hybrid practices to foreground and interrogate the conventions of documentary. This current literature is situated within and reflects a kind

\footnotetext{
${ }^{60}$ Gary D. Rhodes and John Parris Springer, "Introduction" in Docufictions: Essays on the Intersection of Documentary and Fictional Filmmaking, ed. Gary D. Rhodes and John Parris Springer (Jefferson, North Carolina, and London: McFarland \& Company, Inc., 2006), 5.

${ }^{61}$ Steven N. Lipkin, Derek Paget, and Jane Roscoe, "Docudrama and Mock-Documentary: Defining Terms, Proposing Canons," 14.
} 
of "post-documentary" 62 moment in which emphasis is placed on deconstructing documentary codes and claims. Value is here given to the analysts' and spectators' distance, detachment, and critical or ironic engagement with the texts and their subject matter.

As Nichols points out, however, reenactments are often employed in documentaries for their affective force. He writes: "As pathos or logos, reenactments enhance or amplify affective engagement... They resurrect a sense of a previous moment that is now seen through a fold that incorporates the embodied perspective of the filmmaker and the emotional investment of the viewer." ${ }^{\circ 3}$ The emotional impact is further intensified when the representation of a historical trauma is bound to the emotions, experiences, and memories of those depicting it. In describing the scene of the massacre at Siglo XX in Courage, Gerard Dapena remarks that the film's "powerful effect is... heightened by the knowledge that many of the performers were survivors or witnesses of the carnage and willingly relived the tragic events in a cinematic re-presentation of trauma - screaming, tearing their hair and pummeling their chest, falling to the ground covered in blood, carrying wounded to safety." the performer in both the original event and its reenactment is a crucial dimension of the film, which, as discussed above, carries its own kind of evidence. If the film functions as a document through an iconic performance rather than indexical image, the participation

\footnotetext{
${ }^{62}$ I use the term "post-documentary" differently than John Corner in his essay "Performing the Real: Documentary Diversions" Television New Media 3.3 (2002): 255-269. For Corner, the term describes the way traditional values of documentary filmmaking are undermined by the dominance of reality-based entertainment programming exemplified by the explosion of reality television.

${ }^{63}$ Nichols, "Documentary Reenactment and the Fantasmatic Subject," 88.

${ }^{64}$ Gerard Dapena, "The politics of popular memory: Jorge Sanjinés' The Courage of the People," CiberLetras 13 (2005), accessed November 7, 2010, $\mathrm{http}: / / \mathrm{www}$. lehman.cuny.edu/ciberletras/v13/dapena.htm
} 
of the people involved in the original event reintroduces the index, drawing attention to the documentary potential of the theatrical rather than the theatricality of documentary.

Courage partly resembles the kinds of films Ivone Margulies discusses in her attention to reenactment within realist practices. By concentrating on examples typically identified as fiction films with a neorealist aesthetic and influence ${ }^{65}$ that use nonprofessional performers to reenact events from their own lives, Margulies notes that "reenactment radically refocuses the issue of indexicality." displaces the indexical with an iconic performance, and, on the other, recovers the index with an attention to the singularity of places, faces, and bodies. While others have also emphasized the realist aims of film reconstructions, particularly in the way in which early sham films copied newsreel aesthetics, for Margulies realism is not only grounded in the aesthetic features of the films but also in the content and subject matter, specifically in the "affinity of realism for social issues." ${ }^{\circ 7}$ Hence, militant reenactments like Courage embody a documentary urgency with realist aesthetics and critical perspectives.

Margulies therefore stresses the value of Fredric Jameson's notion of oppositional realism, which "refers to films and film movements that present at the same time the selfreferentiality of modernist art and the epistemological retrieval of a marginal reality."68 As examples of such work, reenactments can open the potential for a recovery and

\footnotetext{
${ }^{65}$ See Julianne Burton, "The Camera as Gun: Two Decades of Culture and Resistance in Latin America," Latin American Perspectives 5.1 (1978): 49-76, and Erich Keel, "From Militant Cinema to Neo-Realism: The Example of Pueblo Chico," Film Quarterly 29.4 (1976): 17-24. Both Burton and Keel refer to the influence of Italian Neorealism on the work of Jorge Sanjinés.

${ }^{66}$ Ivone Margulies, "Exemplary Bodies: Reenactment in Love in the City, Sons, and Close-Up," in Rites of Realism: Essays on Corporeal Cinema, ed. Ivone Margulies (Durham: Duke University Press, 2003), 220.

${ }^{67}$ Ivone Margulies, "Bodies Too Much," in Rites of Realism: Essays on Corporeal Cinema, ed. Ivone Margulies (Durham: Duke University Press, 2003), 14.

${ }^{68}$ Ibid., 11.
} 
rethinking of realism through a renewed attention to the profilmic event in their centering of both performance and indexicality as non-mutually exclusive terms.

\section{Repetition as Interpretation}

While theorizations of the use and meaning of documentary reenactments have begun to correct scholarly neglect of the practice within the genre, some consideration has also been given to reenactment in narrative cinema, including Margulies' look at realist films and Marita Sturken's reading of Oliver Stone's docudramas as historical representation. These studies, however, do not belong to the field of scholarship on docudrama but are instead situated within broader projects on the renewal of cinematic realism and on the production of cultural memory, respectively. Despite their different objects and frames of analysis, both theorists address the function of reenactment within narratives on national or personal trauma. The degree to which the representations are faithful reproductions or the question of their legitimacy is less a concern than the ways in which the repetition of a prior image or event promotes the working through of traumatic pasts by transforming and giving meaning to the original.

Sturken examines $J F K(1991)$ as a film that has been heavily criticized for blurring fact and fiction by incorporating and mimicking documentary footage alongside fictional constructions. She argues that what is disturbing for critics but valuable as a historical film is how Stone's mixing of categories and techniques demonstrates the fantasy of history, by reflecting and performing cultural memory:

One could argue...that in mixing fact, fiction, documentary, and reenactment, Stone is producing dramatic texts of memory, which exemplify in compelling ways 
its unstable nature. Memories are constantly rescripted, reenacted, and retold. Perhaps Stone's work is best seen as an active scripting of memory texts, which in turn have the power to affect our memories, rather than as work that subscribes to the traditional codes of historical narrative. Indeed, the reenactment of docudramas reveals the traffic between the realms of cultural memory and history, and indicates the fluid realm of memory itself. ${ }^{69}$

In Sturken's reading of $J F K$, she concentrates on the film as a reenactment not of the historical events but of prior images, specifically the Zapruder footage of Kennedy's assassination, parts of which are included in the film and others mimicked. This is a familiar practice in Stone's docudramas, where he imitates iconic images from photojournalism, television, and documentaries through performance, framing and miseen-scène. According to Sturken, such a reworking of prior and particularly traumatic images causes the spectator to relive the shock and pain of experiencing the original. It has a similar effect to the replaying of footage of catastrophic events, such as the Challenger explosion, which was repeated on television screens frequently following the disaster. Whether as the replaying of documentary footage of traumatic events on television or the imitation of such images in docudramas, reenactment constitutes "the primary mimetic form, the cathartic means by which the nation relives its traumas and difficulties."70

In both cases, the repetition is a kind of reenactment in which new meanings are produced by means of new contexts. Indeed, the reenactment of the image gives the original event its meaning. It seeks to provide an explanation for and an understanding of

\footnotetext{
${ }^{69}$ Marita Sturken, "Reenactment, Fantasy, and the Paranoia of History: Oliver Stone's Docudramas," History and Theory 36.4 (1997): 76.

${ }^{70}$ Marita Sturken, "Personal Stories and National Meanings: Memory, Reenactment, and the Image" in The Seductions of Biography, ed. Mary Rhiel and David Suchoff (New York and London: Routledge, 1996), 32.
} 
the event that the footage itself lacks, in order to transform shock and uncertainty into knowledge and mourning. In $J F K$ the Zapruder images are incorporated and reenacted during the opening sequence with rapid editing techniques that reproduce the confusion and shock of the original event. In the course of the District Attorney Jim Garrison's investigation, a number of subsequent reenactments of the footage concentrate on particular details or are viewed in light of new information. The investigation itself involves repeated reconstructions of the assassination to determine the trajectory of the bullets, the number of shooters, and so on, which Garrison presents in court as evidence of conspiracy. Just as the reenactment of the Zapruder footage is used to explain Garrison's theory, disasters like the Challenger explosion are repeated endlessly in the hopes of reaching an understanding of the event. The interpretations and explanatory narratives that accompany the reenactments, Sturken argues, initiate catharsis and mourning in ways that the initial shock of the original images cannot: "It is the reenactment, the replaying, the fantasizing of the story that allows the mourning process to proceed and the event to acquire meaning." reenactment contributes to the national narrative and cultural memory of the event, and even replaces the original image along with its previous reenactments. For later generations especially, it is as a reenactment, and especially within the popular form of the Hollywood docudrama, that the iconic images are initially encountered and that form the memory and knowledge of the event.

In "Exemplary Bodies: Reenactment in Love in the City, Sons, and Close-Up" Margulies also examines the transformative dimension of reenactments, in which the

\footnotetext{
${ }^{71}$ lbid., 37.
} 
reworking of the original serves a pedagogical purpose. Margulies specifically concentrates on films where subjects reenact their personal or familial traumas, such as a young woman's suicide attempt or a family's distress in dealing with their alcoholic father. By making the private public, these narratives provide moral lessons contained in reenactment's processes of imitation and transformation. Repeating past events "creates, performatively speaking, another body, place, and time...that can recall the original event (through a second-degree indexicality) but in so doing can also re-form it.",72

Reenactment offers the subjects a second chance, whereby doing something again involves doing it over, as a correction and revision of the past. Emphasis is therefore placed on both repetition and change: "the very act of repetition becomes relevant, not because it copies the original situation, providing its best and closest illustration, but because by repeating it produces an improved version of the event." ${ }^{, 73}$ As in Sturken's analysis, reenactment is characterized by the repetition of an original event and a difference from it, which creates new meanings for either the spectator or subject reliving the event. The practice is therefore simultaneously imitative and generative, since the act of imitation generates, and contains within itself, an interpretation of the original. It is through its interpretation or reworking of the past that a reenactment acquires its pedagogical or cathartic function.

For both theorists, moreover, the fact that what is represented is repeated (in another time, place, and context) is central to the meaning and the function of a reenactment. Although I agree that reenactment's status as a reenactment, and not just

\footnotetext{
${ }^{72}$ Margulies, "Exemplary Bodies,” 220.

${ }^{73}$ Ibid.
} 
what is reenacted, is significant to the cultural work it performs, my study does not conflate the practice with repetition. Repetition may be a dimension of reenactments to the extent that subjects reenact events from their own lives or repeat certain actions for the camera, but it is not a defining feature. In Peter Watkins' La Commune, Paris 1871 (2000) (discussed in detail in chapter three), in which residents of Paris reenact the Paris Commune, the performers do not repeat their own prior experiences but rather develop scenes and dialogue based on extensive research combined with their own perspectives on the events. Nor does the film claim to recreate the events of the Paris Commune as they occurred since it alerts viewers to the presence of the cameras and production crew, along with the artificiality of the set, as elements which contribute to the reenactment's singularity and specificity. Whether subjects reenact events from their own lives (as in Courage) or a more distant historical event (as in La Commune), reenactment is understood here as a performance modeled on a prior occurrence - either remote or recent, specific (a documented event) or general (a common activity) - that is mediated by personal memory, cultural memory, and other representations. While the films examined may vary as to what precisely is reenacted, such as a typical process, a traditional practice, a historical event, or a subject's previous experience, they all share an acknowledgement of the filmmaking and thereby address the filming and the performance as an integrated whole in its materiality, its specificity, and as a collective creative activity.

In Courage, the film's own making is referred to in part by the participatory camera employed throughout, but also more directly by framing the historical material in terms 
of the performers' agency and the stakes in its depiction. An opening title indicates that the reconstructions are performed by the residents of Siglo XX and are based on the memories of the miners and witnesses involved in the 1964 massacre. While this statement can be read as an authenticating gesture, since it refers to the reenactment as grounded in "historical fact", it also, and more significantly, points to the production as a collaborative project. The ending of the film, which mirrors and reverses the opening, further signals that this project has a generative function for the participants. In contrast to the reenactment immediately following the opening title, of a 1942 incident in which the Bolivian Army fired upon a group of workers and their families protesting the government's violence towards miners, the closing images return to the same site, this time with the crowd of performers confidently marching and chanting "victory to the people's struggle." A voice-over, which speaks of the "Night of San Juan still [living] in the minds of the survivors," identifies this final performance as taking place in the present. By shifting from a historical representation to the present, and from loss to survival, the film demonstrates its own commitment to the continuation of the workers' movement by renewing the values embedded in the struggle it depicts, as a function of both the text (the film as document of the past) and its production (the reenactment as a performance in the present).

\section{Reenactment as Event}

By addressing the conditions and implications of its production, Courage frames the representation of the past in terms of its continuity within the present, which situates the 
film within what I call reenactment as an event, as opposed to the reenactment of an event. The latter refers to a reconstruction of the past or an illustration of oral testimony that depicts a clearly delimited historical occurrence and places emphasis on what is represented as an object of knowledge. On the other hand, a reenactment as an event is concerned with the act of staging itself and its affect upon the performer; it gives priority to the process of performance in the present. My focus on films that privilege the process of reenactment shifts attention away from the original-copy comparison that has been a consistent preoccupation within the various theorizations of reenactment in cinema, whether in terms of its accuracy or authenticity in representing the original, its expression of a desire for an original, or its interpretation of the original. In the films discussed in this study there is no "original" in the sense of a single demarcated instance that is repeated or emulated; although the films may reference specific historical occurrences, the performances are based on a composite of witness accounts and typical activities of a place and period. Nor is the referent a discrete, static, and distant object. By privileging personal and cultural memories as source material over transcripts and authoritative records, the reenactments seek to demonstrate how the past informs, continues in, and affects the present rather than reconstructs an objective entity fixed in the past. This does not suggest that the historical referents are completely fictitious or imaginary. On the contrary, these films insist on the ethical function of reenactment as that which attests to cultural traditions and historical traumas to counter efforts of erasure. However, this is achieved less by signifying a previous moment, as something that can be known and 
recreated as it happened, than by evoking its current traces and its enduring affective impact.

The distinction between reenactment as an event and reenactment of an event rests in part on different ways of conceptualizing and ascribing meaning to the historical referent. The reenactment as event reflects what Hayden White identifies as twentieth century trauma's resistance to fixity and objectification: "the meanings of these events, for the groups most immediately affected by or fixated upon them, remain ambiguous and their consignment to "the past' difficult to effectuate."74 With attention to the Holocaust as a limit case, White argues that the extreme scale of such historical traumas and their affects on subjects transforms the very concept of an event and its potential for representation. The "holocaustal" event, as he calls it, is incomprehensible and therefore defies attempts at explanation within the traditional categories and linear narratives that strive to confer a single authoritative meaning. Consequently, "the historical event, traditionally conceived as an event which was not only observable but also observed, is by definition an event that is no longer observable, and hence cannot serve as an object of knowledge." $" 75$ If the concept of event grounded in a realist historiography has been fundamentally undermined and is no longer viable, it nevertheless persists within the range of historiographical practices that can be described as reenactments of events, including various living history museums, heritage sites, and live or filmed

\footnotetext{
${ }^{74}$ Hayden White, "the modernist event," in The Persistence of History: Cinema, Television and the Modern Event, ed. Vivian Sobchack (New York and London: Routledge, 1996), 20.

${ }^{75}$ Ibid., 22.
} 
reenactments. $^{76}$ By attempting to achieve a high level of accuracy, depending exclusively on facts, and carefully avoiding anachronisms, a reenactment of an event reconstructs the past under the assumption that it can be made observable and knowable.

\section{An example of a reenactment of an event is Heinz Schirk's Hitler's Final}

Solution: The Wannsee Conference (1984). The film, made for West German television, recreates the January 20, 1942 meeting at which Nazi officials and bureaucrats determined the plans for implementing the Final Solution. The conference is depicted in real time, with the film running the exact duration of the meeting, 85 minutes from the arrival of the guests to their departure. The dialogue follows the detailed minutes taken at the meeting, along with additional archival material, which is spoken by the actors verbatim. Costumes and props were authentically reproduced in precise detail, and the reconstruction was filmed in the house outside Berlin where the original conference was held. Despite the fact that the conference proceedings themselves are rather dull, reviews have described The Wannsee Conference as a haunting and compelling film. Certainly the film's portrayal of the banality with which a mass extermination was planned is disturbing, but what seems to make the film especially haunting is its attempt to imitate the original as accurately as possible and our awareness that the statements made in the film - the racist jokes and cold calculations of human lives - are not inventions but (practically) direct quotes. The degree of accuracy sought by the film further gives the

\footnotetext{
${ }^{76}$ In a study of the "reality effect" produced at the Plimoth Plantation, Scott Magelssen discusses the museum's effort at reconstructing a "complete past", without gaps or inconsistencies in its representation of living history. Scott Magelssen, "Living History Museums and the Construction of The Real Through Performance," Theatre Survey 45:1 (2004): 61-74. Richard Handler and Eric Gable's ethnography of Colonial Williamsburg similarly critiques the site's adherence to "mimetic realism" or "just the facts" as a means to avoid controversial aspects of history. Richard Handler and Eric Gable, The New History in an Old Museum: Creating the Past at Colonial Williamsburg (Durham and London: Duke University Press, 1997).
} 
impression that we can know how the event actually occurred. The knowledge and meaning of the historical event, indeed the event itself, is equivalent to all of the available facts, the setting, the artifacts, and the minutes, which the film assembles into a complete and objective whole. By contrast, in films that foreground the reenactment as an event, the historical referent is marked by ambiguity and incompleteness. In Shoah, for example, which also employs reenactment to uncover the history of the Final Solution, the use of reenactment speaks to the limitations and inadequacy of the facts.

\section{Linda Williams discusses Shoah along with Morris' The Thin Blue Line as} examples of postmodern documentaries that use staging and reenactment, among other fictional techniques, to at once retrieve a past and acknowledge its fundamental inaccessibility. Despite the films' divergent subject matter - about the wrong man being convicted for a murder in The Thin Blue Line and about the mass extermination of Jews during the Holocaust in Shoah - they use similar strategies to address the problem of representing history and historical truths. Both films operate in the interactive mode that resembles cinema vérité by openly and deliberately staging interview scenarios, with the filmmaker's presence and intervention in the scene made known to the viewer. The interview is employed as a central technique to provoke memories, often resulting in conflicting and unreliable claims made by subjects who are not privileged informants. The interviews are accompanied by reenactments that either illustrate or elicit subjects' memories, which fail to coalesce into a single coherent and complete account of how the events occurred. This does not, however, promote collapsing either the historical events or the documentaries themselves into fiction: 
Truth is "not guaranteed" and cannot be transparently reflected by a mirror with a memory, yet some kinds of partial and contingent truths are nevertheless the always receding goal of documentary tradition. Instead of careening between idealistic faith in documentary truth and cynical recourse to fiction, we do better to define documentary not as an essence of truth but as a set of strategies designed to choose from among a horizon of relative and contingent truths. ${ }^{77}$

As Williams contends, Lanzmann and Morris are less interested in representing the truth of an event than in using staging techniques, including interviews and reenactments, to expose how a multiplicity of truths, memories, and meanings is constructed.

In The Thin Blue Line Morris intercuts interview segments with reconstructions of the scene of the crime that had taken place ten years previously involving a police officer being shot at close range on the side of a road. With expressive lighting, saturated colour, and a mise-en-scène inspired by film noir, these scenes illustrate claims made by different interviewees, including lawyers, police officers, witnesses, and Randal Adams, the man convicted for the crime. The reconstruction is repeated numerous times with each repetition drawing attention to a particular detail or adding a new piece of information. Reenactments of Adams' interrogation by police are also included, usually with close-ups attending to such details as an ashtray filling up with cigarettes or the signing of a document, without dialogue apart from Adams' voice-over describing his memory of the experience. These scenes are attached to a particular subject's claims and memories, connected by the subject's voice-over or juxtaposed with the interview. The reenactments are performed by actors and serve to reconstruct the past in much the same way as a detective reconstructs the events of a crime from pieces of evidence and witness reports. But rather than build towards a conclusive explanation of what happened that

\footnotetext{
${ }^{77}$ Linda Williams, "Mirrors Without Memories: Truth, History, and the New Documentary," Film Quarterly 26.3 (1993): 14.
} 
evening, the reenactments foreground the elements that remain obscure along with the gaps and contradictions that emerge from the various testimonies.

In Shoah, Lanzmann also seeks to piece together, through fragmented memories and a few material traces, the history of the extermination camps from its existing remains. As in The Thin Blue Line, Lanzmann's search for evidence of a crime also reveals absences. "What animates Morris and Lanzmann," remarks Williams,

is not the opposition between absolute truth and absolute fiction but the awareness of the final inaccessibility of a moment of crime, violence, trauma, irretrievably located in the past. Through the curiosity, ingenuity, irony, and obsessiveness of "obtrusive" investigators, Morris and Lanzmann do not so much represent this past as they reactivate it in images of the present. ${ }^{78}$

Lanzmann visits the sites of the Nazi's extermination camps throughout Europe, including empty and overgrown lots with no indication of the camp's prior presence in the area. At or near the sites he interviews survivors and witnesses who describe in painstaking detail the layout of the camp, its proximity to villages, the routines of the inhabitants, and the memories of the interviewees. Nine and a half hours of the most minute details fail to present a complete whole but do indicate how mass exterminations were extremely well-organized and rationally executed.

Lanzmann's retracing of a camp's site also includes numerous reenactments of the past, though not as separate scenes juxtaposed with the interviews but incorporated into the interviews and performed by the subjects themselves. The reenactments take place in the present setting and in the physical activity of the interviewees who are made to remember and relive the past by identifying significant locations and retracing precise steps in a space that embodies a traumatic history and evokes horrific memories. A

\footnotetext{
${ }^{78}$ Ibid., 17.
} 
number of the subjects are asked to repeat activities they performed at the camps, including an engineer who drives a train into Treblinka or Simon Srebnik who sings a song he was ordered to sing as a child in Chelmno. These men reactivate the past in the present through their own physical reenactment, which is both based on their memories and stimulates those memories. Although they are specifically requested and performed for the camera, these reenactments are more contingent than either the reenactment of the Wannsee Conference or those in The Thin Blue Line since they provoke responses that might be anticipated but are ultimately spontaneous and unscripted.

One such scene involves an interview in a barbershop with Abraham Bomba, a former barber and Holocaust survivor. Lanzmann stages a scene of memory, having Bomba repeat the very activity he performed in a camp in order to stay alive - cutting the hair of condemned women before they stepped into the gas chambers, whose fate he knew but could not reveal. Bomba goes through the motions (pretending to cut the hair of an unidentified man) while recalling his experiences as a barber in the camp, memories stirred by Lanzmann's frequent questions and Bomba's own repetitive gestures. For twenty minutes, the camera remains on Bomba, who never returns its gaze but is fully aware of it. Bomba's somewhat casual speech and repetitive motion combined with the setting of a public barbershop belie the tension and discomfort that is evident in his refusal to look at the camera. Near the end of the scene he recalls cutting the hair of his friend's wife. The memory is overwhelming and Bomba begins to cry, refusing to go on with his story, but Lanzmann's off-screen voice prods Bomba, convincing him he must continue. As with all of the film's reenactments, Bomba repeats gestures from his own 
prior experience in a present setting. While Bomba's performance denotes the historical and material circumstances that his speech recounts, it does not reconstruct a prior event. Whether the reenactments are accurate and consistent with the facts is irrelevant since, as Joshua Hirsch notes with respect to the lack of archival footage of the camps in the film, "Shoah avoids creating the sense...that by seeing the film one has seen, and hence assimilated, the events themselves."79 Rather than depicting the past as a distant historiographic object, Shoah's concentration on the present "[creates] a cinematic time in which the present and the past are collapsed into one another. The past in the film exists not as a separate time frame...but as a dimension that pervades the present like a fog. ${ }^{" 80}$ The reenactments are exemplary of this collapsing of temporalities, since they do not represent the past but evoke it through the bodily gestures, painful memories, and emotional affects of the subjects.

The scene of Bomba's recollection and emotional breakdown in Shoah is an example of a reenactment as an event. Although an original event exists it does not have precise boundaries and the film's representation does not seek fidelity to the original. Emphasis is not on the production of an image of the past that is complete and accurate but on the performance itself, along with the act of representation in the present as it evokes and embodies the past. The reenactment refers to Bomba's activity, his bodily gestures combined with his remembering, with which the filming is implicated. Both the performance and the camera's gaze are interwoven processes, each acting on the other with an unplanned outcome. Bomba's performance, his presence in the particular space

\footnotetext{
${ }^{79}$ Joshua Hirsch, Afterimage: Film, Trauma, and the Holocaust (Philadelphia: Temple University Press, 2004), 71.

${ }^{80}$ Ibid., 72 .
} 
of the barbershop, and Lanzmann's camera in this space, are dynamically linked, together creating an event for the film.

An attention to reenactment as an event is concerned less with the relationship between the representation and its historical referent, with an original event as a separate and distant object, than with the dynamic between the process of performance and the act of filmmaking as a contingent, constitutive, and mutually affective encounter in a shared time and space. Hence, this study concentrates on films that draw attention to their own production and its consequences for the individuals and communities involved in reenacting historical occurrences with which they have a personal and collective stake. It is precisely by acknowledging their own making that the films identify the reenactments as events in themselves, as performances in the present that not only depict a past but, more significantly, engage in its continuation, preservation, and reactivation. As interventions in the traumatic histories and potential futures of the amateur performers, who are often marginalized subjects, these productions point to the ethical function of reenactment over an epistemological one. The following chapters demonstrate how the ethical implications apply equally to reenactments in fiction films as much as documentaries. Indeed, documentary and fiction here intersect in the way in which reenactment constitutes an event and the production process an intervention. 


\section{CHAPTER TWO}

\section{In This World: \\ Fiction as Document and Intervention}

The film is in a sense a document of the journey we organized for Jamal and Enayat. Although it is a fiction, we did say to them they should do what they want to do in any situation. We would get them across the borders, we would organize the transport and so on, but we weren't trying to get them to be anything they weren't. So, in a way, the film is a record of our journey, of our journey making the film.

Michael Winterbottom, on In This World $^{81}$

Fiction and documentary interpenetrate each other; documentary takes on an 'aura of fiction', fiction becomes documentarised. Instead of film trying to copy life by reproducing it, film and life produce each other, 'reciprocally'.

Christopher Williams, Realism and the Cinema ${ }^{82}$

In Shoah (1985) the filmmaker and the camera's gaze are engaged in a reciprocal interaction with the subjects being filmed, which makes the viewer acutely aware of the camera's material presence. Lanzmann's film therefore illustrates Fredric Jameson's theorization of documentary production as an event within the postmodern period of cinema. In Signatures of the Visible Jameson describes the event of postmodern documentaries as

marked by the active intervention of the film-production-process in its object, which it alters historically. Materialism - or the material signifier - is in such films

\footnotetext{
${ }^{81}$ From the commentary on the In This World EPK [2002].

${ }^{82}$ Christopher Williams, ed., Realism and the Cinema: A Reader (London and Henley: Routledge and Kegan Paul, 1980), 224.
} 
therefore not a function of some historical "truth," which might be set in opposition to the fictive; nor even of an event whose representation we passively contemplate; but lies rather in the way in which the production process becomes an event in its own right and comes to include our own reception of it. ${ }^{83}$

These documentaries draw attention to the production process as an engagement with what is represented. Rather than passively observing action unfold in front of the lens, the camera becomes a participant in the action by intervening in and transforming what is observed. As Jameson remarks, "the very operation of recording and representing [the object] intervenes to change the outcome before our very eyes." ${ }^{.84}$ Hence, in Shoah, both the filmmaker and the process of filming are part of the action, with Lanzmann's offscreen voice and the camera's unwavering stare provoking emotional responses and eliciting the recovery of painful memories on the part of the film's subjects.

With few exceptions, documentaries have typically avoided acknowledging the work involved in making the films, the presence of the filmmaker or the camera, and the way in which the act of observation necessarily affects what is observed: "Contemporary documentary film, to be sure (I'm even tempted to call it postmodern documentary or material documentary), includes and foregrounds [the] dual presence of the event far more self-consciously than the classics of the genre seem to have done (or at least seem to $u s$ to have done). ${ }^{85}$ While postmodern documentaries can be placed within a long tradition of self-reflexive documentary filmmaking, stretching back to the early Soviet films of Dziga Vertov, such practices have historically existed on the margins of documentary cinema. In conventional documentaries, indications of the film's

\footnotetext{
${ }^{83}$ Fredric Jameson, Signatures of the Visible (New York and London: Routledge, 1990), 190.

${ }^{84}$ Ibid., 188.

${ }^{85}$ Ibid., 187.
} 
production are concealed or erased so as not to jeopardize the genre's traditional claims to objective knowledge and disinterested inquiry. On the other hand, to acknowledge the film's making or the filmmaker is to make apparent the documentary's historically and culturally situated perspective, as an embodied gaze that is personally and politically invested in what it represents. Such films foreground the filming process as an intersubjective engagement between that process and the filmed subjects, which points (if only implicitly) to the filmmakers' responsibility towards his or her subjects and to the power inequalities within which filmmaking is implicated, especially in cases of crosscultural encounter. That is not to say that the recent turn towards greater self-reflexivity and openness of the production process necessarily results in ethically sound documentaries. Rather, as Linda Williams notes, "complex ethical questions [are] raised by new forms of documentary practice that seem to have abandoned the traditional respect for objectivity and distance and call for greater degrees of intervention in the lives of subjects in contexts fraught with sexual, racial, and postcolonial dynamics of power."86

This chapter examines reenactment as an intervention of the filmmaking process in its object. In documentaries the use of reenactment is already considered an intervention given that it stages what takes place in front of the camera. However, intervention in this chapter refers not simply to the construction of the profilmic event but to the way in which the project of filmmaking has repercussions for the performers beyond what occurs on-screen. This can apply equally to reenactment in fiction films as in documentaries. The chapter concentrates on Michael Winterbottom's In This World (2002), a feature-

\footnotetext{
${ }^{86}$ Linda Williams, "The Ethics of Intervention: Dennis O'Rourke's The Good Woman of Bangkok," in Collecting Visible Evidence, ed. Jane M. Gaines and Michael Renov (Minneapolis and London: University of Minnesota Press, 1999), 178.
} 
length narrative fiction that employs non-professional actors and incorporates documentary conventions and production methods to provide an account of the treacherous journey taken by economic refugees seeking asylum in London. However, what the film shares with documentaries extends beyond its appropriation of documentary conventions and aesthetics to include the way in which the film's process of production constitutes an event with transformative consequences for the performers. By staging a fictional migration by two young protagonists the production of the film facilitated the actual migration by one of its non-professional actors. In This World therefore constitutes an intervention not just in the way the recording creates what is on screen, which is necessarily the case given that the film stages a fictional reenactment, but also in the way the entire project of making the film altered the life circumstances of the Afghan refugee hired to play the lead role. As such, the making of In This World participates in the events it represents.

\section{Fiction as Document}

In This World is one of a number of recent British films that examine the plight of illegal migrants seeking asylum in London, including Stephen Frears' Dirty Pretty Things (2002), Ken Loach's It's a Free World... (2007), and Pawel Pawlikowski's Last Resort (2000). Winterbottom's film is unique in that it concentrates on the dangerous and precarious journey that migrants must endure in order to reach their destination. The journey is a fictional one constructed by the filmmakers and performed by hired actors. At the same time, the fictional representation functions to document the process of 
migration in its experiential materiality by being filmed on-location, employing local bus drivers, border guards, and fixers to play those parts, by using a documentary mode of production, and by focusing on the physical conditions of the characters' odyssey. This journey is rendered in a starkly realist mode that reflects the film's conditions of production, its location-shooting with natural lighting, non-professional actors, a skeleton crew, and minimal resources. Winterbottom's consistent use of realist conventions establishes "particular relationships to the historical world [his films] represent." 87 The use of actual locations and local residents in In This World attends to the specificity of the locales and it grounds the fictional narrative in the lived circumstances of the people the film represents. The realist form also registers the materiality of the film's production as a process that takes part in the journey being created and inhabits the historical world on screen. In This World at once represents a fictional journey and registers an actual one, which occur simultaneously. They mutually create each other during production, and are collapsed on screen, such that the film's status as a fiction and as a document is not only inseparable but the distinction between the categories becomes irrelevant. The blurring of cultural categories is appropriate to the film's subject matter since In This World is about the crossing of borders, which are (in Benedict Anderson's sense) imaginary yet strongly guarded and not traversed without trepidation and consequence.

The narrative follows two Afghan refugees, 16-year old Jamal and 31-year old Enayat (the actors' real names), as they make a dangerous overland trek from Pakistan to London, through Iran, Turkey, Italy, and France. Armed with a small digital video

\footnotetext{
${ }^{87}$ Brian MacFarlane and Deane Williams, Michael Winterbottom (Manchester and New York: Manchester University Press, 2009), 30.
} 
camera, Winterbottom, his producer Mike Eaton, and their minimal six-person crew traveled the route depicted, filming the non-professional actors, themselves Afghan refugees from Peshawar, in various modes of transport - in the back of pickup trucks, on crowded buses, beneath a transport truck, or on foot. The final film is about their passage, the duration, monotony, and discomfort of the process, the risks the characters must take to reach their destination, and the negotiations involved with border guards and human smugglers. The moments of dramatic tension in the film, when the characters must bribe a border guard with a walkman, or when they get caught at a border and have to walk back to where they came from, only to repeat the attempt again, are constructed events based on stories conveyed to Winterbottom and Eaton on a prior research trip through the area and heard from refugees in London. A scene in which Jamal and Enayat are transported in a metal container, resulting in Enayat's death, also draws on and references a news report from 2000 of Chinese migrants found suffocated in a lorry on a cargo ship at Dover.

Although the narrative draws on personal accounts of migrants' experiences, what constitutes In This World as a reenactment is not simply its references to actual events but rather the way the film and its production trace the route commonly traveled by migrants smuggled from Pakistan to Britain. The tracing of a prior journey is a type of reenactment that tends to engage academic or popular history by following records or diaries of famous travels, such as the reenactment of Captain James Cook's 1768 
expedition through the Pacific for the BBC production The Ship (2002) ${ }^{88}$ In This World contains a historical dimension since the journey it depicts follows what is known as the Silk Road, which refers to a system of ancient trade routes between the East and West for the transportation of luxury items from Asia. Because the Silk Road connected several networks, Frances Wood argues that the name is "somewhat misleading. It suggests a continuous journey whereas goods were in fact transported by a series of routes, by a series of agents, passing through many hands before they reached their ultimate destination. ${ }^{89}$ Wood's remarks can equally apply to the experience of Jamal and Enayat, who are passed through the hands of several smugglers at different points along their journey to the West. While the film was initially titled the Silk Road, perhaps explicitly and ironically to connect the route's traditional function and its current use by smugglers and migrants, Winterbottom is less concerned with evoking the historical than with representing the typical, both in terms of the route itself and the journey of the characters. Jamal and Enayat are therefore presented as types that denote the countless young Afghan males who attempt a similar trek along the same path.

Like many reenactments of marginalized histories and subjectivities, In This World posits a counter-document to official discourses. The film responds to the British government's efforts to reduce the number of asylum seekers allowed permanent residence in the UK since the late 1990s, along with the distinction made between political (legitimate) and economic (illegitimate) refugees in Britain's immigration

\footnotetext{
${ }^{88}$ See Alexander Cook, "Sailing on the Ship: Re-Enactment and the Quest for Popular History," History Workshop Journal 57 (2004): 247-55, and Anja Schwarz, "'Not This Year!' Reenacting Contested Pasts Aboard the Ship," Rethinking History 11.3 (2007): 427-46.

${ }^{89}$ Frances Wood, The Silk Road: Two Thousand Years in The Heart of Asia (Berkeley: University of California Press, 2002), 9.
} 
legislation. ${ }^{90}$ By drawing on personal memories and concentrating on the concrete materiality of the journey, Winterbottom's film seeks to show an often-neglected side of human smuggling; specifically the hardships economic migrants endure in the hope of achieving a more secure existence in the West. As several discussions of the film have observed, In This World effectively conveys the experience of migration. Chris Darke, for instance, remarks on how the quality of the images reflects the process and circumstances of the journey depicted:

It is fitting that the film's images should themselves also have the feeling of having been smuggled across borders. Using digital video cameras, Winterbottom and his crew gained an extraordinary degree of access to a world rarely seen on cinema screens. From hundreds of hours of footage Winterbottom has crafted a film that conveys the texture of its context, the sensation of its circumstances. That is to say, it is sometimes rough, blurred, almost abstract: the sequence filmed during the cousins' night-time crossing of the mountainous border between Pakistan and Iran is given an eerie grain by its degraded, highly pixelated footage. But this is more than a case of stylisation for its own sake. The film builds its textures of images and sounds to convey to its audience the simple fact of duration: long periods of nervous waiting followed by mad scrambles or surreptitious advances towards the next staging post on the epic journey. ${ }^{91}$

\footnotetext{
${ }^{90}$ Applications for asylum in Britain rose dramatically between 1999 and 2002, with the number of applications in 2002 far exceeding every other country in Europe. In This World was released amongst rising public fears of a perceived national crisis, escalating protests throughout the UK, and growing support for the far-right British National Party (which won three local council seats in May 2002). In response, both the Conservative and Labour parties introduced policies taking a "tough" stance on asylum and promising to control the flow of migrants into the country. In 2003 Tony Blair declared his government's intention to cut the number of asylum applications by half within a year. Tom Bentley, "Please, not again!" Open Democracy, February 11, 2005, http://www .opendemocracy.net/globalizationvision_reflections/article_2339.jsp, accessed March 25, 2011. Tina Heath, Richard Jeffries, and James Purcell, "Asylum Statistics: United Kingdom 2003," Home Office, August 24, 2004, http://rds.homeoffice.gov.uk/rds/pdfs04/hosb1 104.pdf, accessed March 25, 2011. Nyta Mann, "Blair's Asylum Gamble," BBC News, February 7, 2003, http://newswww.bbc.net.uk/2/hi/uk_news/politics/2738065.stm, accessed March 25, 2011. British Broadcasting Corporation, "Short History of Immigration," BBC News, http://news.bbc.co.uk/hi/english/static/in_depth/uk/2002/race/short_history_of_immigration.stm, accessed March 25, 2011.

${ }^{91}$ Chris Darke, “The Underside of Globalization: On Michael Winterbottom's In This World," Open Democracy, April 2, 2003, accessed October 2, 2010, http://www.opendemocracy.net/artsFilm/article_1120.js
} 
In a similar vein, Rebecca Prime notes how the episodic narrative structure and the discontinuous editing of In This World "fractures and ruptures the space of the journey as a means of mimicking the confusion and dislocation experienced by the refugee. ${ }^{.92}$ In addition to the form and cinematography expressing the subjective confusion, urgency, and disorientation of the migratory process from a refugee's perspective, the film also objectively documents what it is like to make this particular journey along this specific route by filming on-location, at local bus stations, in crowded markets, on board full buses, and at actual border checkpoints. Attention is given to the particularities of each location and the changes in landscape, culture, and climate as the protagonists make their way from one country to the next. With little dialogue between Jamal and Enayat, In This World concentrates on the physical circumstances of the characters' perilous passage, with many shots of the refugees walking along dusty roads, on bumpy rides in old pick-up trucks, and packed among crates of oranges or other transported goods. By showing the material conditions under which such journeys take place, In This World creates a sort of document of a typical experience, using reenactment to represent what documentary cannot due to the clandestine nature of human smuggling.

That the fictional journey of In This World is to some degree intended as a document is apparent from the film's opening sequence, which incorporates documentary signifiers to frame the narrative. The film begins in the Shamshatoo refugee camp in Peshawar, on the border of Pakistan and Afghanistan, with images of the daily life of the camp's inhabitants - young men working, older men resting, and children playing - who

\footnotetext{
${ }^{92}$ Rebecca Prime, "Stranger Than Fiction: Genre and Hybridity in the 'Refugee Film', "Post Script 25.2 (2006): 62 .
} 
all return the camera's inquisitive gaze. An expositional, documentary-style voice-over identifies Shamshatoo as the home of 53,000 Afghan refugees, describes their living conditions, the daily food rations, and the minimal financial support provided to refugees on the part of international aid agencies. The narrator also introduces the film's protagonist, Jamal, as an orphan who was born in the camp and works in a brick factory for a dollar a day. Whether this introduction to Jamal describes the actor's actual situation or not, it establishes the character and his story as typical and as emerging out of the historical world and lived experience that the opening sequence presents. That Jamal and Enayat's journey is representative of many similar ones is underscored with the voice-over that accompanies an image of the characters as they begin their flight out of Pakistan by providing statistics of the number of refugees in the world and those who attempt to escape their situations. As the voice-over disappears and the film seamlessly transitions to a fictional narrative, non-diegetic inserts of a map track the characters' progress and indicate the distances traveled. Titles also identify the characters' multiple destination points and the duration between their various arrivals and departures along the journey. As Jamal and Enayat arrive at a particular city (Quetta, Tehran, or Istanbul), each location is introduced with establishing shots of cityscapes or residential neighbourhoods, along with documentary-style images of the daily life of local residents, mostly children playing soccer or engaged in domestic chores.

These images of everyday activities, along with the documentary framing of the film, situate both the fiction and the filmmaking in the historical world the film represents. When filming in the Shamshatoo camp, in the crowded streets and markets in 
Pakistan, and in the various neighbourhoods of the cities visited, the subjects and passersby often look directly at the camera. With this return gaze, In This World makes apparent the "dual structure of eventfulness...the event on the side of the subject as well as that on the side of the object"93 that Jameson locates in postmodern documentaries. The film's mode of realism involves an acknowledgement of the camera's material presence in the world it records. ${ }^{94}$ By drawing attention to the act of filming and by filming in actual locations, In This World registers two simultaneous and interwoven journeys - the fictional journey by the characters and the actual journey of the production process. Since the staging of a fictional journey involved making the journey on the part of the actors and crew, reenactment here applies less to the performances by the actors than to the production process as a whole and its tracing of the route taken by the characters.

It is also the production process that is characterized by generic hybridity rather than the film's formal appropriation of documentary conventions alone. Winterbottom employed what Jean-Louis Comolli calls "techniques of the direct method" redefines Direct Cinema from a mode of reportage to techniques of narrative construction that operate outside and against the tight controls of commercial filmmaking. As a method of fiction filmmaking, Direct Cinema involves the use of portable handheld

\footnotetext{
${ }^{93}$ Jameson, Signatures of the Visible, 186.

${ }^{94}$ Both Jameson and Ivone Margulies identify Bazin's theory of realism as encompassing this duality or integration between the filming subject and filmed object. For example, in her introduction to Rites of Realism Margulies asserts that the indexical image in a Bazinian sense "involves...a heightened sense of the eclectic materiality of film." Such images "bear the marks of two heterogeneous realities, the filmmaking process and the filmed event," and their parallel unfolding in time. Ivone Margulies, "Bodies Too Much," in Rites of Realism: Essays on Corporeal Cinema, ed. Ivone Margulies (Durham: Duke University Press, 2003), 3.

${ }_{95}$ Jean-Louis Comolli (1969) in Realism and the Cinema: A Reader, ed. Christopher Williams (London and Henley: Routledge and Kegan Paul, 1980), 234.
} 
cameras, a small crew, location shooting, non-professional actors, a minimal script (or no script), improvised performances and cinematography, and is entirely based on contingency. Without following a predetermined plan or program, the film develops in the process of its making, specifically during the filming, which Comolli describes as "a moment of accumulation" "with an unforeseen outcome: "We are therefore dealing with a particular practice of fictional cinema which is equivalent to a particular practice of direct cinema. We are in fact looking at a film fiction being produced 'live'.,97 This approach combines documentary and fiction in a way that distinguishes itself from the conventions and assumptions of both modes of production, since what is filmed has no prior existence either as a written script or a specific historical event, but is constructed in the process of production, along with the film itself. As the filming and its object respond to each other, the filming becomes part of the filmed event. The relationship of the film to what it records is then not one of reproduction but of mutual and reciprocal production, whereby "[life and cinema] speak to each other and produce each other through and within that speech." 98

For In This World both the performances and the filming were improvised and the narrative was developed during the filming in response to contingencies encountered throughout the process. While screenwriter Tony Grisoni did produce a script, based on a previous research trip taken with Winterbottom, the script was a general plan open to changes and possibilities rather than a fully developed and detailed screenplay. Grisoni describes the resulting flexibility of the production process:

\footnotetext{
${ }^{96}$ Ibid., 243.

${ }^{97}$ Ibid., 239.

${ }^{98}$ Ibid., 233.
} 
There isn't a standard screenplay for this film. The decision frees us from the dead hand of script development. We cast non-actors and choose people whose lives are as close as possible to those of our characters. So, no dialogue. Our cast improvise within the situations we create. We also shoot in sequence, so our journey and that undertaken by our two main actors intertwine. When the crew begin shooting I go on ahead in search of people and places to be incorporated into the narrative. This fluid setup means we are able to respond to whatever we find. ${ }^{99}$

As Grisoni explains, the production involved hiring local people as participants and acquiring necessary materials, including various modes of transport for the characters, along the way. The fictional narrative was constructed amongst the everyday activities in the places filmed, whether crowded cafés, bus stations, or city streets. Winterbottom has stressed that the filming was discreet in such public spaces by employing a consumersized digital camera and undetectable radio mics for the performers. ${ }^{100}$ Many scenes and individual shots include Jamal and Enayat situated within and surrounded by events that were not organized by the filmmakers but were part of the everyday life of a particular place and its inhabitants. One such scene involves the protagonists observing the slaughter of a bull in Pakistan, an event which has no particular bearing on the narrative. However, the scene illustrates the film's merging of the fictional (by Jamal and Enayat's presence) with a documentation of everyday life in the locations visited. Thus, the film provides an example of what Comolli calls “a vast process of exchange, a reciprocal system where reportage and fiction alternate or conjugate within one and the same film,

\footnotetext{
${ }^{99}$ Tony Grisoni, "Journey into Flight" The Observer, March 16, 2003, accessed October 11, 2010, http://www.guardian.co.uk/film/2003/mar/16/berlinfilmfestival2003.festivals ${ }^{100}$ See In This World EPK, included on In This World DVD.
} 
react upon, break down and modify each other, until finally it is perhaps impossible to choose between them."

The blurring of categories that Comolli locates in the filmmaking process is distinguished from typical definitions of docudrama that concentrate on the combining of textual conventions. In This World has often been identified as a docudrama and, of the various types of hybrid approaches, most closely resembles the documentary drama:

this type of TV program/film uses a wholly invented sequence of events, and fictional protagonists, in order to illustrate the salient features of actual occurrences or situations..."documentary" in this form is just as likely to refer to style as to content, and to be about the "look" and "sound" of documentary proper which is directly referenced by imitation...the "look" most imitated is that of "Direct Cinema.", 102

Direct Cinema is here identified as visual style or a set of formal conventions appropriated for a fictional narrative. John Caughie extends this definition in his critique of the documentary drama as an integration of two "looks" established by the camera's gaze - the drama look and the documentary look - whereby documentary's rhetoric of objectivity (marked by such conventions as black and white film stock, grainy footage, or an observational style) is combined with drama's engagement (or suturing) of the spectator through identification and sympathy:

If the rhetoric of the drama inscribes the document within narrative and experience, the rhetoric of the documentary establishes the experience as an experience of the real, and places it within a system of guarantees and confirmations. The look of the documentary is qualitatively different, lacking the reverse field of the dramatic look, 'reversibility.' The documentary look is a look at its object, fixing the object rather than putting its look into play, the object looked at but only itself looking on:

\footnotetext{
${ }^{101}$ Comolli, Realism and the Cinema, 225.

${ }^{102}$ Steven N. Lipkin, Derek Paget, and Jane Roscoe, "Docudrama and Mock-Documentary: Defining Terms, Proposing Canons" in Docufictions: Essays on the Intersection of Documentary and Fictional Filmmaking, ed. Gary D. Rhodes and John Parris Springer (Jefferson, North Carolina and London: McFarland and Company, 2006), 15.
} 
the figures of the drama exchange and reverse looks, the figures of the documentary are looked at and look on. ${ }^{103}$

For Caughie, as in much of the literature on docudrama, documentary and fiction are considered distinct rhetorical strategies that, although integrated to mutually support each other, can be disentangled and isolated for analysis.

In Winterbottom's film, however, the filmic categories are not so easily separated and the line between them is blurred on multiple levels, including the profilmic, performance, and production, rather than by means of the film's textual features alone. In In This World documentary aesthetics are not merely added to a fictional narrative, nor is a pre-existing document dramatized, but rather the fictional narrative and the document are produced simultaneously; the fictional narrative emerges out of the documentary method of production just as the making of the fiction constructs a document. By making documentary and fiction indistinguishable and interchangeable within the film, In This World blurs the division between the categories to assert their equal status as representation, where one has no more claim to authenticity than the other. As opposed to serving as an authenticating device, the documentary conventions and direct method point to the film's process, its own making. As Comolli explains, the direct method of filmmaking is less concerned with establishing the truth of its object than attending to the fact of cinema production itself:

[Direct Cinema] cannot be defined...[as] a search for the greatest possible transparency to the world. Quite the contrary... it is characterized by the mutual modification of the cinema and the world, and the extreme manipulation of the elements of the film-world. Direct cinema is not therefore the place where meanings and forms are fixed, rather that of their greatest instability, their

\footnotetext{
${ }^{103}$ John Caughie, "Progressive Television and Documentary Drama," Screen 21.3 (1980): 30.
} 
ceaseless experimentation, with all that that entails of tentative groping in the dark, reversals, surprises and paradoxes. Direct cinema is the place where cinema is manufactured. ${ }^{104}$

Although In This World draws on stories of migrant experiences, the film does not so much represent (either through documentary or fiction) a specific prior historical event but attends instead to its own production process, which constitutes a reenactment, as a historical event in itself.

\section{Production as Intervention}

As the opening of In This World attends to the production process as an event in itself by acknowledging the camera's material presence, the film closes on a similar note by identifying the filmmaking as an intervention in the lives of the performers with consequences beyond what occurs on-screen. The film concludes with a reference to the actor Jamal's application for asylum in Britain (discussed in detail below) following the film's production. Just as the distinction between the categories of documentary and fiction is blurred, the fictional journey of the characters and the actual journey of the actors are equally collapsed, as Jamal's performance in the role of a migrant becomes entangled with his life circumstances. Attention is therefore placed not only on the film's production as a staging of a migration, but also on how the filmmaking process, as a cross-cultural project that employs non-professional actors, is implicated in what it represents.

Reviews of In This World and interviews with Winterbottom have made a point of addressing the ways in which the production of the film demanded engaging in the kinds

${ }^{104}$ Comolli, Realism and the Cinema, 237. 
of activities that the film represents and puts into question. As one reviewer has remarked, "Ironically the choice to use local amateurs put the team in a situation where they had to make choices not dissimilar [to] those done by Western immigration authorities... [by having] to pick two refugees out of a million for all of whom the basic salary they would be paid represented a fortune." ${ }^{105}$ Once Jamal and Enayat were chosen, the filmmakers encountered difficulties in acquiring the necessary documents to transport the actors across the many national borders. As a result, the production team had to hire a "fixer" and crossing certain borders involved some of the same strategies the film depicts. ${ }^{106}$ Winterbottom explains that although the production sought to operate through legal channels, "the job of getting Jamal and Enayatullah to the UK and back involved forged documents, smuggling and bribery."107

While the resemblance between the film's making and its narrative could be said to authenticate the representation, the attention to the production details may have less to do with claims to authenticity than with the strategic blurring of boundaries that is found throughout Winterbottom's oeuvre in order to generate ambiguity and confusion between categories rather than confirm the truth-value of a representation. Winterbottom is a highly prolific filmmaker who is often seen as lacking an auteurist signature. Yet, Winterbottom's body of work consistently generates ambiguity and provokes discomfort by blurring boundaries between authenticity and fabrication, record and myth, historical subjects and fictional characters, and between genres, as seen in his films 9 Songs (2004),

\footnotetext{
${ }^{105}$ Daniel Lindvall, "In This World," Film International 5.5 (2003): 65.

${ }^{106}$ Caryn James, "How to Improvise in Afghanistan? Don't Ask." The New York Times. September 21, 2003, 13.

${ }^{107}$ Anonymous, "Little boy lost" The Guardian, February 28, 2003, accessed October 12, 2010, http://www.guardian.co.uk/culture/2003/feb/28/artsfeatures.immigration.
} 
24 Hour Party People (2002), and Tristram Shandy: A Cock and Bull Story (2005). 9 Songs is a love story told through a series of sex acts that are not simulated but rendered in explicit detail and comprise the majority of the narrative, which sparked a great deal of controversy upon the film's release. However, while the film tests the limits of acceptability in mainstream cinema by moving into the realm of pornography, it departs from both conventions by representing the sexual encounters as more tedious than titillating. ${ }^{108}$ In 24 Hour Party People the influential history of the Manchester music and club scene of the late 1980s and early 1990s is conveyed through the figure of Tony Wilson (played by British comedian Steve Coogan), an arrogant and unreliable narrator who speaks directly to camera from within the diegetic space. The film is highly selfreflexive in recognizing its own artifice and myth-making, as a construction rather than a reconstruction of historical events, by mixing historical record with popular legend and fictional inventions. The film also blends archival footage with reconstructed sequences so seamlessly that the line between actuality and invention becomes impossible to decipher. Equally self-reflexive, Tristram Shandy casts Coogan again in the lead role with Coogan playing both Tristram Shandy and himself, as the film alternates between the adaptation of Laurence Sterne's novel and the making of the adaptation. Because the "making-of" sequences are equally fictional one reviewer has noted that "it becomes harder and harder to tell who's playing a character and who's supposed to be themselves."109 Winterbottom's films therefore often challenge generic expectations, expose their own mechanisms of construction, and promote a playful confusion between

\footnotetext{
${ }^{108}$ Melanie Williams, "9 Songs," Film Quarterly 59.3 (2006): 59-63.

${ }^{109}$ Jonathan Romney, "The Making of the Unmaking of the Adaptation of The Life and Opinions of Tristram Shandy," Film Comment 42.1 (2006): 37.
} 
actuality and fiction that evinces the instability of these categories and their inherent interpenetration.

With In This World, the confusion between the fictional narrative and the production process adds to the urgency of the material, not only by identifying the fiction's foundation in the historical world but also by addressing the production's implication in the historical world, especially with respect to the amateur actors. Just as Winterbottom obscures the distinction between the fictional journey represented and the actual one of the film's production, the film also invites confusion between Jamal the character and the performer. The ambiguity is initially generated with the introduction of Jamal during the opening sequence, as the actor's life circumstances (as a bricklayer paid one dollar a day) conveyed by the voice-over establish and inform the character that we follow on a fictional journey. The film's conclusion mirrors its opening sequence by again returning to the performer's life circumstances as they have changed after (and by) the making of the film. Following brief images of Jamal in London - washing dishes at a restaurant, wandering through a market, and praying in a mosque - a closing title announces that "On the $9^{\text {th }}$ of August 2002 the asylum application of Jamal Udin Torabi was refused. He was however granted exceptional leave to enter and is now living in London. He will have to leave Britain on the day before his eighteenth birthday." By shifting from Jamal as a character to performer, and from Jamal portraying a migrant to becoming an asylum seeker, In This World again points attention to its own production, specifically to filmmaking as an intervention with life altering consequences for the nonprofessional actor. 
Although the end title gives the impression that Jamal simply stayed in London after the film was completed, he was initially flown back to Pakistan at the end of production, as originally planned. Winterbottom insists that casting originally depended on hiring amateurs who would not be interested in staying in Britain: "We were looking for people who we thought would not want to come: we didn't want to be seen as offering two free tickets to London. The idea was to find two people to take with us for eight weeks, but who would be happy to return to Peshawar at the end of filming.",110 Jamal and Enayat's return to Pakistan was also the condition placed on the filmmakers by British immigration officials for providing the actors with travel documents. ${ }^{11}$ As a number of Guardian articles have reported, with titles such as "Life imitates art as refugee boy finds new home in Britain" and "Afghan boy turns movie role into real life," upon Jamal's arrival in Peshawar he immediately organized another one-way trip to London with the income from the film and while his British visa was still active. ${ }^{112}$ Although Jamal's second trip was different from the first, since he flew to Paris then took a train to London, Jamal in a sense reenacted his original production journey, this time not as a hired actor but as the economic migrant he portrayed in the film. Whether Jamal intended or would have attempted the trip prior to his participation in the film or whether he was inspired by his role is uncertain, but his involvement in the film certainly facilitated his second journey by providing the necessary documents and finances.

\footnotetext{
${ }^{110}$ Anonymous, "Little boy lost," The Guardian, February 28, 2003, http://www.guardian.co.uk/culture/2003/feb/28/artsfeatures.immigration, accessed October 12, 2010.

11 'Vanessa Thorpe, "Life imitates art as refugee boy finds new home in Britain," The Observer, April 6, 2003, http://www.guardian.co.uk/uk/2003/apr/06/film.immigration, accessed October 12, 2010, ${ }^{112}$ Fiarcha Gibbons, "Afghan boy turns movie role into real life," The Guardian, November 6, 2002, http://www.guardian.co.uk/uk/2002/nov/06/immigration.afghanistan, accessed October 12, 2010.
} 
Jamal's story indicates how the film, in terms of the entire project of filmmaking rather than the recording process alone, intervenes in its object. By attending to cinema as an intervention, In This World exhibits an affinity with the kind of documentary filmmaking practiced by Jean Rouch, whose production methods heavily inform Winterbottom's own approach. In a recent, first book-length study of Winterbottom's oeuvre, Brian McFarlane and Deane Williams note that the techniques and "circumstances" of the production of In This World "recall Rouch's experiments with narrative in films such as Moi, Un Noir (1958) and the New Wave predilection for the 'plan-of-action' script."113 Rouch, who was affiliated with the French New Wave and whose filmmaking serves as a pivotal example in illustrating Comolli's argument on the direct method, incorporated fiction into his documentary practice by arranging scenarios for his subjects to react to and improvise action within. As an ethnographer, Rouch was acutely aware that the act of observation or recording necessarily transforms the object of observation; he therefore employed intervention as a filmmaking methodology by provoking subjects into unrehearsed responses. For Rouch the camera does not passively record what takes place in front of the lens but rather penetrates a situation, adapts to it, and incites action. In Rouch's cinéma-vérité approach, filming creates what occurs in front of the camera and produces a specifically cinematic "reality" or cinematic truth (hence, cinéma-vérité), as an event that would not exist without the filmmaking process and within which the camera is an active participant. As mentioned, In This World is equally self-reflexive in acknowledging the camera's presence, but it also extends what

\footnotetext{
${ }^{113}$ McFarlane and Williams, Michael Winterbottom, 33.
} 
constitutes the instrument of intervention beyond the act of filming to the whole apparatus or process of production.

As Jameson points out, in the case of postmodern documentaries the intervention in the profilmic event on the part of the production process involves a transformation of the object of representation. For Jameson this takes place on-screen, as a process observable by the spectator. In In This World the transformative dimension applies not only to what occurs on camera but also refers to the possibilities made available to the actors by their participation in the production. By hiring Afghan refugees and by tracing the route of asylum seekers, the film's making provided Jamal and Enayat access to places that would be extremely difficult if not impossible to see otherwise. In a press kit for the film Andrew Eaton explains, "Jamal and Enayatullah were...discovering new things every day. They had never been out of Pakistan before. So everything they experienced that we were filming, they were experiencing for real. It was strange for them." 114 Through their involvement in the film and during the production, Jamal and Enayat acquired mobility and were able to move with a degree of ease and security that is denied to their characters and is ordinarily unavailable to the actors under normal circumstances. Rather than emphasizing how the film's production "grants" Jamal and Enayat the privilege of travel, however, with Jamal's return trip to London following the production the film demonstrates the actor's agency in using the film for his own ends. Indeed, the actors' agency is a priority in the film because Jamal and Enayat are participants in a collaborative project. Prime, for example, contends that "by following an improvised narrative, the film weaves the voice of the immigrant 'other' into its very

\footnotetext{
${ }^{114}$ Andrew Eaton quoted in the production notes for In This World [2002].
} 
structure. The fluidity of In This World allows the voices of the invisible not only to be heard, but to be seen."115 Yet, it is especially with the ending of the film, and ironically with a title card, that Jamal's "voice" is perhaps most strongly and poignantly asserted as an actor with a personal stake in Britain's treatment of migrants.

\section{Filmmaking Across Borders}

By addressing its own production and its repercussions for the performers - in short, by foregrounding reenactment as an event - In This World directs attention to its making as a process that inhabits and is implicated in the historical world on-screen. In so doing, the film speaks to the political and ethical dimensions of filmmaking, specifically to cross-cultural dynamics of production entangled within neocolonial relations of power and privilege. Cinema is here part of the global flows of capital, commerce, media, technology, and people the film represents, not only in terms of the circulation of films but also in terms of film production as a transnational practice. The global interconnections and border crossings depicted are also embodied in the film's form, both in the combination of documentary and fiction conventions, which is itself a challenge to generic boundaries, and in the intersubjective encounter registered between the camera and its subjects. As its own conditions and methods of production are made visible, In

This World indicates that how the film is made, with the centrality of amateur actors, their improvisational performances, the small crew, and so on, are as much political and ethical choices as pragmatic or aesthetic ones.

\footnotetext{
${ }^{115}$ Prime, "Stranger than Fiction," 63.
} 
In In This World, the traffic of people across borders is juxtaposed with the traffic of goods, of capital, and of commerce. In London Jamal wanders through an outdoor market replete with products that most likely came from elsewhere. Similarly, markets in Peshawar and Pakistan sell CDs or stereos manufactured in other parts of the world. In most cases where Jamal and Enayat cross national borders between Central Asia and London they do so by being concealed in pick-up trucks, on a cargo ship, or beneath a transport truck carrying various commercial trade goods, from crates of oranges to footballs. Soccer is an especially ubiquitous and transnational presence in the film, which contains many brief shots of boys kicking a football around in a dusty field in Peshawar, in the streets of Quetta and Istanbul, and on a beach in Sangatte. The movements of migrants and of commodities are also accompanied by financial transactions. Money is transferred or exchanged in a number of different countries and currencies, including dollars, euros, rupees, Iranian rials, and Turkish lira. There is a marked discrepancy between the ease with which commodities and capital travel across borders and the difficulties and risks faced by migrants. At one point, Jamal and Enayat are turned back at a border and must make the attempt to cross again. At another, they dodge bullets during a nighttime crossing in a mountainous region of Turkey. In a production diary for In This World published in Vertigo, Grisoni remarks on how the war on terror has at once exacerbated attempts at mass migration and increased the policing of national boundaries:

Today's border between Afghanistan and Pakistan was drawn in 1893 as part of the British Empire's need to buffer Russian imperialism. For many people the border has no meaning. Electrical goods, opium, car parts and hash all flow 
freely across it. In 2001, as a result of the huge numbers of refugees fleeing the U.S. bombing campaign, the authorities declared the borders closed to people. ${ }^{116}$

Jamal and Enayat are representative of the numerous refugees who flee not only conditions of poverty but also war zones in which ordinary people are caught within struggles between international military forces. If their travel is fraught with dangers, and many die before reaching their destination, home is equally characterized by pervasive insecurity.

The state of insecurity is heightened as migrants move by way of human trafficking networks in which they become commodities for smugglers to make their profits. The handlers who claim to ensure the boys' safety repeatedly exploit Jamal and Enayat for financial gain. In addition to their families' initial (and substantial) payment for the journey, Jamal and Enayat are forced to provide additional funds to all of their contacts along the way in order to continue moving forward. After they are caught trying to enter Tehran and sent back to Pakistan, the boys have to pay their fixer their last bit of money to repeat the same attempt over again. Later, in Istanbul, they are required to work in a factory that manufactures cutlery to pay for lodging and further travel. When in transit, Jamal and Enayat are used as free labour, by helping to load boxes onto trucks, then treated as another piece of cargo shifted from one truck to the next and squeezed among the other goods to be transported. The objectification of migrants in the business of smuggling and the disregard for individual lives apart from their economic value is reinforced in a scene drawn from newspaper headlines, in which the protagonists and a young family are transported to Italy in a shipping container without food, water, or

\footnotetext{
${ }^{116}$ Tony Grisoni, "In This World," Vertigo 2.4 (2003): 6.
} 
oxygen. When the container is opened at its destination most of those inside had suffocated.

As human migration takes place alongside commercial trade, it is also accompanied by the transnational flow of communication and mass media, which figures prominently in In This World. Telephones, computers, televisions, and satellite dishes are all part of the changing topographies from Afghanistan to London. Throughout their journey, at almost every stop, Jamal and Enayat phone local contacts or family back home. When they phone their contact in Iran, the fixer is preoccupied with surfing Arabic Internet porn. Jamal and Enayat later watch television in their room in Iran. Television screens are also present in public spaces, with videos of Middle Eastern pop music playing in a diner in Turkey and a market in Pakistan. As already mentioned, the markets in Pakistan and Peshawar are full of digital and electronic media devices, such as CDs, stereos, and cassettes for sale. This omnipresence of information technologies in the film appears incidental. Yet, in light of recent events in the Middle East, whereby cell phones and the Internet have been employed as political tools in popular uprisings against totalitarian governments, the prevalence of communication media in In This World makes the film seem all the more prescient; it speaks to the tension between the (sometimes violent) efforts of nation states to control flows of people and information, and the ways in which these technologies have been used to locate new means of undermining and permeating those boundaries. In the contemporary revolutionary movements in Egypt and elsewhere, social networking sites have been used not only to mobilize the largely youth-oriented protests but also to disseminate information globally on events as they 
occur in real time. Cell phone cameras have been especially useful in documenting the violent military action against protesters and generating many of the images broadcast internationally by news agencies - images that undermined the state propaganda and precipitated similar uprisings in neighbouring countries.

In In This World, the representation of various means of transportation and communication across physical distances registers the contemporary global condition of intense interconnection and interaction. The film illustrates Arjun Appadurai's argument that "with the advent of the steamship, the automobile, the airplane, the camera, the computer, and the telephone, we have entered into an altogether new condition of neighborliness, even with the most distant from ourselves." 117 Hence, cars, phones, a computer and a ship all appear in the film, which also includes a moment in Shamshatoo where Jamal looks at a photograph of his uncle on a plane. This sense of global interconnection is further embodied in the form of In This World, in the way the film points to its filming process as participating in the transnational flows it represents and as a cross-cultural encounter that is mediated and facilitated by the camera. As mentioned earlier, the film consistently conveys a reciprocal and intersubjective relationship with the people on-screen through the exchange of looks between the camera and its subjects. This is especially apparent during the opening and closing scenes in the Shamshatoo camp, which primarily consist of shots of children looking directly at the camera. Unlike the more wary adults, the children express a shy and playful curiosity, often smiling, posing and even performing for the foreign observer. In the Electronic Press Kit for In

\footnotetext{
${ }^{117}$ Arjun Appadurai, Modernity at Large: Cultural Dimensions of Globalization (Minneapolis and London: University of Minnesota Press, 1996), 29.
} 
This World, which documents the film's production, Winterbottom explains the concerted effort on his part to avoid a voyeuristic gaze at unsuspecting objects: "I was quite keen to...show that we weren't pretending we weren't there... Because it's easy to pretend, or it's easy to forget that the people, the Afghan refugees at the camp are just as interested in us as we are in them and they're just as aware of us and think about us in very similar ways [to] the way that we think about them." This mutual curiosity and interactive engagement continues throughout the film, as bystanders frequently glance or stare at the camera. At one point, in Turkey, a young girl leaning out of a window responds to the camera's gaze with a smile and a peace sign. This reciprocal encounter, which reveals the subjects' awareness of being filmed and their engagement in a self-presentation for the film, also underscores the observer's own presence as a situated viewer and as an equally foreign "other" to the inhabitants of the places visited.

Alongside the camera's interactive dynamic with local bystanders, the filming of Jamal and Enayat in the course of the journey establishes an intimacy with the two Afghan protagonists. Initially, in the opening sequence, the film identifies its own culturally situated perspective with the mediating British voice-over that introduces the camp, Jamal, the plight of refugees, and so on. The expositional documentary conventions employed at the beginning signal a gaze from the outside looking in, connoting the kind of distancing that is familiar in news reports from the region. As the film transitions to the fictional narrative, however, the voice-over disappears and the distance is replaced by a spatial intimacy with Jamal and Enayat that characterizes the rest of the film. The camera is typically quite close to the protagonists who are often 
filmed in small enclosed spaces, whether while traveling or resting, and usually framed in close-up or medium-shots. Since the dialogue is minimal and the audience is not privy to the characters' personal histories or emotional states, the spatial proximity of the filming invites the spectator not so much to identify with the Afghan refugees but to share in their experience of a journey fraught with insecurity from an inside perspective. The shift from an expositional to observational form, and from an outside to inside viewpoint, generates what Michael Almereyda regards as a confusion of subjectivity that pervades In This World: "The problem of subjectivity - Whose film is it? From what definable perspective, what consciousness, is this story coming from? - is a key challenge for any filmmaker, and here Winterbottom seems to invite confusion." ${ }^{, 18}$ By oscillating between the intimacy and interactivity with subjects, In This World maintains a constant duality; it gives primacy to the voice of the refugees (both characters and actors) while simultaneously acknowledging the filmmakers' presence, whose culturally situated gaze is neither erased nor concealed but decentred.

The multiplicities and ambiguities of the film's voice in part emerge from the blurring of cinematic categories, which Kent Jones reads as an oppositional political strategy. Jones specifically situates the primacy given to non-professional actors and improvised performances as part of a broader trend in independent filmmaking beginning in the 1990s. ${ }^{119}$ Although hybridity is not new, contemporary practices are uniquely positioned as a politically inflected response to the degree of artifice and control over the image found in commercial cinema, the star system, and the political sphere, with the

\footnotetext{
${ }^{118}$ Michael Almereyda, "In This World: To Be and to Have," Film Comment 39.5 (2003): 73.

119 Other significant examples that Jones discusses are the works of Apichatpong Weerasethakul and Abbas Kiarostami. See Kent Jones, "I Walk the Line," Film Comment 41.1 (2005): 30-33.
} 
minute attention paid to sleek aesthetics and tightly scripted narratives. Jones further distinguishes the recent turn towards contingency-based modes of filmmaking and storytelling from approaches that resemble or adopt Neorealist aesthetics when he asserts that the "films under consideration here are a different breed...more involved with gameplaying than the moral vouchsafing of reality to their audiences." ${ }^{20}$ Winterbottom's film is indeed closely aligned with such experiments with improvisational narrative construction as Abbas Kiarostami's Ten (2002) and Apichatpong Weerasethakul's Mysterious Object at Noon (2000), which are more self-reflexive and formally experimental than traditional realisms. The films can instead be described as minimalist in their rejection of conventional dramatic structures and tropes in favour of a narrative simplicity that belies the films' complexity and richness. In addition, none of these films fits neatly in the given categories of fiction and non-fiction, as the narratives are developed through the constant interaction between constructed circumstances and preexisting ones; staged events and daily life inform each other to such a degree that familiar categories are completely collapsed into one another.

However, to identify the narrative construction of In This World as "gameplaying" with viewers is to obscure the way the film elicits an ethical engagement with the characters, the actors, and the people represented. The notion of game-playing implies a potential cynicism that is wholly absent in Winterbottom's film, which instead conveys a seriousness, sincerity, and ethical responsibility that it equally demands of its audience. This is particularly apparent in the way the film's aesthetics of intimacy and reciprocity evince a mutually affecting encounter in a shared social space. The evidence

${ }^{120}$ Ibid., 31 . 
of the camera's presence and the ambiguity of the film's voice are not just formal exercises but an acknowledgement of the production as an event that takes place in the historical world and involves a relationship with the people on camera - a relationship that has political meanings and ethical implications.

\section{Conclusion}

By acknowledging the materiality of filming and the consequences of production, In This World attends to filmmaking as a social and ethical encounter with and in the world, which is registered within the film but also extends beyond the film. The reciprocal dynamic between filming and the profilmic that Comolli locates in the direct method, and that is equally central to reenactment as an event, is also a dimension of In This World but can be applied more broadly to the way the lives of the performers and the film's production mutually inform each other. While Jamal and Enayat's identities and backgrounds as refugees are the basis of the film's fictional characters, their participation in the production also alters their lives both during and after the filmmaking. As a reenactment, In This World is less concerned with maintaining fidelity to an original event than with the process of staging a typical journey on the part of the performers. Just as the reenactment is here not limited to the events on screen, it is also not finished with the end of filming but rather continues with and encompasses the impact on the performers following the production. In This World therefore resists closure; by addressing Jamal's return to Britain, the title at the end of the film at once points to the film's staging of a journey and points beyond itself to the implications of the production 
in the historical world. In addition, much like Shoah, In This World prevents a reading of the events it depicts as closed and complete prior occurrences safely contained in the past to insist instead on the continuity, urgency, and typicality of the migrant experiences represented, which Jamal's story serves to confirm.

Indeed, In This World has more in common with the documentary practices of Lanzmann and Rouch, and the way these filmmakers integrate fiction with documentary, than with typical docudramas. Just as the fictional techniques in Lanzmann's and Rouch's films do not refer to formal elements but to the filmmaking as a self-conscious construction, the documentary dimension of In This World cannot be reduced to the subject matter, the film's "look," or its adoption and imitation of documentary conventions. What Winterbottom's approach shares with documentaries encompasses more than the film's aesthetics or rhetorical strategies; it also includes the film's attention to its own filming process and to this process as an intervention. The documentary aspect of Winterbottom's film then, along with other reenactments as events, is less a matter of stylistic or textual features than the way in which questions of process, intervention, and ethics - what are typically concerns of documentary practice - enter the domain of fictional filmmaking.

The following chapters expand on the elements of reenactment introduced by Winterbottom's film: the stakes of performers in the material reenacted and their agency in the film's production; reenactment as an off-screen process which is transformative for the participants; and, the ethical dilemmas of employing non-professionals in a crosscultural production context. Each case is concerned with the transformative effects of 
reenactment on the performers and situates the film as one element within a larger project of engaging social activism, continuing traditional knowledge, or working through historical trauma. Since the amateur performer is a central feature throughout the following discussions, the next chapter provides a detailed investigation of the role and significance of employing non-professionals, with a particular focus on the personal and experiential dimension of reenactment for performers engaged in historical representation and media production. 


\section{CHAPTER THREE}

\section{The Amateur in Reenactment: \\ Experience, Identity, and the Personal in La Commune (Paris 1871)}

"[T]he Commune of 1871, with its limitations and its grandeur, its historicity and its open door on the future possibilities for human freedom, continues to live... It speaks with a new voice to every revolutionary age and circumstance, from Lenin in 1917 to the masses of Paris or of Peking in 1968. Its brief existence revealed for all time that mankind can be free. All will be compelled to return to it until mankind is free."

Richard Greeman, "The Permanence of the Commune", 121

"The Commune isn't dreams, it's acts."

A cast member in La Commune

(Paris 1871)

Reenactments often depict national historical traumas, such as the British Army's opening fire on protestors in Northern Ireland in Bloody Sunday (2002), the violent struggle for Algerian independence in The Battle of Algiers (1966), and the massacre of striking miners by Bolivian authorities in The Courage of the People (1971). In all these examples, the films also employ people who were directly involved in or witnessed the original events. Since reenactment's status as a staging of the past can jeopardize its documentary value, the use of non-professional performers often serves an authenticating function in a film by adding veracity and verisimilitude to its representation. However, as either survivors or witnesses of the original event who "relive" their own past, "ordinary people" whose lives correspond to the ones being depicted, or descendants of

\footnotetext{
${ }^{121}$ Richard Greeman, "The Permanence of the Commune," The Massachusetts Review 12.3 (1971): 395.
} 
more remote national or cultural histories, the performers' reenactment of traumatic historical events can also involve incredibly intense, intimate, and emotional investments. Such investments are central in the construction of Peter Watkins' La Commune (Paris 1871) (2000), a film that is less concerned with the accuracy and realism of its representation than with involving regular people in the depiction of their own history. The film reenacts the Paris Commune with 220 Parisian amateurs whose subjectivities (as immigrants, women, workers, etc.) not only correspond to the roles they play, but also heavily inform their improvisational performances. The performers' experiential and personal engagement with the material become formative in the film's representation and its meaning for both viewers and participants.

The privileging of "personal experience" in docudramas is frequently identified in critiques of the genre as eclipsing an effective political or pedagogical engagement with historical material. Reducing complex historical events to narratives of personal experience is thought to inhibit the viewer's critical understanding of larger sociopolitical processes, as docudramas typically concentrate on a central protagonist's private psychological struggles and invite the viewer's empathy and identification over critical detachment. This chapter distinguishes La Commune from conventional realist docudramas by examining how experience and the personal apply to the non-professional actors' activation and investment in the representation of history rather than to narrative structure, character development, or spectatorship. Watkins' film is of particular interest as an experiment in collaborative filmmaking that is informed by his previous work. In a career that spans fifty years and numerous countries, Watkins' films demonstrate ongoing 
concerns with historical representation, a subversion of realist codes, and an insistence on using amateur performers. As his most recent film, La Commune exemplifies Watkins' growing view of filmmaking as both a political and pedagogical exercise in which the amateurs' identities, emotional investments, and improvisational performances are crucial elements of the project.

Although I consider La Commune in relation to Watkins' other films and his particular methods, this chapter is less a study of an auteur's unique strategies than of the insight the film can provide into the more general tendencies and potential meanings of non-professional actors in cinematic reenactments. Watkins' film can be situated within a broader category of politically-oriented (or militant) reenactment, which includes such works as The Battle of Algiers, October (1928), Courage of the People, Bloody Sunday, and The Battle of Orgreave (2001). These films all exhibit a pedagogical purpose, a sense of urgency in representing historical events, and a privileging of marginalized communities and subjects. All are concerned with representing ordinary people involved in collective action and use non-professional actors as main characters and extras, the very people whom the films are about and whose participation and stakes in the reenactment contribute to the meaning of the final product. La Commune is especially interesting as a case study for the way in which its own production is continually acknowledged throughout the film to make apparent the representation as a staging of history and the actors as amateurs reenacting their collective past.

This chapter begins by differentiating Watkins' methods of combining documentary and fiction from the realist docudrama's incorporation of documentary 
aesthetics for authenticating purposes. Watkins' films instead question the evidentiary claims of the documentary genre by foregrounding the genre's signifiers of objectivity as conventions that mediate knowledge from a situated perspective. At the same time, however, La Commune evinces a documentary impulse that is located not simply in the form or historical referent but in the performances of non-professional actors, through the experiential process of production, the subjectivity of the amateur, and the basis of performance in self-expression. That the performances are at once the "fictional" and "documentary" dimensions of the film exemplifies the complex hybridity and duality of Watkins' films, which frequently oscillate between aesthetics of immediacy and empathetic engagement on the one hand, and acknowledgement of mediation and critical distance on the other. In La Commune the emphasis placed on the amateur performer, his or her national and cultural identity, along with the personal foundation and experiential dynamics of performance, are indicative of a documentary impulse while the film simultaneously challenges the very notions of documentary evidence. My investigation of the film concentrates on the non-professional performer as a significant site of these dualities, or contradictory movements, which serves not to authenticate the representation but to blur temporalities (past and present) and categories (documentary and fiction).

\section{Documentary Form: Conventions and Critique}

Throughout his professional career, Watkins has consistently worked within the contexts of documentary and television while critiquing the conventions of both in his productions. Watkins' first professional films, Culloden (1964) and The War Game 
(1965), were produced for the documentary department of the BBC and contributed to the revival and "golden age" of the documentary drama on British television. ${ }^{122}$ These films, however, differ significantly from the social realist documentary drama tradition that emerged at the same time with films by Ken Loach at the BBC's drama department. Critics of Loach's documentary dramas point to the cohesion of categories that characterize the films, so that "there is no contradiction for the spectator between the drama and the document, but only a confirmation; the tensions are all within the drama, rather than between it and its referent. The discourse is ultimately one of unproblematic truth." 123 By contrast, Watkins' application of documentary conventions (voice-over narration, direct address interview, and vérité-style shooting) to a historical setting in the first film and a futurist one in the second generates far more disjunctive and disturbing effects. The documentary conventions not only give the historical and fictional events a sense of immediacy, but also interrogate the documentary genre (and its truth claims) specifically and the television medium generally. These techniques continue in his current films, resulting in hybrid works that are formally more challenging for the spectator than the conventional docudrama.

As a key example of the BBC documentary drama of the period, Loach's Cathy Come Home (1966) demonstrates the authenticating function of documentary conventions typical of the genre. Cathy Come Home addresses the housing crisis in

\footnotetext{
${ }^{122}$ Before joining the BBC Watkins made several amateur films, notably The Diary of an Unknown Soldier (1959) and Forgotten Faces (1960), which won amateur film awards. His films since, although produced for various television companies internationally, have remained rooted in an amateur sensibility with Watkins' continual preference for non-professional performers, $16 \mathrm{~mm}$ or video cameras, a collaborative approach, and improvisational production and performance methods.

${ }^{123}$ John Caughie, "Progressive Television and Documentary Drama," Screen 21.3 (1980): 31 . See also Derek Paget, "Tales of Cultural Tourism," in Why Docudrama? Fact-Fiction on Film and TV, ed. Alan Rosenthal (Carbondale and Edwardsville: Southern Illinois University Press, 1999), 47-63.
} 
Britain through the story of a young wife and mother who, following her husband's job loss and the family's eviction, spirals into increasing poverty and homelessness that are impossible to recover from and which are exacerbated by the social institutions meant to provide care and assistance. Although a fabricated story, Cathy Come Home was filmed in actual locations, incorporated radio interviews into the soundtrack and used a newsreel shooting style - a significant departure from the studio-based television dramas of the period. The film also contains a visual montage of working class neighbourhoods accompanied by Cathy's voice-over and a sound montage of actual residents describing their poor living conditions. While these insertions can be quite jarring and were abandoned by Loach in his later work, they establish the fictional narrative's reference to conditions in the historical world and reinforce its truth-value. The documentary material augments the film's drama, its attention to Cathy, which ensures the spectator's sympathy for and investment in the character and extends that response to the broader issue of homelessness. Documentary and drama are thus combined to mutually reinforce each other and are equally necessary in generating the kind of outrage that audiences expressed at the failure of institutional support for the poor following the program's initial broadcast.

In contrast to the social realist docudramas, Watkins' films avoid the conventions of drama or fiction in order to engage fully with the tradition of documentary; rather than adopting the genre's truth claims Watkins" "fake" or "meta" documentaries instead use the conventions of journalism for staged material in order to question the assumptions and guarantees of documentary authenticity. In Culloden the reenactment of the 1746 
battle between the British Army and the Jacobite militia is filmed much like a television news report, complete with a disembodied voice-over, interviews with the historical subjects, and "on-the-spot" reportage techniques to give the impression of a historical event happening live. ${ }^{124}$ The voice-over introduces the various players, with particular attention to the ordinary men and boys fighting, the British soldiers and Highland rebels, who return the look of the camera and speak to the viewer in direct address. The subjects continually acknowledge the presence of the camera; at one point the leader of the Jacobites, Prince Charles Stuart, places his hand on the lens, refusing to be filmed following his disastrous defeat by the British. Handheld, vérité-style footage further indicates a subjective quality of the camera as it moves through the space and among the action as an embodied observer and participant in the unfolding event. During the battle the camera is frequently startled, jostled, and overwhelmed by smoke from constant explosions while attempting to capture the human wreckage in the midst of a chaotic slaughter. Watkins explains that the film's techniques intend to imitate and recall the news coverage of Vietnam: "I employed the style used in Vietnam War newsbroadcasts [sic] in order to bring a sense of familiarity to scenes from an $18^{\text {th }}$ Century battle, in the hope that this anachronism would also function to subvert the authority of the very genre I was using.",125

Watkins indeed consistently undermines the very journalistic conventions he appropriates. As the voice-over provides background information on the Highlanders'

\footnotetext{
${ }^{124}$ Jared Rapfogel notes how the presentation of an eighteenth century battle as a live televised event prevents the "comfortable distance" created by most period dramas. Jared Rapfogel, "Cautionary Tales and Alternate Histories: The Films of Peter Watkins," Cineaste 32.2 (2007): 23.

${ }^{125}$ Peter Watkins, "Media Statement: Media Crisis - Suggestions for Use and Personal Prologue," Peter Watkins, accessed November 9, 2010, http://pwatkins.mnsi.net/partl_home.htm.
} 
clan system and statistics to show how they were outnumbered, outmaneuvered, and ill equipped, it is never neutral in either tone or content. Rather, the narrator refers to the clan system as "human rent," to Stuart's choice of battle site as "suicidal," and to the leader himself as having "no plan" but "convinced of his invincibility." By placing responsibility for the massacre on the leaders and social structures of both sides, the film is differentiated from historical dramas in Watkins' refusal to romanticize and mythologize the past. ${ }^{126}$ Culloden instead draws attention to the brutality of the British Army as the soldiers hunted down remaining rebels and abused the prisoners following their victorious massacre. During the battle scenes, both the images and narration are graphic and gruesome, showing the terrified wounded, screaming and flailing, with bloodied eyes, faces, and body parts, while the narrator identifies their names, ages, and how they died (one shot, another disemboweled). Despite the gruesome detail and the sense of "liveness" with which the battle scenes are rendered, however, frequent obstructions to the camera's view (such as Stuart's hand or explosions on the battlefield) provide continual reminders that our access to the past is ultimately mediated and limited. ${ }^{127}$

The newsreel aesthetic that creates an impression of the historical event's immediacy at the same time draws attention to the artifice of those conventions and the film as a whole. In Culloden, the absurdity and impossibility of television recording an

\footnotetext{
${ }^{126}$ In his discussion of the film, Nicholas Cull presents Culloden as an attack on the romantic mythology of Charles Stuart that transformed the Jacobite leader (known as Bonnie Prince Charlie) into a hero in Scottish history. Nicholas J. Cull, "Peter Watkins' Culloden and the alternative form in historical filmmaking," Film International 1 (2003): 49-53.

${ }^{127}$ For a detailed discussion of how Culloden thematizes questions of the present's access to the past, see Ina Rae Hark, "On Eyewitnessing History: The Compromised Spectator in Peter Watkins's Culloden," The South Atlantic Quarterly 84 (1985): 294-301.
} 
event in 1746 both emphasizes and denaturalizes the conventions, making them open to interrogation. The handheld camera, off-screen interviewer, and voice-over narration, out of place in the historical setting, alert the viewer to the mediated nature of all historical representation and the constructed nature of the film. The same effect is achieved in The War Game, a "conditional tense" 128 documentary that applies the same documentary reportage techniques to a future scenario depicting a nuclear attack on Britain. Watkins remarks on the deliberate confusion intended by the film:

[The War Game] was the first of my works to deliberately mix opposing cinematic forms (in this case, a series of static, high-key lit, recreated interviews with establishment figures, colliding with jerky scenes of a simulated nuclear attack). Which - if either - was 'reality'? - the fake interviews in which people quoted actual statements made by existing public figures, or the newsreel-like scenes of a war which had never taken place? ${ }^{129}$

Using the formal strategies of television reporting - the shaky camera following the action and on-the-spot interviews - to represent events from a distant past or a possible future makes those codes particularly pronounced, as codes. This disjuncture between form and content in the films foregrounds the television and documentary conventions to provoke questions as to their reliability and trustworthiness.

\section{La Commune as Media Critique}

Following his brief tenure at the $\mathrm{BBC}$, Watkins continued to produce films and programs that adapt televisual reporting conventions to fictional material, whether historical or

\footnotetext{
${ }^{128}$ Paul Ward, "The Future of Documentary? 'Conditional Tense' Documentary and the Historical Record," in Docufictions: Essays on the Intersection of Documentary and Fictional Filmmaking, ed. Gary D Rhodes, and John Parris Springer (Jefferson, North Carolina, and London: McFarland \& Company, Inc, 2006), 270.

${ }^{129}$ Peter Watkins, "Media Statement: Media Crisis - Suggestions for Use and Personal Prologue," Peter Watkins, accessed November 9, 2010, http://pwatkins.mnsi.net/partl_home.htm.
} 
futurist settings, as a pointed critique of media forms and apparatuses. ${ }^{130}$ La Commune is the most recent example of this approach by framing the Paris Commune as a live televised event. The film begins with the workers' initial uprising following the FrancoPrussian War, which led to the citizens of Paris taking control over the city in response to poor wages, working conditions, and high unemployment. When the National Guard, a militia formed by the French government, defected and became the military force of the Commune, the provisional national government led by Adolph Thiers quickly fled to Versailles and declared civil war with Paris. Although defeated by the Versaillais in a bloody massacre, for seventy days the Communards managed to establish a democratic republic with its own governing body that operated in the interests of the poor and working class. The Parisians' self-government is depicted in the film through two competing news stations that report on the events, Versailles TV and Commune TV. The Versailles TV broadcasts contain the familiar signifiers of objective and authoritative journalism, with an anchorman who dispassionately conveys the day's news and invites experts and authorities for additional commentary. In contrast to the (relatively) sleek

${ }^{130}$ Watkins left the BBC following a tiring and public battle with the organization over its refusal to broadcast The War Game, which was subsequently banned from any televised screening until 1985. The broadcaster claimed Watkins' film was inappropriate for television; the images were deemed too violent and realistic, with the potential to confuse audiences because of their newsreel quality. The filmmaker and others have argued that what actually troubled producers and executives about The War Game was less a problem of form than of content since the film challenges the British government's plans and preparations in the case of a nuclear attack. As Watkins left the organization frustrated with the restrictions placed both on a filmmaker's freedom and on public information, the bitter controversy had a lasting impact on his later work by further fueling his critique of television's forms and practices. For further reading on the banning of The War Game and the film's production see: Tony Shaw, "The BBC, the State and Cold War Culture: The Case of Television's 'The War Game' (1965)," The English Historical Review 121 (2006): 1351-84. Patrick Murphy, "The War Game - the Controversy," Film International 3.3 (2003): 25-28. James Chapman, "The BBC and the Censorship of the War Game (1965)," Journal of Contemporary History 41.1 (2006): 75-94. Alan Rosenthal, "The War Game: An Interview with Peter Watkins," in New Challenges for Documentary, ed. Alan Rosenthal and John Corner (Manchester and New York: Manchester University Press, 2005), 110-120. 
production values of Versailles TV (including a studio, logo, and opening jingle), Commune TV is a makeshift alternative that reports from inside the Commune through "on-the-street" interviews that presents "the voice of the people." Although Commune TV is certainly favoured, and serves as the viewer's primary framework through which the historical events are mediated, the contrast between the two media formats puts into question the very possibility of objective reporting. Moreover, Commune TV is not exempt from the film's broader criticism of media strategies and structures. While some Communards welcome the opportunity to express their views and concerns to the camera, others are suspicious of the reporters, and rightly so. Following their initial intention to report honestly and openly, one of the reporters realizes her ability to influence public opinion and chooses not to question controversial actions on the part of the Commune's Central Committee. The film itself, however, does question some aspects of the Commune (especially the treatment of women) along with the entire media apparatus, regardless of which side it is on.

The critique of the media in La Commune extends to other formal techniques, including cinematography, pacing, shot length, and the entire film's length of almost six hours. While Watkins' appropriation of journalistic codes has remained consistent, his more recent films exemplify a significant shift from earlier productions by replacing the fragmented editing and distinct voice-over narration that characterize a large body of his work over the years with long takes and a lack of non-diegetic sound. ${ }^{131}$ The new

\footnotetext{
${ }^{131}$ Joseph Gomez and James Welsh locate this aesthetic shift with Watkins' second anti-nuclear film The Journey (1983-85), which also marks Watkins' turn towards a grassroots approach to film production and pedagogical objectives of the filmmaking process. Joseph A. Gomez and James M. Welsh. "Micro-Study 2: Peter Watkins, the Gulf War, and the Media Project (1991)," Film \& History 22.1-2 (1992): 41-46.
} 
aesthetic approach in Watkins' films is an alternative and oppositional strategy to what he calls the Monoform, an increasingly standardized audio-visual language that relies on fast-paced editing to shape a range of media products, from Hollywood films to commercials and news reports. ${ }^{132}$ In La Commune, which was filmed with a handheld black and white video camera, an action or dialogue is presented in its entirety in real time. The result is a slow-paced six-hour film that demands a great deal of patience on the part of the spectator as it provides an immensely detailed account of the Paris Commune. The film reenacts in chronological order key events of the two-month period from the seizure of power by the Communards to their bloody massacre by the national army. By concentrating on the Eleventh District of Paris, a particularly working class area, La Commune presents a comprehensive examination of the establishment of the Central Committee, women's unions, worker-run factories, public schools, and law, that is difficult to imagine, if not impossible to achieve, in a more conventional form. ${ }^{133}$ In addition to the formal strategies used, the film's critique of dominant media practices also takes place on the level of the production process, as a highly collaborative project between Watkins, his crew, and the actors. Watkins distinguishes the kind of collaboration involved in his approach to filmmaking from the hierarchical organization of director, cast, and crew within the film and television industries, which exercises control over form and content - and, ultimately, "truth" - through distinctions between levels of professionalism. In La Commune, he sought to reduce his own authorial control

\footnotetext{
${ }^{132}$ See Watkins, "Media Statement: Media Crisis," Peter Watkins, accessed November 9, 2010, http://pwatkins.mnsi.net/part1_home.htm.

${ }^{133}$ In a review of the film Paul Arthur observes, "the attention to everyday particulars of governance explores territory rarely mapped by any film genre." Paul Arthur, "La Commune (Paris 1871)," Film Comment 39.4 (2003): 72.
} 
as much as possible in order to allow the amateur cast the freedom to construct their characters, the dialogue, and scenes through their own research, discussions, and improvisational performances, thereby making the actors creative participants in the film's construction. The significance placed on the production process, the participatory mode of filmmaking, and the transformation of the social relations of production, all recall Bertolt Brecht's epic theatre. Scholarship on earlier films (especially Culloden) has already noted Brecht's influence in the lack of an individual hero, the development of conditions over action, and the distancing of the spectator from the text, which are equally apparent in La Commune. ${ }^{134}$ More importantly, however, the similarities extend beyond the mere use of "Brechtian devices" to the way in which the very means and relations of production are politicized.

The non-professional actor is a central factor in Watkins' oppositional stance towards conventional media practices and his attempt to develop alternative modes of television production and communication. In particular, La Commune embodies the Brechtian objective of transforming consumers of media into producers by involving amateurs in a collaborative process that foregrounds the performers' experiential and personal engagement with their collective past. The rest of this chapter therefore turns to a consideration of how experience and the personal are defined in relation to the amateur performers, the production process and the historical reenactment.

\footnotetext{
${ }^{134}$ See Terry Lajtha, "Brechtian Devices in Non-Brechtian Cinema: Culloden," Literature Film Quarterly 9.1 (1981): 9-14.
} 


\section{Experience}

Experience is frequently evoked in the literature on historical reenactment as a representational practice that concentrates on the experience of historical agents and that seeks to recreate the experience of a prior event for reenactors. The sense of having experienced a historical event through its reenactment is often equated with having knowledge of the event and is founded on the degree of realism achieved in the mimetic recreation of material conditions. Historians tend to question this conflation of experience with knowledge since the immediacy of a sensory response to the environment is privileged over a more critical and distanced understanding of the past. As a historical reenactment La Commune places emphasis on its representation as popular historiography in which the public is engaged in the interpretation of their national history. The film, however, is less interested in a realist reconstruction of the past, either for the actors or spectators, than in provoking reflection on the process of staging the past in the present. This attention to reenactment as an event nonetheless foregrounds and politicizes the experience of the amateur performer by raising questions not only on how history is typically represented but also who has the authority to represent it.

Historical reenactment is both valued and critiqued as a populist form of pedagogy concerned with the everyday, the marginal, and the experiential. Vanessa Agnew identifies the practice as a form of affective history "characterized by conjectural interpretations of the past, the collapsing of temporalities and an emphasis on affect, individual experience and daily life rather than historical events, structures, and 
processes." 35 She points out the value of reenactment in "[offering] a framework within which large-scale historical processes may be reduced to a comprehensible scale.",136 While the attention to "history from below" is reenactment's strength, critics and scholars argue that the emphasis on experience naively equates the reenactor's experience with the historical agent's, favours a sensory engagement over an intellectual one, and ultimately reveals more about contemporary anxieties and circumstances than historical events. ${ }^{137}$ Agnew observes that reenactors strive for transformation and authenticity associated with the harsh physical conditions that they willfully subject themselves to by avoiding the modern comforts and conveniences for sleeping, cooking, or hygiene. It is especially through the authenticity in the minutiae and details - of clothing, food, speech, weapons and other materials - that reenactors seek to generate an experience of the past by making the historical event or period concrete and tangible, particularly by enduring bad food, diarrhea, itchy clothes, insects, bad smells or boredom: "Reenactment thus emerges as a body-based discourse in which the past is reanimated through physical and psychological experience."138 Experience is here understood as a subjective and affective response to material conditions, the result of a specifically individual and visceral engagement with one's surroundings by immersing oneself in a simulation of the past.

La Commune is distinguished from both typical historical reenactments and conventional historical films by exhibiting no interest in creating an illusion of

\footnotetext{
${ }^{135}$ Vanessa Agnew, "History's Affective Turn: Historical Reenactment and Its Work in the Present," Rethinking History 11.3 (2007): 299.

${ }^{136}$ Ibid., 302.

${ }^{137}$ Dennis Hall, "Civil War Reenactors and the Postmodern Sense of History," Journal of American Culture 17.3 (1994): 7-11. Richard Handler, "Overpowered By Realism: Living History and the Simulation of the Past," The Journal of American Folklore 100.397 (1987): 337-41. Agnew, "History's Affective Turn."

${ }^{138}$ Vanessa Agnew, "Introduction: What is Reenactment?" Criticism 46.3 (2004): 330.
} 
"experiencing the past" for either the performers or the viewer. The reenactment was filmed entirely within a fluorescently lit abandoned factory, such that even "outdoor" activities took place in an interior setting, surrounded by blank walls. The film therefore lacks the kind of picturesque exterior scenes common in period films, a lack that is accentuated by the black and white video cinematography, which further contributes to the film's austere aesthetic. Like Culloden, La Commune avoids what Jared Rapfogel calls the "spectacle of period dress and props" common in historical dramas and reenactments. ${ }^{139}$ Although the performers wore costumes and used props, such as bayonets and some furniture, the resources were sparse, with little makeup (primarily dirt) for the actors and minimal special effects (only smoke for the firearms). With this minimalism of the mise-en-scène $L a$ Commune places emphasis on the theatricality over verisimilitude of its historical depiction, by identifying the actors as actors and the sets as sets. This is immediately apparent from the film's opening sequence, as a handheld video camera enters a door to the factory then maneuvers its way past a collection of silent crew members sitting among lights and monitors to settle on a pair of actors who address the camera directly. Speaking to the viewer, the two cast members introduce themselves and their roles (as reporters for Commune TV), mention that the filming had just been completed, it took three weeks, and the text will be added later. As they continue to discuss the film and its production, the camera moves past the actors to wander through the empty set, attending to each room and the props, while the viewer is asked to "imagine" the historical setting. Rather than taking the spectator or the performer on a journey back in time, the film highlights its own artifice and makes obvious its

\footnotetext{
${ }^{139}$ Rapfogel, "Cautionary Tales and Alternate Histories," 23.
} 
representation as a staging (and interpretation) of history that prevents the kind of suturing or simulation required in generating an "experience" of the past.

La Commune exemplifies what Hayden White refers to as a historical discourse that narrates over one that narrativizes. The latter is a "discourse that feigns to make the world speak itself and speak itself as a story."140 The former, however, identifies itself as a discourse, with a narrator or speaking subject who reports on events and openly constructs historical knowledge. In La Commune, the construction of a historical representation is made apparent not only through its theatricality but also by the way in which the film's production is made visible as part of the representation. Along with the opening sequence, the film includes intertitles, especially at the beginning and end, which explain the process and aims of the production as well as the funding and distribution of the film. Such titles frequently appear throughout the film to add context through statistics or quotations from famous figures and publications of the period, whether to complement, contradict, or ironically comment on what is shown. For instance, a title following a speech by Adolph Thiers states that his claims are false. Another, juxtaposed with images of women organizing for better living conditions and work opportunities, quotes writers such as Emile Zola referring to the Commune women as "harpies." These titles do not simply add information for a more complete picture of historical events but rather function as self-reflexive devices, along with the reportage techniques and unrealistic mise-en-scène. ${ }^{141}$ By attending to its own making in this way, La Commune

\footnotetext{
${ }^{140}$ Hayden White, "The Value of Narrativity in the Representation of Reality," in On Narrative, ed. W.J.T. Mitchell (Chicago: University of Chicago Press, 1981), 3. Emphasis in original.

${ }^{141}$ The use of intertitles and the theatricality of La Commune, as relatively new techniques in Watkins' arsenal, differ from but also expand on his previous historical reenactments, which have consistently
} 
provokes a more general consideration of the ways in which history is produced and portrayed.

That La Commune continually identifies its reenactment as taking place in the present marks a significant departure from most historical reenactments and related practices of living history, which tend to carefully avoid anachronisms in order to ensure a complete and authentic representation of the past. ${ }^{142}$ Watkins instead deliberately incorporates anachronisms, acknowledges inaccuracies, and adds fictional elements. The narrative unfolding of historical events is also repeatedly interrupted by scenes of actors out of character and intertitles that address current social conditions, political events, and media practices, such as the reporting on the Iraq War, the occupation of the St. Ambroise Church by illegal aliens in 1996, and the present state of women in the workforce in France. With increasing frequency throughout the course of the film, $L a$ Commune also includes scenes in which actors gathered in small or large groups discuss the Commune, the film, and the issues that both raise in relation to the contemporary

\footnotetext{
"[concerned] themselves with their present place and purpose, their discours, questioning both the contemporary significance of historical material and the modes of cinematic presentation of that material." Stuart Cunningham, “Tense, Address, Tendenz: Questions of the Work of Peter Watkins," Quarterly Review of Film Studies 5.4 (1980): 507.

${ }^{142}$ A number of studies on historical reenactments and living history museums discuss the limitations imposed on the representation and interpretation of the past by the emphasis placed on authenticity in these practices. Scott Magelssen points out how the concern with realism at the Plimoth Plantation smooths over gaps in historical knowledge. John Cash observes that the strict adherence to authenticity in Civil War reenactments places parameters on the interpretation of historical events. Richard Handler and Eric Gable argue that a focus on "just the facts" in Colonial Williamsburg avoids dealing with controversial aspects of a historical period, neglects consideration of the relationships between past and present, and prevents questions of how historical knowledge is constructed. Scott Magelssen, "Living History Museums and the Construction of the Real Through Performance," Theatre Survey 45.1 (2004): 61-74. John Cash, "The Usable Past Reconsidered: An Ethnography of Civil War Reenactors," in Times, Places, Passages: Ethnological Approaches in the New Millenium, ed. Attila Paladi-Kovacs, Gyorgyi H Csukas, and Akademiai Kiado (Budapest, Hungary: International Society for Ethnology and Folklore, 2001), 246-57. Richard Handler and Eric Gable, The New History in an Old Museum: Creating the Past At Colonial Williamsburg (Durham and London: Duke University Press, 1997).
} 
socio-political context. The lack of distinction in appearance between the discussion scenes and the reenactment, since they are both filmed in black and white video with long takes and the actors remain in costume and on set while out of character, creates a disjunction between dialogue and mise-en-scène that blurs temporalities without collapsing them. In differentiating the film from the nostalgic fetishization of the past in historical reenactments, Roxanne Panchasi identifies these disruptive elements as "productive anachronisms" that can be discomforting for viewers but function as a valuable educational tool by depicting the processes of analysis and interpretation. ${ }^{143}$

The involvement of the performers in the film's analysis and interpretation of the Paris Commune, as part of a broader collaborative production method of La Commune, is what constitutes the experiential dimension of the reenactment. According to Watkins, all the cast members were required to conduct independent and prior research on the Commune, their characters, and the socio-economic conditions in France during the period in order to stimulate critical reflection on both the historical event and the current state of public education:

The Paris Commune has always been severely marginalized by the French education system, despite - or perhaps because of - the fact that it is a key event in the history of the European working class, and when we first met, most of the cast admitted that they knew little or nothing about the subject. It was very important that the people become directly involved in our research on the Paris Commune, thereby gaining an experiential process in analyzing those aspects of the current French system which are failing in their responsibility to provide citizens with a truly democratic and participatory process. ${ }^{144}$

\footnotetext{
${ }^{143}$ Roxanne Panchasi, "If the Revolution Had Been Televised: The Productive Anachronisms of Peter Watkins's La Commune (Paris 1871)," Rethinking History 10.4 (2006): 553-71.

${ }^{144}$ Peter Watkins, "La Commune (de Paris, 1871)," Peter Watkins, accessed November 22, 2010 , http://pwatkins.mnsi.net/commune.htm. Emphasis added.
} 
This pedagogical engagement of the cast continued during the filming with discussions among actors and with the filmmaker through which the performers developed their characters, dialogue, and scenes. Watkins describes this approach to the film's construction as "dynamic and experiential, for it forced [the actors] to abandon pose and artifice, and led to an immediate self-questioning on contemporary society - which they had to confront on the spot." ${ }^{, 145}$ What Watkins identifies as the experiential process of $\mathrm{La}$ Commune refers to the activation of the performers in the production through their own research and improvisation, whereby the actors' individual perspectives on the material contribute to the collective creation of the film. The historical representation is therefore grounded in the contingencies of performance rather than a priori requirements of script, accuracy, and authenticity.

Although the kind of engagement with history that the film encourages is not based on the efficacy of simulating the past or the affects produced by such a simulation, it does register the historical event in the concreteness of actions. The notion of experience here applies less to an individual sensory engagement with the material environment than to the creative potential of the social dynamics generated in the making of La Commune. As an experiment in non-hierarchical and collaborative filmmaking that gives voice to ordinary citizens, the film not only represents the Paris Commune but also looks to the Commune as a model for its production process. The parallel between the reenacted event and the reenactment as an event is indicated in the resemblance between the scenes of discussion among the Communards and those among the actors when out of character: just as the historical figures work through the logistics of establishing worker ${ }^{145}$ Ibid. 
cooperatives or a women's union, the cast members debate the possibility or necessity of a popular uprising in a current climate. The dialogue between the actors further reveals how the reenactment aimed not only to depict but actually to foster the conditions for the kind of social change sought by the Communards, if on a much smaller scale:

"People won't become militants because of this film."

"Don't you find that the experience of this film showed us that incredible things happened between us?"

"Let's not think we made a revolution."

"No, but we experienced that human relations....that's essential for me. That's where it starts. Human relations...relating to a person sitting next to you all the time, even when things change, as they often do. To convey things...to give and to receive all the time. I had that feeling of giving and receiving. Especially receiving, a lot and from everyone... on all levels."

By attending to the practicalities of the Commune in its representation and echoing the original event in the film's production, La Commune transforms what might otherwise be seen as a failed utopia into a tangible possibility. In other words, it transforms dreams into acts.

The film thus constitutes a reenactment not simply by producing a representation of the Paris Commune but by having the entire production process embody and realize the values and aims of the original event. This kind of imitation of the Commune - the application of its democratic principles to media production - is distinct from a simulation of the historical referent, since the prior event is understood not as something to experience, as in an experience of the past, but as a model for action in the present. By expanding reenactment beyond its historical representation to include the way the film was made, La Commune further situates the filmic text as only one element, rather than a privileged site, in a much larger project of media activism that prioritizes its meaning for 
the performers involved. As a result, a number of the cast members formed the organization Le Rebond dedicated to continuing the project by distributing the film and promoting education and dialogue on the issues it raises. ${ }^{146}$ The participants' ongoing commitment to the film directs attention to the second crucial facet of the reenactment, its personal dimension for the amateur performers.

\section{The Personal}

Joseph Gomez begins his book on Watkins' films and filmmaking practices by noting, "the dominant personal quality of his work has largely been ignored beyond the obvious recognition of...a level of intensity which is usually dismissed as 'hysterical.' The fact remains, however, that Watkins is one of the most personal filmmakers working today." 147 This opening statement in part refers to the radical independence of Watkins' work and his consistent refusal to compromise the films' political stances in the interests of producers. It also refers to the way in which the films are heavily informed by Watkins' own experiences, his deeply held beliefs, and an intense anger towards the media, the military, and nuclear armament. In his more recent films, however, the "personal quality" equally applies to the performances of the non-professional actors as collaborative participants in the production whose own interpretations, perspectives, and emotional responses to the material contribute to the representation. That the performers are amateurs who work without a script is significant as they represent the public as opposed to professionals whose performances are determined by learned conventions.

\footnotetext{
${ }^{146}$ See www.rebond.org.

147 Joseph Gomez, Peter Watkins (Boston: Twayne Publishers, 1979), 17.
} 
With his roots in amateur filmmaking, Watkins thus sees his films as providing a forum for the self-expression of ordinary citizens who are denied a voice within the current framework of televisual communication.

The concentration on "personal experience" in more typical docudramas has been the focus of much criticism in the literature on the genre. The personal here applies to the formal - specifically dramatic - conventions that privilege a central protagonist whose individual perspective and course of action provides the narrative frame through which historical events are mediated. In a comprehensive study of the British docudrama, Derek Paget argues that complex issues are made easily accessible and non-threatening by being reduced to familiar, character-driven narrative structures: "It is a fact of our culture that most film, and play, makers seem to assume no issue can be understood unless mediated through a Representative Individual with whom the audience can identify." 148 The result tends to be a personalization of history and politics, whereby a focus on a single heroic figure overshadows collective actions and political processes. Paget's observations are not limited to the British context but also extend to American versions of the genre. In both cases, what most troubles critics is how such individualized narratives invite identification with the protagonist and empathetic investment in character in place of a detached spectatorship more conducive to critical readings. If an attention to the personal is often set in opposition to and seen as precluding critical and analytical engagements with historical material, for Watkins a consideration of individual agency and provocation of emotional responses are crucial for

\footnotetext{
${ }^{148}$ Derek Paget, True Stories? Documentary Drama on Radio, Screen, and Stage (Manchester and New York: Manchester University Press, 1990), 26.
} 
such engagements, while his films lack character development, prevent identification with characters, and construct a collective protagonist. The films are therefore equally collective and personal as well as critical and emotive, both in terms of how the past is represented and the process of representing it.

La Commune avoids privileging a single character over others and continually reinforces the centrality of the collective - of the production and of the Commune itself by having most scenes of the Communards involve multiple actors and every camera shot include a minimum of two characters in the frame. At the same time, however, Watkins is concerned with showing individual characters' backgrounds, motivations and interests in order to highlight the diversity of the Communards, along with their effort to work together across differences to achieve common goals. The beginning of the film includes a sequence of brief static shots in which certain characters introduce themselves to the camera, identifying their names, professions (teacher, baker, jeweler, etc.), economic situations, and living or working conditions. Intertitles are inserted between the shots to situate these individual experiences within a broader social context, such as statistics on the cost of living and income for the respective professions. The sequence provides the background and motivation for the Paris uprising on an individual level by drawing attention to the material conditions as lived in daily struggles, wherein abstract social categories and individual lived experiences are mutually determining forces.

The identification of individuals is a significant and consistent device in Watkins' films. In his early work it is exhibited in the way the camera lingers on faces framed in close-up as they gaze back at the viewer. In reference to the earliest example of this 
practice, in the amateur production The Forgotten Faces (1960), ${ }^{149}$ Gomez remarks that these faces "stare out at us not so much to arouse our sympathy as to reinforce one of [Watkins'] dominant themes... it is an appeal to us, the audience, to take positions, to give expression to our feelings and beliefs when it is necessary to do so." ${ }^{.150}$ Similarly, Stuart Cunningham argues that "the 'fourth look,' the look from within the diegesis out to the spectator" in Edvard Munch (1973), "continually contests any 'absorption of the subject' into the film's lavish mise-en-scène."151 The characters' gazes into the camera are certainly employed as a distancing device that forces the viewer into self-awareness, but they are equally and simultaneously used to arouse emotional responses towards the material. In Culloden, over images of the Jacobite Rebels' exhausted faces, including those of children, the narrator provides their names, ages, motivations for fighting, and, later, how they died. The way the film specifies the victims of the battle, one by one, draws our attention to the human cost of war, and it certainly incites disgust, horror, or outrage, along with a sense of injustice, if not necessarily grief and sympathy. The viewer's emotional engagement is thus grounded not in our identification with particular characters but rather shock at the material conditions and consequences of the battle. The kinds of strong emotional reactions Watkins' films provoke in viewers are therefore directed away from an investment in character towards an ethical concern with political structures, their violence and their victims.

\footnotetext{
${ }^{149}$ The Forgotten Faces is a reenactment of the 1956 Hungarian Revolution. The reenactment took place in a street in Canterbury and was performed by the amateur theatre group Playcraft, which Watkins was involved with for several years and collaborated with for all of his early amateur films, including The Diary of an Unknown Soldier (1959).

${ }^{150}$ Gomez, Peter Watkins, 25-7.

${ }^{151}$ Cunningham, "Tense, Address, Tendenz," 509.
} 
Watkins equally elicits intense emotional responses on the part of actors, whose individual and collective investments in their roles, the historical event and its legacies constitute the personal dimension of the films. The personal here refers to the emphasis placed on the self-expression of non-professional actors within their performances, which are improvised based on the performers' own responses and feelings towards what is depicted. That the actors are encouraged to draw on their own emotions may in part resemble method acting; however, this approach to amateur performance includes two other central and integrated features. First, the dialogue and actions are necessarily improvised and thus considered as the actors expressing themselves, their own attitudes, beliefs, values, and perspectives, rather than constructing distinct characters. Secondly, the performer's political status and social position coincides with the role he or she plays. In La Commune, for example, the cast includes local activists, workers, illegal aliens, Polish immigrants, the unemployed and bourgeoisie to represent those roles in the film, such that the actors' political viewpoints or cultural backgrounds correspond with those of the historical figures they portray. In La Commune, as in Watkins' previous work, this blurring of actor and character leads to highly emotionally charged performances by amateurs deeply invested in the political and historical circumstances the films represent.

The affective intensity of the performances in Watkins' recent films recalls his earlier psychodrama experiment in Punishment Park (1970). Based on the crackdown on student movements and anti-war demonstrations during the Nixon administration, the film depicts a near-future scenario where dissidents are sentenced to a torturous game of being hunted by federal police in the middle of the desert. Prior to their punishment in 
the desert, the student activists arrested for civil disobedience must defend their actions during an interrogation by a civilian tribunal. For the production, Watkins hired young radicals (some who had been arrested), law enforcement officials, and conservativeminded citizens to play the corresponding roles. Instead of using a script, the actors in the tribunal scenes, both the defendants and interrogators, constructed statements that resembled their actual attitudes, even though, according to Gomez, the tribunal members amplified their conservative views to present a more extreme right-wing perspective. ${ }^{152}$ The confrontation between opposing ideological positions, expressed by actors without prior contact or rehearsal, stimulated an explosion of anger on both sides that is meant to reflect the polarization of American attitudes at the time. The film has thus been described as a psychodrama by, in Watkins words, creating "a framework within which the very participants in the film release their pent-up emotions and frustrations and fears." $" 153$ Although how raw or real these emotions are may be debatable, the affective energy of the performances is undeniable. In part due to the sheer intensity of the performances, Punishment Park is often seen as Watkins' least complex film, since the characters are one-dimensional and many scenes are reduced to little more than a yelling match. ${ }^{154}$ Yet, the lack of character development is a common feature throughout Watkins' oeuvre, indicating the psychodramatic basis of his approach, which is less concerned with developing rounded characters than depicting social roles. His films thus collapse the personal with the social, since the actors' personal (i.e. their own and

\footnotetext{
152 Gomez, Peter Watkins, 103.

${ }^{153}$ Watkins quoted in Gomez, Peter Watkins, 104.

${ }^{154}$ See James M. Welsh and Steven Philip Kramer, "Film and History Interview - Peter Watkins:

Therapeutic Cinema and the Repressive Mind," Film and History 7.2 (1977): 6-13.
} 
supposedly actual) beliefs, attitudes, and emotions depict political positions as opposed to fully formed characters.

In La Commune, the members of the cast equally match their parts, in terms of class identity, cultural background, and political ideology, and were encouraged to express their own political attitudes within the parameters of the narrative events. In a documentary on the making of La Commune, The Universal Clock (Geoff Bowie, 2001), when an actor who plays an "expert" on the Versailles news broadcasts asks how he should develop the character, Watkins replies "I want you to be yourself." The notion that non-professional actors are simply being themselves rather than acting is a common objective and assumption within both cinematic reenactments and realist docudramas, thus suggesting a denial of conscious performance altogether. In La Commune, however, the actors' constant acknowledgement of the camera with their return gazes subverts such naturalized performances. By having the amateurs "being" themselves, the film does not efface performance but rather foregrounds the performer as a performer. Watkins therefore subordinates the "character" as a distinct and separate entity to which the actor must conform: "When I say playing the part, I mean being a mixture of somebody else and themselves which is usually very integral, because I never make any attempt to make somebody, somebody else." ${ }^{\text {,155 }}$ To prevent acting according to predetermined characterization, conventions, or end result, Watkins sought spontaneous reactions and dialogue on the part of the actors. Throughout the film the Communards speak to the Commune TV camera, answering questions posed by the reporters, to which the actors had to respond in the moment without a script or preplanning. Even if improvised, that

\footnotetext{
${ }^{155}$ Watkins quoted in Gomez, Peter Watkins, 137.
} 
the actors perform for the camera, in a deliberate and obvious performance, is evinced by the intensity and exaggerated quality of their responses.

At the same time, the very vehemence of the amateur actors' speeches and reactions is suggestive of the sincerity of these performances. When answering the TV reporters' questions, the Communards at points respond with fiery anger, yelling at the camera, whether about the media, the Versaillaise, or the entire socio-economic situation. Although the arguments are often lucid and well developed, perhaps undermining any claims to their spontaneity, the passion with which these speeches are delivered gives the impression of overwhelming emotion. This emotive force is particularly powerful in scenes that involve large collective action or celebration, such as the singing of "La Marseillaise" in the streets following the Communards' initial victory in which a large portion of the cast erupts with immense energy and excitement. The actors' performances are certainly deliberate, as well as encouraged and provoked by the television cameras, the reporters, and Watkins himself. ${ }^{156}$ Yet, the intensity of the performances is compelling and explosive, reflecting a high level of commitment on the part of the actors to their actions and statements. The verbal and physical forcefulness of the speeches can also be seen as excessive in their lack of subtlety, at least in comparison to conventional, or naturalistic, film and television acting. This excess, by both challenging realist conventions and signaling the performer's sincerity, defies the cynicism and control that Watkins attributes to dominant media practices. Watkins has repeatedly argued that the media fears the expression of genuine emotion, or what he

\footnotetext{
${ }^{156}$ The Universal Clock includes footage of the filming of the communal scenes, in which Watkins gesticulates to the actors to heighten the energy of the performance.
} 
calls "personal tension," 157 the potentially explosive anger and frustration felt by ordinary people towards repressive systems, which his own films foreground by having amateurs voice their own emotionally charged political convictions.

Indeed, the use of the amateur is a central strategy by which Watkins counters the artifice that he sees as characterizing the majority of work, both documentary and fiction, produced within the current film and television industries. He argues, for example, that the media prevents meaningful engagements with the historical world by distancing viewers from their own emotions and experiences: "the commercialized audiovisual stimulation...[is] removing us farther and farther from our own human forms of monitorable reality and experience - and replacing them with a surrogate world where 'history', 'reality', 'experience' are synthetic processes shaped by others." ${ }^{\text {,58 }}$ By contrast, Watkins' own work confronts viewers with the disturbing realities that are usually avoided - the threat of nuclear attack, the brutal horrors of warfare, the criminalization of dissent, or the exclusion of a public voice from media apparatuses. $\mathrm{He}$ further challenges the construction of "synthetic" experiences within his methods of production, specifically by insisting on the importance of amateur performers. Although Watkins' formal strategies have changed over the years, his intentions with La Commune can be traced back to the early films, such as Culloden or Forgotten Faces, in which the "primary aims was [sic] to substitute the artificiality of Hollywood... with the faces and

\footnotetext{
${ }^{157}$ Watkins quoted in Lester Friedman, "The Necessity of Confrontation Cinema - Peter Watkins Interviewed," Literature Film Quarterly 11.4 (1983): 243.

${ }_{158}$ Peter Watkins, "Filmmakers, Festivals and the Repression" Peter Watkins, accessed December 7, 2010, http://pwatkins.mnsi.net/festivals.htm. Emphasis added.
} 
feelings of real people." ${ }^{\prime 59}$ If the early films placed much attention on faces as those of ordinary people, the later work concentrates more on personal and spontaneous expression through performance.

As all of these films expose the artificiality of documentary conventions, they locate the "real" not in the genre, aesthetics, or even the subject matter, but rather in the performances by non-professional actors. This does not mean, however, that the amateur functions as an assurance of the representation's authenticity. On the contrary, that which is here identified as "real" - the self-expression of the actors - is also that which reinforces the film's own artifice with the excessive and hyperbolic quality of the performances and their obvious status as performance.

\section{The Amateur}

By placing attention on the performers' emotional investments in the material being represented, Watkins' films demonstrate how the role and meaning of the amateur in reenactments extends beyond that of an authenticating device. To be sure, non-actors are often employed to contribute to a film's realism, which is apparent from Paul Greengrass' comments on his use of "real soldiers" in Bloody Sunday: "... we decided to use real soldiers, people who'd actually served in Northern Ireland, and had their own memories of the conflict, and had lost friends, it gave it a reality and it gave the whole piece an edge...an edge of authenticity." ${ }^{160}$ However, although Greengrass emphasizes the

\footnotetext{
${ }^{159}$ Peter Watkins, "Media Statement: Media Crisis - Suggestions for Use and Personal Prologue," Peter Watkins, accessed November 9, 2010, http://pwatkins.mnsi.net/part1_home.htm. Emphasis in original. ${ }^{160}$ Quoted in Aileen Blaney, "Remembering Historical Trauma in Paul Greengrass's Bloody Sunday," History \& Memory 19.2 (2007): 128.
} 
authenticity that the non-professional actors bring to the representation, his remarks also point to the kinds of stakes involved for the performers in reliving their own past. It is precisely the investments of the performers in the historical events, though of a more distant past, that are so central for Watkins and which are heightened by the correspondence between the actors and their roles, especially with respect to national, cultural, and class identity. This correspondence, rather than establishing equivalence between contemporary subjects and historical agents, evokes the continuity of present class, race, and gender struggles with those of the past. The films therefore place emphasis on the actors as descendants of those they represent, who belong to a tradition (in La Commune, a tradition of social action) and bear the legacy of the reenacted events.

In both La Commune and Culloden, references to the legacy and continuity of the past are especially poignant during the films' closing sequences. Culloden concludes with a handheld camera slowly tracking along a row of Jacobite rebels, pausing on each face as it stares directly back at the viewer with a dour expression while the voice-over narration explains the long-term consequences of Culloden:

The year of the prince has ended...but for the English government this was just the beginning. Systematically and with due Parliamentary legislation, they proceeded to eliminate everything that made this man unique and that gave him the strength they so feared...They removed the authority of his chief and in one blow smashed forever the system of his clan...Thus they reduced him to a harmless unwanted oddity. And finally forced him in his hundreds of thousands to leave the land of his birth for the canning industries of the North, for the diseased ridden slums of the South, for the lumber camps of Canada and the stockyards of Australia. And wherever he went he took his music, his poetry, his language and his children...Thus within a century from Culloden, the English and Scottish Lowlanders had made secure forever their religion, their commerce, their culture, their ruling dynasty and in so doing had destroyed a race of people. They have created a desert and called it peace. 
The use of "this man" in the passage has a double meaning; by referring to the entire Highland culture, it encompasses at once the historical subjects of the diegesis and the film's actors as descendants of those who fought in the battle. ${ }^{161}$ As the voice-over directs our attention from the past to the present, the close-ups of the Highlanders take on a documentary function and phenomenological dimension, drawing attention to the materiality of the actors in the present, their specificity and embodiment in a particular time and place. Combined with the narration, these images enact a shift in signification from the iconic to the indexical by identifying the actors as actors who embody the past as the future generation of the historical subjects they depict. The faces that stare out from the image, smeared in dirt and still in costume, thus signify both past and present simultaneously.

The final scene in La Commune resembles that of Culloden. The camera tracks across a long line of actors standing silently against a wall, which recalls the Mur des Fédérés (or Communards' Wall) in the Père Lachaise Cemetery, along which 147 Communards were executed. Although without narration this time, the faces similarly return the look of the camera with mournful expressions, both as historical characters waiting to be shot and as contemporary Parisians mourning the fate of their ancestors. This duality, which is established in the opening of La Commune and is increasingly emphasized throughout the course of the film, becomes especially pronounced during the penultimate sequence with the reenactment of the last days of the Commune. As the Communards rush to construct barricades and gather firearms to fend off the approaching

\footnotetext{
${ }^{161}$ The amateurs who portray the Jacobite army are all local residents from the city of Inverness, in the Scottish Highlands. Both the filming of Culloden and the original battle took place near the city.
} 
national army, the Commune TV camera and reporter wander amongst the excitement and chaos, stopping whomever they can to first ask, "What is going on?" Once the character explains the events, the reporter addresses the actor: "Would you do this today?" While previously the film juxtaposed the reenacted scenes with those of actors out of character, by the end the oscillation between past and present, and between character and actor, occurs in a single scene and in the midst of the reenactment. As in Culloden, the final sequences of La Commune shift our attention from the characters to the performers and thus towards a consideration of the weight and the inheritance of the historical event for current or future generations, which is here addressed not through the narration but through the actors' statements as they are asked to reflect on their own commitment to the (continuing) struggles of their ancestors.

In both films the amateur performers are sites of multiple dualities: past/present, icon/index, and character/actor. These dualities are never presented as opposing binaries but as overlapping and fluid states or dimensions of experience, expressing Watkins' ideas on history: "I believe that we are all history, past, present, future, all participating in a common sharing and sensing of experiences which flow about us, forwards and backwards, sometimes simultaneously, without limitations from time or space." ${ }^{\prime 162}$ In $L a$ Commune, this temporal fluidity is evoked in the formal use of television reportage conventions to depict historical events, in the theatrical mise-en-scène that registers past and present simultaneously, and in the use of amateurs to represent their own national and cultural history. However, the past is not just passively embodied by the performer through his or her identity, but is rather actively continued by the entire project of the

\footnotetext{
${ }^{162}$ Watkins quoted in Gomez, Peter Watkins, 125.
} 
film's reenactment, in the actions, debates, and collaboration of the actors, their collective investment in the process, and their reflection on the relevance of the historical event for a contemporary context. Hence, Panchasi points to the film's emphasis on continuity in her remarks on the use of reenactment in La Commune:

It does not so much resurrect the Paris Commune as it refuses the death of this historical, revolutionary moment to begin with. Rather than reviving a past seen as fixed or pure, the politics and method of this filmic reconstruction insist upon a past that is still very much present, in memories, legacies, and possibilities for the future. ${ }^{163}$

The presence of the past is manifest in the way the values and goals of the Paris Commune are incorporated into the production process of the film; in the actions and self-expression of the performers as an experiential engagement with the past that stimulates a revolutionary energy; and in the performers themselves whose social, political, cultural and national subjectivities are shared with their historically situated characters.

As residents of Paris engaged in a form of political activism through their participation in La Commune and its alternative means of production, these amateurs continue a tradition of social action in France that evokes the Commune as an ongoing objective. The Paris Commune remains a politically and emotionally charged period of French history, one that is regularly commemorated. The memory of the Commune especially reemerges in periods of conflict and contexts of protest, such as May '68, during the centennial anniversary in 1971, and most recently with the rise of neoliberalism in the mid 1990s. Michael Wayne situates Watkins' project within the context of the militant response to neoliberal policies. He writes, "in 1995, prime

${ }^{163}$ Panchasi, "If the Revolution Had Been Televised," 565. 
minister Alain Juppé's plan to slash social entitlement and welfare budgets provoked large-scale militant public sector worker strikes which ended Juppé's career and eviscerated the Chirac presidency. At the Gare du Nord station graffiti on the walls declared: 'No, the Commune is not dead!"” 164 Since Watkins began preparing the film in 1998 and filming in 1999, and hired many workers and young activists as actors, $L a$ Commune draws heavily on this oppositional public sentiment in France and the popular memory of the Paris Commune it expresses.

In the context of the film's collaborative production methods, the experiential and personal dimensions of reenactment refer to the amateurs' investment in and ownership of the historical representation. As members of the public, the cast of radical youth, workers, immigrants and so on represent their collective history based on their own research, interpretations, interests, and emotional engagement with the material. However, Scott MacDonald points out in relation to Watkins' earlier grassroots project, The Journey (1983-85), that despite the effort at dispersing authorial agency and establishing collective authorship, Watkins remains the (perhaps necessary) central, facilitating and organizing, authorial voice. ${ }^{165}$ Watkins has himself admitted that $L a$ Commune was an experiment in reducing directorial control on his part but that he could not eliminate it altogether. Moreover, the majority of actors who were selected by the filmmaker largely seem to share and reinforce his own beliefs and perspectives. Yet, this should not take away from the significance of the amateur performer, whose own commitment to and stakes in the ideals of the Commune, their cultural traditions, and the

\footnotetext{
${ }^{164}$ Michael Wayne, "The Tragedy of History: Peter Watkins's La Commune," Third Text 16.1 (2002): 58.

${ }^{165}$ Scott MacDonald, "Filmmaker as Global Circumnavigator: Peter Watkins's The Journey and Media Critique," Quarterly Review of Film and Video 14.4 (1993): 51.
} 
film's production process are prioritized in the film and are crucial to its meaning for both performers and viewers.

Watkins' appropriation of documentary conventions for staged material, whether representing the past or the future, throws into question the assurances of objectivity and truth-value of those conventions. Although the films are based on extensive research and may refer to actual events, statements, or conditions, Watkins' particular method of generic mixing disrupts a straightforward reading of both categories and prevents a reduction of the films to either pure fiction or pure documentary. Instead, the dualities throughout Watkins' approach - what might be perceived as contradictory movements both trouble and transcend conventional categories. This hybridity further extends beyond his films' formal strategies and takes place within the casting and performances, in the way the films function as psychodramas where the actors play roles but improvise dialogue to express their own strongly held convictions, they have specific personal connections to the roles they play, and their participation in the film involves intense engagements with their national past. To various degrees these features of Watkins' work can be found in other filmic examples of historical reenactment, in films that employ non-professional actors whose memories, identities, and emotional investments inform the productions. Although Watkins undermines documentary's formal conventions as guarantees of authenticity, his films assert the material process of 
reenactment and the genuine convictions of the amateurs in the performers' experiential and personal engagement with the material. In La Commune, the performances thus constitute evidence of the persistence of the past, of the continuity of the Commune's ideals and their relevance in the present. This is less a matter of authenticating the representation, which is itself recognized as an interpretation, than an acknowledgement that the fictional and the real, like the past and the present, are not independent spheres. Hence, La Commune directs us to its own production process as a historical event that is simultaneously a fabrication. 


\section{CHAPTER FOUR}

\section{Performing Knowledge: \\ The Making of The Journals of Knud Rasmussen}

Our name Isuma means 'to think,' as in Thinking Productions. Our building in the centre of Igloolik has a big sign on the front in Inuktitut that says 'Isuma.' Think! Young and old work together to keep our ancestors' knowledge alive. We create traditional artifacts, digital multimedia and desperately needed jobs in the same activity. Our productions give an artist's view for all to see where we came from: what Inuit were able to do then and what we are able to do now.

Zacharias Kunuk ${ }^{166}$

At the moment that they entered the igloo, the children whistled softly and grinned at each other. Some of them had never been inside an igloo before; others had never seen one so big. I don't think they'll ever forget that moment. There's a sign up in the Isuma office that says: 'SMILE: IT'S ONLY A MOVIE!' - but at times like this, it feels like something much bigger. Imagine being 8 years old, and acting in a film that gives you your first experience of an igloo! Such moments are a crucial part of Isuma's project - seldom remarked upon internationally, but clearly vital on the ground.

S.F. Said, on the set of The Journals of Knud Rasmussen ${ }^{167}$

The previous two chapters demonstrate how the blurring of boundaries between

documentary and fiction and between past and present in filmed reenactment is generated

by the context and conditions of production, by employing amateur performers and by

drawing attention to the filmmaking as an intervention. This chapter concentrates on

\footnotetext{
${ }^{166}$ Zacharias Kunuk, "I first heard the story of Atanarjuat from my mother," in Atanarjuat the fast runner (Toronto: Coach House Books and Isuma Publishing, 2002), 15.

${ }^{167}$ S.F. Said, “Frozen Bread?" [weblog entry] Igloolik's Embedded Journalist, April 15, 2005, accessed January 10, 2011, http://www.sila.nu/live/page?atom_id=sfsaidblog\&date=2005-04-15.
} 
another pairing relevant to the production process, the archive and performance, as distinct but integrated means of preserving and transmitting knowledge. The archive ${ }^{168}$ refers to the historical records, written documents, and artefacts that are housed in libraries or museums and are imbued with a certain authority as historical knowledge. Performance refers to the way in which memory, history, and tradition are maintained through such practices as oral narration, rituals and ceremonies. Both archival and performance-based knowledge are significant to the narrative and the production of The Journals of Knud Rasmussen (2006), a film that centers on the meeting between the Danish ethnographer and an Inuit shaman. Journals is the second and most recent narrative feature by Inuit filmmaker Zacharias Kunuk and his team at Igloolik Isuma Productions. Isuma is an independent production company dedicated to the revival and continuation of traditional Inuit knowledge through the production of films and videos in which amateur Inuit performers reenact a way of life remembered and recorded within oral history.

By reenacting Igloolik elders' stories on video, Isuma asserts cultural continuity and challenges the assumption of inevitable extinction that underpins ethnographic representations from the early twentieth century, such as Nanook of the North (1922). However, Isuma's positioning in relation to ethnographic portrayals is not simply one of

\footnotetext{
${ }^{168}$ Literature on the archive indicates a range of meanings and uses of the term, which may be broadly conceived or more limited depending on the disciplinary context of its usage. The definition employed in this chapter is indebted to Diana Taylor's theorization of the distinction between archival materials and performance practices in The Archive and the Repertoire: Performing Cultural Memory in the Americas (Durham and London: Duke University Press, 2003). Taylor's argument is discussed in more detail later in the chapter. For an outline of various conceptualizations of the archive among archivists, historians, and cultural theorists, see Marlene Manoff, "Theories of the Archive from Across the Disciplines," portal: Libraries and the Academy 4.1 (2004): 9-25. See also two issues of History of the Human Sciences, 11.4 (1998) and 12.2 (1999), which include articles on the archive from a variety of perspectives and fields of study.
} 
opposition but involves a more dynamic engagement and negotiation. In his observations of "heritage projects" within Native American communities, James Clifford demonstrates how efforts at reviving traditions often entail the appropriation of ethnographic texts and anthropological artefacts to give these archival materials new meanings within performance contexts. ${ }^{169}$ Journals exhibits this simultaneous incorporation and decentering of ethnographic knowledge throughout the film's narrative and its production. On one hand, oral history, alongside elders' memories, informs the form, function, and foundation of the narrative to establish an Inuit point of view that undermines the authority of ethnographic texts. On the other, the production of Journals involved archival research and employed ethnographic accounts, photographs, and museum collections as a valuable resource in the construction of the script and the miseen-scène. Archival objects and documents were also employed as catalysts and references for performance practices, including storytelling and reenactment, which are the privileged means of communicating and passing on Inuit history.

This chapter thus attends to reenactment as a mode of transmitting knowledge. In so doing, it expands the sphere of reenactment beyond the performances on screen or the filming process to encompass a range of "behind the scenes" activities that comprise the film's production, including the building of sets, sewing costumes, and make-up application. During the production of Journals, Isuma documented these activities with a collection of videos, photos, and weblogs posted on the film's website. This

\footnotetext{
${ }^{169}$ James Clifford, "Looking Several Ways: Anthropology and Native Heritage in Alaska," Current Anthropology 45.1 (2004): 8. See also Routes: Travel and Translation in the Late Twentieth Century (Cambridge, Massachusetts and London: Harvard University Press, 1997) and "Four Northwest Coast Museums: Travel Reflections," in Exhibiting Cultures: The Poetics and Politics of Museum Display, eds. Ivan Karp and Steven D. Lavine (Washington and London: Smithsonian Institution Press, 1991), 221-54.
} 
supplementary material situates the film and its making in a broader social and cultural context and deprivileges the text as an isolated and discrete object. The website indicates a complex of processes involved in preparation for filming (including rehearsals, set construction, organizing the mise-en-scène) that constitutes the field in which traditional knowledge is performed and wherein the film as a record of Inuit history (the reenactment of an event) becomes merely one dimension of a much larger project of preserving and continuing ancestral skills (reenactment as an event). In order to revive the traditional methods for making clothing and artefacts, the reconstruction of material culture for Journals was modeled on the oral narratives of local elders along with ethnographic documents gleaned from archival research. By drawing on both areas of historical knowledge, Isuma's film and its production establish sites of synthesis, where the categories of performance and archive meet, merge, integrate, and mutually inform each other. More significantly, however, the field of making becomes a site where knowledge is activated and put into practice, whereby the past is remembered, repeated, taught, and learned through its reenactment.

\section{Performance and the Archive}

In recent years, a diverse range of disciplines (history, philosophy, cultural theory, anthropology, among others) have taken an interest in the concept of the archive. ${ }^{170}$ Depending on the context in which it is used, the term "archive" can refer to an actual repository where records are kept, the whole of the historical record, public or private

\footnotetext{
${ }^{170}$ Manoff, "Theories of the Archive from Across Disciplines," 9. A number of scholars have identified an "archival turn" in the last decade. See Carolyn Steedman, Dust: The Archive and Cultural History (New Brunswick, New Jersey: Rutgers University Press, 2002) and Ann Laura Stoler, "Colonial Archives and the Arts of Governance," Archival Science 2 (2002): 87-109.
} 
memory, or the drive to collect and store the traces of the past. The definition employed in my discussion of reenactment in ethnographic cinema and Isuma's Journals is borrowed from Diana Taylor's The Archive and the Repertoire: Performing Cultural Memory in the Americas. ${ }^{171}$ For Taylor, the archive is not a place of storage so much as a category of knowledge production that signals the types of items available for storage; it is a way of saving the past in a tangible and unchanging representational form - writing, pictures, objects. In contrast to archival methods of preservation, Taylor posits what she calls the repertoire, an alternative domain of knowledge production and memory maintenance in which "embodied practice" constitutes the means of carrying and transmitting history. The repertoire includes but is not limited to performance events (storytelling, rituals, festivals), as engagements with the past that provide evidence of collective memory expressed through the body. This understanding of performance as "a way of knowing" 172 elucidates the centrality of reenactment within Isuma's work, which both depends upon and contributes to the repertoire. This is apparent from the way Isuma makes public the production process of Journals, a film that should be seen less as a discrete text or archival object than as part of a larger practice of embodied engagements with Inuit history.

Taylor's distinction between the archive and the repertoire is a division between what are typically perceived as "enduring materials" and "so-called

\footnotetext{
${ }^{171}$ Diana Taylor builds on the work of Richard Schechner and Victor Turner, whose foundational research in the field of performance studies explored the intersections between theatre and anthropology. This interdisciplinary area of study provides a broad definition of performance, which includes a range of behaviour practiced in daily life, the workplace, and cultural sites. See Richard Schechner, Performance Studies: An Introduction (New York: Routledge, 2006) and Between Theatre and Anthropology (Philadelphia: University of Pennsylvania Press, 1985), and Victor Turner, The Anthropology of Performance (New York: PAJ, 1986).

${ }_{172}$ Taylor, The Archive and the Repertoire, 3.
} 
ephemeral...embodied practice/knowledge." historical records along with "documents, maps, literary texts, letters, archaeological remains, bones, videos, films, CDS, all those items supposedly resistant to change."174 Whether texts or objects, archival entities are bounded and stable, characterized by consistency across time and space: "Archival memory works across distance...[and] succeeds in separating the source of 'knowledge' from the knower... What changes over time is the value, relevance, or meaning of the archive, how the items it contains get interpreted, even embodied." 175 By contrast, the repertoire, which includes oral narration, sports, ceremonies, historical reenactment, or song and dance, involves transmission between subjects occupying a shared space. Unlike the stability of archival objects, the bodily behaviours of the repertoire and the knowledge they carry are renewed in each situation of performance and adjust to the particular social and material conditions in which they occur. Taylor argues that just as archival materials can change (degrade, deform, disappear, etc.), the context dependant acts of performance often maintain a consistency of meaning. Performance practices thus "function as vital acts of transfer, transmitting social knowledge, memory, and a sense of identity through reiterated [behaviour]."176

In the discussion below, my use of the term archive in relation to ethnographic material on Inuit culture refers to the body of knowledge contained in the writings, photographs, films, and artefacts produced and collected by anthropologists. The term

\footnotetext{
${ }^{173}$ Ibid., 19.

${ }^{174}$ Ibid.

${ }^{175}$ Ibid.

${ }^{176}$ Ibid., 2 .
} 
also connotes the authority that has typically and historically been attached to this kind of knowledge making. Although the term may have a range of applications across disciplines, most scholars agree that the archive, whether literal or metaphorical, is associated with institutional power and establishes boundaries with respect to what counts as knowledge. ${ }^{177}$ Taylor's argument centers on the archive/repertoire distinction not as necessarily oppositional ${ }^{178}$ but as historically separated along cultural lines, such that the absence of written records and material archives within oral cultures has been indicative of a lack of history and civilization. ${ }^{179}$ From a similar perspective, Rebecca Schneider points out how practices like oral history and historical reenactment are typically viewed as "ritual," "ethnic," and "primitive" regardless of the cultural context in which such performances take place. ${ }^{180}$ Both Schneider and Taylor demonstrate how, despite a recent expansion of the types of material included within archives, the dominance of archival knowledge persists in contemporary scholarship with the assumption that performance means loss or disappearance, an idea that Taylor calls "profoundly political."181 That which disappears leaves nothing behind, no material traces, no permanent evidence, and therefore no identifiable history. Both theorists stress

\footnotetext{
${ }^{177}$ See Stoler, "Colonial Archives and the Arts of Governance," and Jacques Derrida, Archive Fever: A Freudian Impression (Chicago and London: The University of Chicago Press, 1996).

${ }^{178}$ Taylor notes that the categories "work in tandem" and "exist in a constant state of interaction". Taylor, The Archive and the Repertoire, 21.

${ }^{179}$ Fatimah Tobing Rony illustrates the presumed dichotomy between cultures that are identified as ethnographiable and those that are historifiable - terms coined by Claude Levi-Strauss. As a classification attributed to oral cultures, the ethnographiable are perceived as "people without history, without writing, without civilization, without technology, without archives... as opposed to people classified as 'historifiable'... those considered to have written archives and thus a history proper." This distinction posits Western cultures as active agents of history and producers of knowledge and non-Western cultures as passive objects of knowledge - there are those who make history and those who are history, respectively. Fatimah Tobing Rony, The Third Eye: Race, Cinema, and Ethnographic Spectacle (Durham and London: Duke University Press, 1996), 7.

${ }^{180}$ Rebecca Schneider, "Performance Remains," Performance Research 6.2 (2001): 102.

${ }^{181}$ Taylor, The Archive and the Repertoire, 5.
} 
instead the ways in which performances also save but save differently and should be defined not by loss but by continuity with the past.

As modes of preserving history, the archive keeps the past in the form of static entities and the repertoire continues the past by activating knowledge in the present through embodied practices. Norman Cohn, one of the members of Isuma, points to this differentiation between fixity and continuity in his remarks on preserving Inuit knowledge: "The lab [the Igloolik Research Centre] archives knowledge - it doesn't perpetuate it. If Rachael [an Igloolik elder] makes a tent and her three daughters learn how by watching her, then the knowledge is not archived. It is active and perpetuated."182 As a pedagogical activity conducted in part for an audience of observerstudents (the three daughters), Rachael's building of a tent is a performance that transmits knowledge between generations. The knowledge that is here perpetuated is part of a living culture rather than contained, fixed, and housed for posterity - what Derrida calls the domiciliation of the archive. The continuation of knowledge and history within living circumstances demands adaptation to changing conditions. It is precisely this adaptation over time that ensures cultural continuity rather than signals loss. Isuma exemplifies this process by combining the Inuit tradition of oral storytelling (as a way of preserving knowledge and history) with state-of-the-art film and video production. The tradition therefore does not remain static over time but is remade and translated within and for a contemporary context.

\footnotetext{
${ }^{182}$ Norman Cohn quoted in Michael Robert Evans, "Frozen light and fluid time: The folklore, politics, and performance of Inuit video" (PhD thesis, Indiana University, Bloomington, 1999), 103.
} 
If Isuma's films and videos belong to the category of the archive, the production of these representations is committed to the perpetuation of knowledge within the repertoire. According to Taylor: "A video of a performance is not a performance, though it often comes to replace the performance as a thing in itself (the video is part of the archive; what it represents is part of the repertoire)." ${ }^{n 183}$ Moving image recordings are certainly objects that communicate knowledge across space and time, with a representation that remains consistent with each viewing. However, in Isuma's work, performance as embodied memory and knowledge is not simply that which is fixed on tape but is also, and more significantly, the context which the texts emerge out of and feed back into. In other words, the archival object is both a product and a tool of the repertoire; it serves as a catalyst for embodied activities within the performance spaces of production and reception. Thus Isuma's preservation of Inuit history, traditions, and knowledge is less a matter of producing video records of a traditional way of life than of stimulating the memories of the past, in stories and skills, during the filmmaking process. In addition to the reenactment of traditional Inuit ceremonies, rituals, dances, games, competitions, and oral narratives that takes place within Journals, performance as embodied memory is crucial to the film in two primary ways. First, the production continues the practice and function of oral storytelling by having elders convey their memories for the film's narrative and by using film to pass on the history, knowledge, and lessons contained in these stories to future generations. Second, the production of the mise-en-scène for the historical representation reenacts and transmits traditional skills, such as igloo construction, facial tattoos, and clothing designs. The activities of film production may

\footnotetext{
${ }^{183}$ Taylor, The Archive and the Repertoire, 20. Emphasis in original.
} 
not be a performance in the conventional sense but they are embodied acts of mimicry and pedagogy that transmit knowledge much like the tent construction in Cohn's remark, whereby the younger Inuit learn traditional practices from the elders by observing and imitating. By placing emphasis on the oral foundation of the film and how it is made, Isuma challenges the dominance of archival ways of knowing and refuses the reduction of their practice to a collection of texts.

Before explicating these two dimensions of knowledge transmission in Journals, I first turn to the use of reenactment in early ethnographic cinema to which Isuma's own use of reenactment responds and that have equally contributed to activating the knowledge of the repertoire within contexts of production and reception.

\section{Reenactment in Early Ethnographic Cinema}

Isuma's project shares certain features with that of early ethnographic cinema, such as the use of reenactment as a central representational strategy, the attention to ethnographic details of quotidian activities, and the merging of pedagogical with entertainment intentions. In the ethnographic representations of the early twentieth century, however, reenactment has a different meaning and function. In the films by Edward S. Curtis and Robert Flaherty reenactment was employed to document and dramatize what were perceived as rapidly disappearing, if not already extinct, life worlds. Both filmmakers' efforts to reconstruct "authentic" pre-contact indigenous cultures represented these cultures as fixed in the past, without a present identity or a future existence. The notion that indigenous cultures were vanishing since first contact with Europeans, which 
persisted for decades within written and visual ethnographies, has been challenged from both inside and outside the discipline of anthropology. In the 1980s a self-reflexive interrogation of the methodologies and conventions governing ethnographic representations directed a critical gaze on the assumptions of salvage anthropology. ${ }^{184}$ Over the last four decades, the emergence and growth of indigenous media production has also been instrumental in disrupting ethnography's status as a privileged arena of knowledge about non-Western peoples while asserting contemporary identities. ${ }^{185}$ In addition, new indigenous audiences of ethnographic representations (including artists, museum curators, and media producers) have appropriated these texts for their own ends, transforming their meaning and function. ${ }^{186}$ In these reception contexts the reenactments

\footnotetext{
${ }^{184}$ See James Clifford, The Predicament of Culture: Twentieth-Century Ethnography, Literature, and Art (Cambridge, Massachusetts, and London: Harvard University Press, 1988) and James Clifford and George E. Marcus, eds., Writing Culture: The Poetics and Politics of Ethnography (Berkeley, Los Angeles, and London: University of California Press, 1986). Clifford and Marcus interrogate the assumptions and conventions within ethnographic writing and museum display. Their studies question the way in which ethnography has traditionally represented other cultures and how, through these representations, the discipline of anthropology has understood and justified its own project as a scientific field of knowledge. For critiques of methodological approaches in ethnographic filmmaking see David MacDougall, Transcultural Cinema, ed. Lucien Taylor (Princeton, N.J.: Princeton University Press, 1988) and Jay Ruby, Picturing Culture: Explorations of Film and Anthropology (Chicago: University of Chicago Press, 2000).

${ }^{185}$ See Faye Ginsburg, "The Parallax Effect: The Impact of Indigenous Media on Ethnographic Film" in Collecting Visible Evidence, eds. Jane M. Gaines and Michael Renov (Minneapolis and London: University of Minnesota Press, 1999), 156-175.

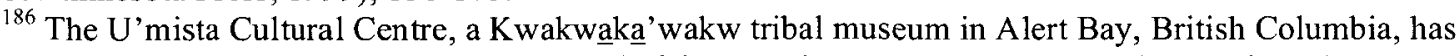
organized screenings' of Curtis' In the Land of the War Canoes, combined with live music and performances by the descendants of the film's cast. The project also featured two photography exhibits that engage with Curtis' photographs, including contemporary restagings of the historical images by Sharon Eva Grainger. The project placed emphasis on the production of images as a negotiated encounter to consider the subjects' performances and stagings as instances of Kwakwaka'wakw self-presentation. Photographer Jeffrey Thomas also uses Curtis' imagery, along with other romanticized portrayals of the history of First Nations people, in evocative combinations with a contemporary urban environment. Carl Beam's mixed media collages also generate provocative critiques and associations by combining historical ethnographic representations with contemporary images from popular culture. Photographer Rosalie Favell reconfigures representations from film, television, painting, and advertising into self-portraits that investigate familial history and cultural identity. Video artist Bear Witness promotes critical readings of stereotyped portrayals of Native subjects by reediting clips from familiar films with added text and a new soundtrack. Documentary filmmaker Alanis Obomsawin incorporates ethnographic material, especially
} 
that were founded on the assumption of loss are reframed as evidence and tools of the repertoire.

What I am identifying as reenactment in ethnographic films (and in Isuma's work) refers not simply to the representation of the past, nor a specific historical occurrence, but to the performance of traditional cultural practices typical of a prior period and a particular place. These practices can range from the mundane details of daily life, such as cooking or sewing, to hunting methods, games, and ceremonial activities. Anthropologist and filmmaker Asen Balikci distinguishes the objectives of ethnographic film reenactments from historical films when he remarks that in "visual anthropology cultural reconstruction acquires a different meaning. The general aim is to partially reconstruct sequences of traditional behaviour as part of a routinized social process. No attempt is made to portray the extraordinary or the unique." ${ }^{187}$ Balikci outlines three categories of anthropological reconstruction that are distinguished by the types of activities performed and the scale of the cultural process represented. The first category is limited to a single task by an individual or small group and concentrates on the process and techniques used in the construction of material objects, such as building a canoe or carving a sculpture; the second involves larger groups in organized performances, such as traditional songs or dances, which have precise structures, roles, and conventions; the scope of the third includes the first two but situates them within an entire life world in

illustrations, in many of her films to depict the history of colonialism in which current struggles over land claims and Native rights are situated.

${ }^{187}$ Asen Balikci, "Reconstructing Cultures on Film," in Principles of Visual Anthropology, $2^{\text {nd }}$ ed., ed. Paul Hockings (Berlin and New York: Mouten de Gruyter, 1995), 181. 
order to provide "a rounded illustration of the indigenous way of life."188 Curtis' In the Land of the War Canoes (1914) and Flaherty's Nanook of the North (1922) together cover the range of these categories. Although the films concentrate on different types of activities - large communal events and solitary or familial everyday tasks, respectively in both cases the filmmakers depict indigenous cultural practices, tools, and artefacts that were no longer in use as a result of being banned (the potlatch in In The Land of the War Canoes) or altered (hunting methods in Nanook of the North). These activities, moreover, are framed within fictional narratives and are imbued with a spectacular and dramatic quality that make apparent (if unintentionally and only in contemporary readings) the indigenous actors' self-conscious performances for the camera.

In In the Land of the War Canoes the reenactment of Kwakwaka'wakw ceremonial performances is framed within a fictional melodrama of love, revenge, and sorcery acted by Kwakwaka 'wakw participants and filmed on location in British Columbia. The narrative dimension of the film, however, Fatimah Tobing Rony rightly observes, is “labored: Curtis's film is really an excuse to string together footage purporting to offer a view of the Kwakwaka'wakw way of life before the nineteenth century." 189 Indeed, most of the screen time is devoted to traditional dances, many of which were filmed in real time with long takes and which disrupt the story's momentum. In one sequence of six relatively long takes, each shot depicts a different dance. Some of the scenes show a few dancers circling a fire, an object or person, while others have large groups of dancers and drummers (including men, women, and children in multiple rows)

\footnotetext{
188 Ibid., 183.

${ }^{189}$ Rony, The Third Eye, 94.
} 
in front of a wall framed by totem poles and facing the camera as if on a stage. Many of the actors also wear elaborate costumes and masks representing various animals. In one shot, a row of women is seated in front of a curtain drumming while a man dances in the foreground. After a minute the curtain falls to reveal several rows of dancers in bird costumes with enormous beaks gesturing to the beat of the drums. While the film's concentration on ceremonial dances and its theatrical display removes these practices from their application within daily life, In the Land of the War Canoes was initially admired for demonstrating the use of Kwakwaka'wakw artefacts - the totem poles, canoes, and masks typically found in museum exhibits - within a context of live action. $^{190}$

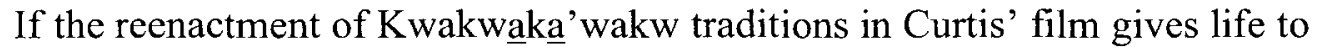
Kwakwaka'wakw material culture, it is premised on the supposed extinction of indigenous peoples. For Curtis, the impetus to record traditional Native American ways of life was based on the assumption that the cultures were disappearing, in part as a result of modernization processes brought about by European contact and colonialism. As a photographer and filmmaker, Curtis produced what Rony calls an "archive of 'vanishing Indians" "191 - an extensive collection of images that document Native American history by staging picturesque scenes of a romanticized and a mythologized past. Reenactment was put in the service of salvage ethnography, where the intention was not to ensure the survival of indigenous cultures but to create a record of what was dying out before it had completely and inevitably disappeared: "a central premise of much of anthropology was

\footnotetext{
${ }^{190}$ Joanna Hearne, "Telling and retelling in the 'Ink of Light': documentary cinema, oral narratives, and indigenous identities," Screen 47.3 (2006): 317.

191 Rony, The Third Eye, 79.
} 
that the native was always already vanishing, and the anthropologist could do nothing but record and reconstruct, racing against the evolutionary clock." ${ }^{192}$ By employing reenactment as a necessary strategy, In The Land of the War Canoes aims to depict the Kwakwaka'wakw as they would have looked prior to contact, as authentic natives tied to purely traditional life worlds and thus confined to the past, much like in Curtis' photographs:

His images did much to further the 'vanishing Indian' trope and the idea of the authentic or pure Indian, frozen in time and untouched by Euro-American culture. Close scrutiny of Curtis's photographs reveals his strategic and careful arrangement of his subjects to conform to an idea of the precontact 'primitive'... He supplied wigs and costumes, and removed wristwatches, umbrellas, suspenders and signs of written language in order to eliminate evidence of acculturation, hybridity, and modernity. ${ }^{193}$

Curtis' reconstructions reinforced the view of indigenous cultures as static, unable to change without disappearing or to invent themselves in new ways, thereby denying Native Americans presence as modern subjects.

Like Curtis, Flaherty had no interest in representing a contemporary Inuit culture that had incorporated hunting rifles, cotton clothing, and a cash economy by the time Nanook of the North was made in 1922. The film instead presents an Inuit way of life as primitive, uncontaminated by modern civilization, and set in a mythic, precontact past. The reenactment of the particularities of daily life and spectacular scenes of hunting are shaped into a fictional drama of an Inuit family living off the land and their struggle to survive in the harsh Arctic conditions. The Inuit who play Nanook, his two wives and children, enact ordinary everyday activities, such as the family sleeping in an igloo,

\footnotetext{
${ }^{192}$ Ibid., 91.

${ }^{193}$ Hearne, "Telling and retelling in the 'Ink of Light'," 311.
} 
children playing games, and Nanook teaching his son how to shoot a bow and arrow. The film also spends some time on the processes by which Nanook builds an igloo, repairs his kayak, and ices the runners of his sledge. The main attractions, however, are the hunting sequences, especially the harpooning of a walrus early in the film and the climactic scene of a seal hunt, which generate much of the film's dramatic tension and suspense. In both cases, traditional hunting practices are represented as daring battles of strength between Man and Nature. In the walrus scene, several hunters strenuously attempt to pull the animal onto land before being themselves pulled into the water. In the seal hunt, Nanook engages in a similar tug of war through a hole in the sea ice. These scenes typify the overall tone of the film in its focus on the whole Inuit way of life as a conflict with the environment. The intertitles in particular place emphasis on a brutal climate and a constant threat of starvation as characterizing Inuit existence. While the film attends to some of the skills required for living off the land in the Arctic, it ultimately impresses upon the viewer the simplicity of a traditional life world concerned with meeting the basic needs of survival.

Recent scholarly critiques of Nanook of the North point to the predetermined and intentional performances on the part of the Inuit subjects, their acting for the camera, as undermining the documentary intentions of the film. In a discussion of the film's trading post sequence, in which Nanook is introduced to a gramophone and "feels the record three times with his mouth, as if tasting it," Faye Ginsburg notes that we "now recognize 
the scene as a performance rather than documentation of first contact." ${ }^{" 194}$ We are certainly aware today of the many artifices in Flaherty's representation - that the character of Nanook was played by an Inuk named Allakariallak and that his two wives in the film may have been Flaherty's. The fakery and acting in many scenes even seems boldly apparent, especially during the seal hunt, as Allakariallak performs a slapstick routine (falling and sliding on the ice, twisting and struggling with the rope) while pretending to pull an already dead seal from the sea ice. ${ }^{195}$ Allakariallak also looks at the camera frequently and laughs, including in the gramophone scene, where he pretends to be unfamiliar with western technologies despite the fact that he and Flaherty's other Inuit assistants helped to repair the camera on numerous occasions. Rony therefore sees this moment in the film as assuring contemporary audiences of the naiveté of the indigenous subjects. In her critical analysis of Nanook, among other early films of indigenous cultures, Rony argues for a perspective that "acknowledges performance rather than empirically represented Primitives in timeless picturesques." ${ }^{196}$ To recognize the indigenous performers as actors opposes the still common assumption, including with respect to fiction films, that Natives in films are always signifiers of the real. Rony thus draws attention to "performance strategies as resistance, recontextualization, parody, and

\footnotetext{
${ }^{194}$ Faye Ginsburg, "Screen Memories: Resignifying the Traditional in Indigenous Media" in Media Worlds: Anthropology on New Terrain, eds. Faye Ginsburg, Lila Abu-Lughod, and Brian Larkin (Berkeley, Los Angeles, and London: University of California Press, 2002), 39.

${ }^{195}$ Much of the fakery and inaccuracies are exposed in the film Nanook Revisited (1990), which returns to the location where Nanook of the North was filmed to convey the community's oral history of its production. The documentary also reenacts the making of the seal hunt scene to demonstrate its artifice. Conflicting claims between Inuit oral history and Flaherty's written accounts of the production demonstrate distinct forms of memory from different cultural traditions.

${ }^{196}$ Rony, The Third Eye, 13.
} 
even simple restraint." ${ }^{197}$ Nanook's laugh is now more frequently read as a sign of Allakariallak's agency and resistance, as well as his performance for the camera, rather than a marker of authenticity.

Just as recognition of the indigenous subjects as actors acknowledges their agency, an attention to the reenactment of traditional activities as a performance of knowledge on the part of the actors further undermines the underlying assumption of vanishing. If reenactment was a marker of loss, it is also indicative of persistence and continuity. The contradiction is demonstrated in the introduction to The Silent Enemy (H.P. Carver, 1930), a fictional narrative about an Ojibway ${ }^{198}$ tribe facing starvation. Although the film is silent and was filmed on location, it opens with a shot of the actor Chief Yellow Robe in a studio delivering a monologue in synchronized sound:

This picture is a story of my people...in years of famine we suffered. Soon we will be gone. Your civilization will destroy us, but by your magic we will live forever. We thank the white man who helped us to make this picture. They came to our forests, shared our hardships. They listened to our old men around the campfire. We told them the stories our grandfathers taught us. That is why this picture is real. Look not upon us as actors, we are living our own life today as we lived it yesterday. Everything you see is as it always has been: Our buckskin clothes, our birchbark canoes, our wigwams, and our bows and arrows. All were made by my people as they always had done.

The speech begins with the "vanishing Indian" myth by remarking on the way the Ojibway will inevitably disappear as a result of both environmental (famine) and cultural forces ("Your civilization will destroy us"). Yet, in order to assert the film's authenticity, this opening scene identifies practices of cultural continuity, both in the telling of stories and in the making of clothing and artefacts ("as they always had done") by the

\footnotetext{
${ }^{197}$ Ibid., 17.

${ }^{198}$ Jay Ruby notes that the "film is an amalgam of elements from several cultures with a cast from three or four groups." Jay Ruby, "Film Reviews," American Anthropologist, 96.1 (1994): 222.
} 
supposedly vanishing people represented. While The Silent Enemy, In the Land of the War Canoes, and Nanook of the North purport to depict dying cultures assigned to the past, their representations depended on the knowledge of indigenous traditions and further made that knowledge present by putting it into practice in the on-camera performances and off-camera production process. Thus, as some critics have pointed out, there is a definite irony embedded in the use of reenactment to create records of vanishing cultures. The very fact that the traditional practices are reenacted demands the survival and revival of the knowledge necessary for the activities to be performed.

In addition, the way in which such films are read and used by the indigenous subjects they represent turns these representations into resources for the recovery of traditions, skills, and knowledge interrupted by centuries of colonialism. For example, Joanna Hearne discusses how ethnographic images, both photographs and films, have been appropriated and reframed by indigenous communities, particularly with respect to Curtis' photography. Hearne notes that "Native viewers have used the photos to revive cultural traditions rather than to document their loss, as happened when Piegan men revived the Sundance on their reserve after forty years, partly inspired by Curtis's photographs of the ceremony."199 This is equally the case with Kwakwaka'wakw viewers of In the Land of the War Canoes:

Like his photographs, Curtis's film, while staging the Native actors and their cultural expression in a melodramatic cover story, has also provided images that contemporary Native communities have integrated into their attempts to recuperate cultural ties. Along with other ethnographic materials from the same period, the film has contributed to a visual archive available for indigenous repurposing, often at an intimately local level of familiar recognition. ${ }^{200}$

\footnotetext{
${ }^{199}$ Hearne, "Telling and retelling in the 'Ink of Light'," 319.

${ }^{200}$ Ibid., 308.
} 
Reception thus involves an interaction between the archive and the repertoire, whereby the film as record becomes a reference for the performance and continuation of traditional knowledge. Hearne further identifies the rejuvenation of Kwakwaka'wakw knowledge and tradition within the production of Curtis' film by reenacting ceremonies that had been banned and making props and costumes for the film. "The filmmaking provided the opportunity and economic incentive - though for a limited time - for Kwakwaka'wakw to revisit and relearn skills in making ceremonial objects and clothes, thus indicating how film production might serve as a site of cultural revival and renewal rather than an instance of vanishing. ${ }^{201}$ Along with the performances that take place on screen, the contexts of production and reception also generate performance practices that position the films as tools and catalysts of the repertoire.

In Isuma's project, while the production of Journals is a site for the revival of traditional practices, it is also a site for the reception of ethnographic representations, where the ethnographic texts are used as models for the making of material culture and both processes - production and reception - are instrumental in perpetuating Inuit knowledge.

\section{Igloolik Isuma Productions}

Isuma's project is committed to both reviving Inuit traditions and renewing traditional practices for contemporary conditions through the local production and dissemination of media. As an independent video production company based in Igloolik, Nunavut, Isuma

\footnotetext{
${ }^{201}$ Ibid., 315.
} 
combines videomaking, oral storytelling, and reenactment to bring the knowledge and values of a past way of life into the present as a guide for the future. The company was formed in 1989 (incorporated in 1991) by Zacharias Kunuk and Norman Cohn, ${ }^{202}$ with two additional partners and co-owners: Igloolik elder Pauloosie Qulitalik and the late Paul Apak. ${ }^{203}$ The members work collaboratively, ${ }^{204}$ sharing administrative power, decision-making, and creative control among themselves and with the community of Igloolik. In Cohn's words, "Inuit skills of working together join with southern ideas of community videomaking in a new model of professional production." ${ }^{205}$ After a decade of producing numerous short videos and a television series, which were distributed on Television Northern Canada and exhibited internationally in museums and art galleries, Isuma expanded their practice to the production of feature films on high-definition digital video. Their first feature and the first Inuktitut-language film, Atanarjuat The Fast Runner (2001), won the Camera D'or at Cannes among numerous other awards and received wide theatrical release internationally. As the scale of the productions expand and their audience broadens internationally, Isuma's filmmaking remains firmly rooted in the historical traditions and contemporary needs of their local collaborators and viewers.

\footnotetext{
${ }^{202}$ Norman Cohn is the only non-Inuit member of Isuma. Cohn worked as a video artist in New York and Montreal before moving to Igloolik in the mid-1980s to collaborate on projects with Kunuk at the Inuit Broadcasting Corporation.

${ }^{203}$ Paul Apak passed away during the production of Atanarjuat the fast runner, for which he wrote the script.

${ }^{204}$ Isuma insists on being recognized as a team without a hierarchical structure. Yet, as Laura Marks points out, the reception of Isuma's videos in the south has tended to single out Kunuk as the primary auteur.

Laura U. Marks, "Inuit Auteurs and Arctic Airwaves: Questions of Southern Reception," Fuse 21.4 (1998): 13-17.

${ }^{205}$ Norman Cohn, "The Art of Community-based Filmmaking," in Atanarjuat the fast runner (Toronto: Coach House Books and Isuma Publishing, 2002), 27.
} 
From the production of their early videos to the feature films, the company has maintained a community-centred approach dedicated to Igloolik's economic sustainability. Igloolik residents are involved at every stage and in various facets of the production process, from development and planning to acting and filming. For Atanarjuat, local residents were hired as assistants or consultants, and received technical training. As Faye Ginsburg explains, Isuma's work is not simply a collection of films and videos but a practice of community development by providing training and employment:

the materiality of making a feature film in an Inuit world demands forms of imagination that extend far beyond the film text. As Igloolik Isuma moved into feature filmmaking - a more expensive and commercial form of media production than their previous video work, and one that requires considerable labor - all this has become an important form of economic development for Igloolik. In the end, more than 100 Igloolik Inuit, from the young to the elderly, were employed as actors, hairdressers, and technicians as well as costume makers, language experts, and hunters who provide food, bringing in more than $\$ 1.5$ million into a local economy that suffers from a 60 percent unemployment rate. ${ }^{206}$

The credits for Journals list four costume designers with twenty-four seamstresses, along with seven igloo builders and seven dog wranglers, and twelve people composed ajaja songs for the soundtrack, with seven performers. All the names are Inuit and this is just a fraction of the entire crew. In addition, for a small town of 1200 , Igloolik is saturated with media production facilities and activities, including a production centre for the Inuit Broadcasting Corporation ${ }^{207}$ along with a number of initiatives connected with Isuma,

\footnotetext{
${ }^{206}$ Faye Ginsburg, “Atanarjuat Off-Screen: From 'Media Reservations' to the World Stage," American Anthropologist 105.4 (2003): 828.

${ }^{207}$ The Inuit Broadcasting Corporation was launched in 1981 as a publicly funded broadcaster run by the Inuit Tapirisat of Canada and dedicated to producing television programming made by and for Inuit. The formation of the organization initially redefined television in the North from a tool of assimilation to one of self-determination. The IBC has five production centres throughout Nunavut and creates a range of programs in Inuktitut, French, and English. For more on the IBC's creation, funding, programming, and
} 
such as a women's video workshop (Arnait Ikkajurtigiit), the non-profit training organization Tarriagsuk Video Centre, the Inousiq Youth Drama Workshop, a local television station and channel and, most recently, two ambitious websites: SILA, an educational and interactive website to teach Inuit children about their history and culture, and IsumaTV, a portal through which indigenous film and video makers can share and exhibit their work. In terms of their ongoing film production, over the last few years Isuma completed their second feature, Journals, for $\$ 6.3$ million (following the $\$ 2$ million budget for Atanarjuat), ${ }^{208}$ which made the company "the town's largest private employer" in 2005, ${ }^{209}$ and produced Arnait's first feature film Before Tomorrow (2008).

With each new venture, Isuma also remains committed to reenacting oral narratives of local history and passing on that history to younger generations of Inuit. All of their productions are set in the Igloolik area and are based on stories conveyed orally by local elders, whether of ancient legends (such as Atanarjuat) or personal memories. Igloolik residents are the source of the narratives, the performers in the reenactments, and the first audience of the final product, as the primary viewers for whom the films and videos are made. Prior to its international premiere at Cannes, Atanarjuat was screened for several days in the town's gymnasium, the largest space available. Tapes of the film

infrastructure, see: Marks, "Inuit Auteurs and Arctic Airwaves"; Michael Meadows, "Ideas form the Bush: Indigenous Television in Australia and Canada," Canadian Journal of Communication 20 (1995): 197-212; Gail Valaskakis, "Communication, Culture, and Technology: Satellites and Northern Native Broadcasting in Canada," in Ethnic Minority Media: An International Perspective, ed. Harold Riggins. (Newbury Park: Sage, 1992), 63-81.

${ }^{208}$ For a discussion of Isuma's struggle with Telefilm to receive funding for Atanarjuat, see Ginsburg, "Atanarjuat Off-Screen."

${ }^{209}$ Denis Seguin, "Hollywood Far Far North," Canadian Business Online, August 29, 2005, http://www.canadianbusiness.com/after_hours/opinions/article.jsp?content=20050829_70181_70181, accessed January 30, 2011. 
were also distributed throughout the community and sent to stores across Nunavut. ${ }^{210}$ Currently, all of their feature films and earlier television material are also made available for viewing and free downloading on the IsumaTV website. By bypassing more conventional structures of film distribution, the company demonstrates a concern with making their work accessible, especially for a population without theatres and with few financial resources. By prioritizing an Inuit audience, creating much needed jobs in the community, and focusing on Igloolik history specifically, Isuma hopes to inspire pride in the place and its past, especially on the part of local youth, whose rate of suicide in the area is six times the national average. ${ }^{211}$ The depressed economy in Nunavut along with its crisis in teen suicide give impetus and urgency to Isuma's constantly expanding practice which, in Kunuk's words, intends "to show youth that a living past means a living future.",212

In its aim to teach Inuit youth about the past and ensure cultural continuity, Isuma employs electronic and digital media to do the cultural work previously performed by oral storytelling. For centuries Inuit oral narration maintained a system of knowledge and history management that transmitted cultural knowledge and beliefs from elders to the youth. Along with other colonial developments (such as trading, formal education, and a written language), the introduction of television in the North displaced storytelling as the common pastime and contributed to a growing generation gap as younger Inuit learned English and gathered new knowledge from external sources that alienated unilingual

\footnotetext{
${ }^{210}$ Zacharias Kunuk, "The Public Art of Inuit Storytelling," The 2002 Spry Memorial Lecture, November 25, 2002, http://www.com.umontreal.ca/spry/old/spry-kz-lec.html, accessed January 30, 2011.

${ }^{211}$ Seguin, "Hollywood Far Far North."

${ }^{212}$ Zacharias Kunuk quoted in Ginsburg, "Atanarjuat Off-Screen," 828.
} 
elders and undermined their teachings. Isuma attempts to bridge such ruptures by reenacting a past based on elders' stories and memories and distributing the material by means of the communication technologies Inuit children have now grown up with, especially with their earlier videos made for Northern television. The pedagogical function of these videos is evident in the observational aesthetic employed to illustrate the kinds of activities typical to a nomadic way of life in the 1930s and 1940s. Rather than reconstructing a specific historical event, the videos follow performers as they hunt a caribou or build an igloo using the tools and methods, and wearing the clothing, appropriate to the year being depicted (including guns, metal cooking implements, or cloth skirts). In the thirteen-part series Nunavut (Our Land) (1995), which traces the daily life of a single family over the course of a year in 1945, each tape focuses on a specific seasonal task. The camera frequently attends to the details of the activity in close-up and patiently observes the full process of an action in long take, such as the gestures of a hunter's hands as he skins a caribou. The concentration on process and detail demonstrates precisely how such activities are performed and gives respect to the richness and depth of the skills required for living off the land.

Just as oral storytelling preserves Inuit culture and history by passing on traditional values and knowledge to future generations, Isuma's work performs the same function for their primary audience. Even though hunting is still a regular part of life in the North, traditional methods are no longer a vital means of meeting basic necessities (i.e. food, shelter, etc.); it is therefore the values embedded in this body of knowledge and a traditional way of life that Isuma imparts for application in a contemporary context. 
Their videos indicate how survival depended not only on the knowledge necessary for hunting but also on a sense of responsibility to a community and problem solving as a team. While Atanarjuat departs from the earlier work by depicting a narrative based on oral legend, Shari Huhndorf describes how the film equally "carries critical lessons" for the present:

In the story, the shaman's curse precipitates the near collapse of a community that had long depended on respect for elders, strict attention to proper family relations, and sharing resources in times of scarcity. By showing the disastrous consequences of departing from these traditions, Atanarjuat insists on their contemporary value and relevance...In this way, the film helps to counter the cultural loss that resulted from the government's assimilationist policies, and it provides a means of recovering and reimagining a past distorted or obscured by colonialist practices, including mainstream media. ${ }^{213}$

Although Atanarjuat is set in an atemporal pre-contact past, the film nonetheless refers to a recent history along with current political and social circumstances, specifically by addressing the effects of colonialism. The knowledge and narratives of the past are thus identified as a resource with which to cope with contemporary social problems, intergenerational conflicts, and the immense cultural transitions of the twentieth-century.

Some of these changes are depicted in Journals, which in certain ways returns to Isuma's earlier approach by drawing on local elders' stories to portray a recent historical period. Since with each new project Isuma takes their work in a new direction, Journals was co-produced with the Danish company Barok Films with a cross-cultural cast and crew that included several Danish and Greenlandic actors ${ }^{214}$ along with the Igloolik cast, most of whom also had roles in Atanarjuat. Unlike the pre-contact setting of the previous

\footnotetext{
${ }^{213}$ Shari Huhndorf, "Atanarjuat, The Fast Runner: Culture, History, and Politics in Inuit Media," American Anthropologist 105.4 (2003): 824.

${ }^{214}$ While the Danes are professional actors, the Greenlandic actors are amateurs.
} 
film, Journals is set in 1922 (the year Nanook was made) as a period of transition, that of the final conversion of the Inuit to Christianity from Shamanism. The narrative concentrates on the meeting between the Danish explorer Knud Rasmussen, during his Fifth Thule Expedition to the Canadian Arctic, and Avva, one of the last remaining shamans in the Iglulik ${ }^{215}$ area. The first half of the film depicts cultural exchanges between Rasmussen's crew and Avva's family; while the Danes distribute thimbles to the women and play opera on a gramophone for the children, the Inuit invite their guests to a ceremony with drumming, competition games, and ajaja songs. Much time is also given to Avva's explanation of the customs, beliefs, and taboos grounded in Shamanism to demonstrate the Inuit view of themselves and their world prior to the influences of traders, missionaries, and ethnographers. During the second half, Avva's family escorts Rasmussen's two companions (the trader Peter Freuchen and anthropologist Therkel Mathiassen) to Iglulik. Following a hazardous journey with heavy blizzards and a lack of food or hunting opportunities, the group arrives at their destination to find the Inuit community there singing hymns rather than ajaja songs and eating meat considered taboo for shamans, which the starving travelers are invited to eat if they join the congregation. After a long and firm resistance to Christianity, Avva ultimately succumbs to the pressure and renounces his shamanistic powers. The film thus demonstrates how a coherent and cohesive Inuit worldview, with a system of beliefs that had maintained the culture through millennia, was rapidly and tragically replaced.

\footnotetext{
${ }^{215}$ The alternative spelling of Igloolik is used both in the film and in Rasmussen's published account of his expedition.
} 
The impact of missionaries, traders, and ethnographers on Inuit culture during the last century is either directly depicted or strongly implied in all of Isuma's films and videos. In reenacting a traditional way of life, their practice responds to the decline in many cultural activities and traditions since the establishment of Christianity, permanent settlements, and television in the North. Kunuk, however, does not advocate a nostalgic, and impossible, return to a pre-colonial past. On the contrary, Isuma stresses continuity between the past and present by promoting the incorporation of traditional Inuit values into contemporary Inuit lives, just as such values are applied to their own collaborative methods and community-oriented approach to media production. Their project is therefore a future-oriented one that revives the past in order to secure cultural survival, in terms of the economic, social, and psychological wellbeing of the Igloolik community specifically and the people of Nunavut generally.

That Isuma places emphasis on the past in the present is evinced by the way their work draws attention to itself as a representation and a construction of history. A number of the early videos, for instance, include obvious anachronisms within their historical settings, whether by having a hunter in the 1940 s wear a wristwatch with his skin parka or by revealing a barcode stuck to the bottom of a character's cup of tea. These details are not minor mistakes that were overlooked during the editing process but fully intentional insertions that signal the actors' and the videos' self-conscious reenactment of the past. These insertions constitute what Hearne calls the "contextual frame or indication of the storytelling performance" which "[situates] 'old' stories in a postcontact, identifiably contemporary setting that both brings the story itself forward and 
indicates the metanarrative process of producing the story, the mechanics of its telling. 216 Hearne notes that whereas Curtis and Flaherty sought to erase or deny evidence of the modern contexts in which their reenactments took place, a common feature of historical representations by indigenous filmmakers is the acknowledgement of the place, time, and conditions of production. In Atanarjuat this contextual framing is provided during the film's closing credits, which are accompanied by short video clips demonstrating the production process. These images show the camera tied to a sled, the performers in costume and smiling towards the camera, as well as one of the actors wearing a leather jacket, jeans, and headphones. Both the anachronisms and the production footage resist a reading of Isuma's historical representations as salvage or nostalgic longing for a pure past. Not only is the past clearly mediated but its reenactment takes place both in and for the present, as a performance that reflects contemporary interests.

\section{Oral History and Performance in The Journals of Knud Rasmussen}

As the dissemination of Isuma's films and videos promotes continuity with the past by teaching and passing on traditional values, the production of these historical representations is equally instrumental as a process by which traditional knowledge is activated, perpetuated, and transmitted in the present. While Isuma creates records of a traditional Inuit way of life, their work is not just a project of archiving the past by fixing stories and traditions on tape. Rather, the significance of reenactment lies in the way oral storytelling and traditional activities are put into practice through their performance both

\footnotetext{
${ }^{216}$ Hearne, "Telling and retelling in the 'Ink of Light'," 309.
} 
during and prior to filming. As mentioned, in the videos the actors hunt caribou, skin the animals, build igloos, and construct sod houses. With the production of narrative feature films, Isuma shifted away from representing these kinds of activities in their entirety. However, Journals, which is based on documented events, includes long sequences that concentrate on the performance of traditional songs, competition games, and ordinary daily tasks. Although these scenes slow the pace of the narrative trajectory, the inclusion and attention paid to these practices indicates the priority placed on reenactment as an event, as a process of staging that here performs traditional knowledge. The centrality of embodied means of carrying and transmitting history is further demonstrated in the way Journals thematizes the repertoire/archive distinction by foregrounding oral narration as a source of historical knowledge and as the foundation of the film's representation, over and alongside ethnographic documents.

The film's title, The Journals of Knud Rasmussen, refers to the Danish explorer's account of his four-year journey from Greenland to Alaska, through Northern Canada, between 1921 and 1924. Following a ten-volume published report on the ethnographic, archeological, and geological data collected by his team, Rasmussen published a twovolume narrative of the journey, which was translated into English as the one-volume book Across Arctic America. Rasmussen was particularly interested in recording the spiritual beliefs and the material conditions of life of the Inuit he encountered throughout the many regions he traveled. Since Rasmussen's book covers the entire period of his expedition, Isuma's film touches on a small segment by concentrating on Rasmussen's two visits with Avva in Iglulik. Moreover, the title of Journals is rather misleading since 
the film neither focuses on Rasmussen nor does it take his written records as an authoritative account on which the representation is based. The film instead concentrates on Avva and his daughter, Apak, as the central characters whose tense relationship is a main thread throughout the narrative, whereas Rasmussen is made a peripheral figure. While Rasmussen's account provides a framework and a point of departure that establishes the time period and general course of events, the writing of the script depended on oral history to fill out most of the narrative details. In order to develop the Inuit characters and construct their story, Kunuk turned to local elders' memories of the period: "We know Knud Rasmussen's journals, but Aua and Umik didn't have a journal, so we had to dig that out of oral history. I sat down with Elders who saw these people, knew their personalities and knew what they did, and we teased that information out."217 The title is therefore a deliberately ironic reference to the ethnographic archive, as the film depicts that which has not been previously recorded - the Inuit point-of-view. Cohn suggests how reworking written ethnographies from an Inuit perspective challenges the authority (and misconception) of anthropological texts as the primary source of historical knowledge: "The irony is that the world thinks Inuit oral history was told by white folks, because they're the ones who have written the books [...] In fact, as tourists, few outside the culture have a clue what was going on. 218

Journals' decentering of ethnography's archival sources of knowledge by grounding the narrative in oral history is immediately apparent from the film's opening sequence. The film begins with a static shot inside a cramped log cabin where three Inuit

\footnotetext{
${ }^{217}$ Kunuk quoted in SF Said, "Everday White," Sight and Sound 16.9 (2006): 38.

${ }^{218}$ Cohn quoted in Sonia Gunderson, "Zacharias Kunuk: Giving Inuit a Voice," Inuit Art Quarterly 21.1 (2006): 14.
} 
women sit still looking towards the camera while a crackling recording of men singing an ajaja song plays on the soundtrack. Several more Inuit enter the frame and position themselves so that everyone is visible and facing the camera, at which point the shot fades to black and white and transforms into a still image with the appearance of an ethnographic photograph. As the camera zooms in on the face of Apak (Avva's daughter), her voice-over replaces the singing on the soundtrack, but the voice belongs to an older woman rather than the young face in the photo. The voice-over begins at the same time that a title in small print appears in the left hand corner of the screen, which reads: "Scenes of events recorded in The Journals of Knud Rasmussen." This sound and text combination (and juxtaposition) provokes the central question of whose story and point-of-view is being represented. As the voice of an elder telling the story of her past, Apak's narration indicates the narrative's basis in an oral history that exists behind and alongside the ethnographic photographs and written records yet has been obscured by the authority attributed to archival materials. Furthermore, while both the initial sound recording and the photographic image represent the archiving of traditional Inuit culture (the ajaja song for example) in the early part of the twentieth century, the following scene identifies the changes taking place at the time. A series of shots from inside the same cabin show the group from the photo engaged in various activities that signal an already established relationship with traders, missionaries, and ethnographers: A woman plays an accordion, a man smokes a pipe, another spells his name in syllabic writing, and two older men record an ajaja song. This is the same group from Iglulik who by the end 
of the film, which takes place ten years later, have converted to Christianity and denounce ajaja singing as a satanic ritual.

The full weight and meaning of this ending is understood in relation to Avva's meeting with Rasmussen, which initiates Avva's explanation of the system of beliefs that is replaced and its value within the Northern climate, landscape, and way of life. This is relayed in a lengthy monologue that alternates between Avva's direct address to the camera and his voice-over narration. The tale begins in voice-over, with a description of the circumstances surrounding Avva's birth and his acquisition of guiding spirits, then shifts to a long take of the shaman speaking in direct address, framed in a medium shot with a spirit at his side. The shot of Avva telling his story is occasionally intercut with images of his wife, Orulu, listening and several slow-motion exterior shots. At one point, during a description of taboos, Rasmussen interjects from off-screen to ask Avva why Inuit observance of certain rules is so essential to shamanism. Avva's answer can be seen as having a dual purpose, as simultaneously a passionate defense of these traditional beliefs directed to a Western audience (represented by Rasmussen) and an urgent appeal to a contemporary Inuit audience to continue and remember their past:

You too cannot answer why life is the way it is. All our customs come from life and turn toward life. We can't explain everything but you can see for yourself...We follow our ancestors' rules because they work. They protect us so we can live without worry, even if our customs are different from yours...Our world is good and Inuit have our place in it.

The length of the speech and its direct address delivery make Avva's story a focal point of Journals, one wherein oral performance as content (Avva on screen speaking to the 
camera), as form (the voice-over narration), and as function of the film (imparting lessons to Inuit viewers) intersect.

With Rasmussen's study of the Inuit way of life in the early part of the twentieth century as the frame for Journals, the film is composed of disjunctive scenes that foreground the performance and observation of cultural practices. Dramatic action is subordinated to the presentation of Inuit epistemology, beliefs, customs, ordinary tasks, daily life, songs, dances, and ceremonies. Michael Robert Evans aptly describes the form as less a narrative than "a collage of images and ideas that represents Inuit views at the time." 219 Performance practices that imply an audience, especially for oral storytelling and communal ceremonies, are key moments (and ones recorded by Rasmussen in his account of his stay with Avva) around which the film is organized. There are three oral narratives delivered either in voice-over or direct address to the camera by the main characters, Avva, Apak, and Orulu. Like Avva's story, Orulu's oral history is initiated by Rasmussen's questions and is relayed in a chapter of his book. It takes place exactly halfway through the film, in conjunction with a lengthy ceremony that includes drumming, ajaja songs, and masked characters also described by Rasmussen. The film's ending returns to the traditional songs and dances, which are evoked on the soundtrack and in dreamy, slow-motion images that have the quality of a distant memory, to juxtapose these practices with another set of performances, that of a Christian church service at Igloolik, where a congregation sings hymns and the camp leader sermonizes to

\footnotetext{
${ }^{219}$ Michael Robert Evans, Isuma: Inuit Video Art (Montreal and Kingston, London, and Ithaca: McGillQueen's University Press, 2008), 24.
} 
the converted group. Thus Journals establishes the replacement of one system of rituals for another.

Upon its theatrical release in Canada and the United States, Journals received a number of unfavourable reviews, many of which cite Avva's story as a particularly disruptive element in the narrative trajectory. The reviewers who expected another Atanarjuat were disappointed by the slower pace and less conventional structure of Isuma's second feature. Critics described the film as "unfocussed and choppy"220 and as having a "lethargic pace"221 (associated with journal writing) that substitutes drama with an anthropological study. One reviewer complains of "scene after scene of people chilling out in an igloo, not really saying enough to merit subtitles;",222 another asserts that "too much time is devoted to long takes of Awa [sic] and his brood singing and dancing in their igloos, amid chunks of oral history from subsidiary characters that slow the narrative."223 Journals, indeed, spends time on daily life in Avva's camp, especially with scenes of women sewing and chatting amongst themselves without subtitles. The significance of these scenes, along with Avva's oral narration and the ceremonies that take place - precisely what the reviews criticize - has less to do with their purpose within the narrative than with the fact of the performances in and for the film. For example, the meaning and importance of Avva's story for the viewers and participants in Igloolik is attributed to the story's revival after over eighty years of silence. Thus, the significance of the film's basis in oral history and its reenactment of daily practices lies in the

\footnotetext{
${ }^{220}$ Shlomo Schwartzberg, "The Journals of Knud Rasmussen" Boxoffice, January 2007, 95.

${ }^{221}$ Vanessa Farquharson, "Identifying with an endless landscape," The National Post, September 29, 2006. Toronto edition, PM 6.

${ }^{222}$ Ibid.

${ }^{223}$ Leslie Felperin, "The Journals of Knud Rasmussen" Variety, September 10, 2006, 73.
} 
activation of both during the film's production, by having local elders recall their past for the script and having the actors perform the tasks, rituals, songs, stories, and dances that were an essential part of a traditional way of life.

That Isuma prioritizes the performance of traditional knowledge, more than simply producing a record, is evinced by the way the filmmaking involves reenacting the entire process of an activity or ceremony, beyond what is required or included in the final film. Laura McGough, for instance, comments on the immersive quality of the profilmic event during the making of Nunavut (Our Land):

What I find most compelling about Nunavut is the performative aspect of the work. That is to say, the collective playing-out by both the filmmakers and the actors of a historical moment - in this case, the way of life in the Igloolik region at the end of World War II...The daily rituals of their forebearers - whether building a sod house or walrus hunting - are performed in real-time. There is a real immersion at work here; actions are never partially created just for the camera. The result is not so much a historical recreation, but rather a process of reconnection. ${ }^{224}$

This also applies to certain scenes and activities in Journals, which were filmed in a similar way despite the different kinds of production requirements associated with feature filmmaking, such as a full script and rehearsals. As an observer on set throughout the entire shoot, British journalist S.F. Said was especially struck by the degree of improvisation and spontaneity incorporated into the film's production, particularly when filming communal rituals and events. Said describes the mood and process on set during the filming of a ceremony with ajaja singing and drumming in which "the singing and dancing goes on long into the night, [with] the actors taking their turns in the middle. It's all improvised, and feels very much like being at a real party" while Cohn "shoots it all

\footnotetext{
${ }^{224}$ Marie-Hélène Cousineau and Laura McGough, "Nunavut: A Dialogue on Locality, Television and Media Art," Igloolik Video by Artists Catalogue, Igloolik Isuma Productions, http://atanarjuat.com/media...centre/presskit.htm, accessed June 14, 2002.
} 
documentary-style, moving around the igloo freely with the camera slung over his shoulder, getting right up close to the action as one actor after another does their thing." 225 The same approach was employed when filming the cabin scene from the opening sequence:

The actors...have never rehearsed these scenes, or even been in this space together. They all know the script, but the way in which the script will be realised will be discovered as we go along tonight...There is no storyboard; the set-ups get decided here and now...It's fascinating to me how these scenes are made. The film-makers set up the camera, and then encourage the actors to interact with each other. The scenes often take different angles and emphases from the script, depending on what evolves...

The next set-up features a long improvisation by three women and an accordion. Perhaps only a few seconds of this will make it into the final film. This style of film-making means that a lot of material will be shot which will never be used; but even so, it's done in one take. ${ }^{226}$

Said's remarks indicate how during the reenactment within these scenes the filming of the action is only one dimension of the event and not a particularly privileged one. Emphasis is here placed not on the filming producing a record of the past but on the actors reenacting their past and thus learning the traditional practices through their bodily performance in the present.

The rehearsals are also an important dimension of this pedagogical function of reenactment and its activation of traditional knowledge. Prior to the filming the younger actors must learn from the elders how to sing ajaja songs, manage a dogsled, or tend to a qulliq (a soap stone lamp that burns seal fat). Their preparation for the performances involves practicing these skills, along with the Inuktitut language, to demonstrate a

\footnotetext{
${ }^{225}$ SF Said, April 21, 2005, "Party Night!" Igloolik's Embedded Journalist blog, October 5, 2009, http://www.sila.nu/zope/live/page?atom_id=sfsaidblog\&date=2005-04-21\&l=en\#1114280892.19, accessed. ${ }^{226}$ Said, April 6, 2005, "First Night Shooting" Igloolik's Embedded Journalist blog, October 5, 2009, http://www.sila.nu/live/page?atom_id=sfsaidblog\&date=2005-04-06.
} 
proficiency and comfort that will translate to the screen. Like the storytelling function of the film, which transmits knowledge and values from elders to the younger generations, the film's entire production has a similar pedagogical purpose, as traditional skills are put into practice, taught and learned in the process of performance.

\section{Production as Performance}

The transmission of knowledge in the production of Journals extends beyond the performances during filming and the actors' preparations for their roles to also include the construction of sets, props, and costumes for the film. The making of the mise-enscène encompasses a range of activities that equally constitute a performance of the past in the sense that these activities revive traditional skills as an embodied activation of the repertoire. This broader context of production includes the labour of various crew members, from research and planning to make-up application, and involves the transmission of the knowledge, memory, and skills necessary for building an igloo for the set or sewing the actors' costumes from skins, according to the designs and style of the historical period depicted. This field of making is thus a reenactment, as a collective and bodily process that brings the past into the present by recalling, repeating, and continuing the everyday practices of participants' ancestors. Just as the film's narrative is based on both oral history and Rasmussen's records, the production of the mise-en-scène depended on elders' memories along with archival resources. Photographs from Rasmussen's expedition, his writings, and objects located in various museum collections provided valuable models and points of reference for the reconstruction of artefacts, facial tattoos, 
or clothing designs. The ethnographic archive is here repurposed as a resource that contributes to the performance of the repertoire in the mimetic activity of the film's production process.

While oral history and local elders' memories were the primary source of historical knowledge, additional foundational research for Journals consisted of studying numerous written accounts of Arctic travels in the 1920s, museum collections of artefacts from the period, and Rasmussen's many photographs. Kunuk and Cohn read the records of Rasmussen and his companions, Peter Freuchen and Therkel Mathiassen, along with those of whalers, traders, and missionaries. ${ }^{227}$ Kunuk also traveled to the Smithsonian Museum (Washington, DC), the Museum of Natural History (New York), the Canadian Museum of Civilization (Ottawa), and the British Museum (London). ${ }^{228}$ Kunuk describes his encounter with the collections of preserved artefacts as an exciting experience of learning how clothing and shamanic items were originally constructed:

It was amazing. It touched me a lot because all the time we're making films, creating cultural programs, always imagining this and that, such as props. We will ask hunters to make this and the ladies to sew that. Then in the museum, you'd pull open a drawer and there's a 180-year-old amauti (women's parka). You could see how they stitched it and the beautiful work they put into the coat... That tour was an education for me. Like I learned about a Shaman's necklace. I thought the bear claws hung down (outward) ...It's the other way around from how we always assumed it was made. ${ }^{229}$

Such items from the museums, along with photographic records, served as guides for the costume and make-up departments, both of which relied on archival materials to decorate certain characters' clothing correctly and paint women's face tattoos appropriately to the

\footnotetext{
${ }^{227}$ Gunderson, "Zacharias Kunuk," 16.

${ }^{228}$ Ibid., 17.

${ }^{229}$ Zacharias Kunuk, "Zacharias Kunuk” Live from the Set: Profiles, April 3, 2005 , http://www.sila.nu/live/page?atom_id=profile-zack\&l=en, accessed October 15, 2009.
} 
period. By copying photos and objects to make props for the film - what Sonia Gunderson calls "re-artefacting" 230 - the knowledge contained in the static records of the archive is applied to a dynamic context of embodied practice and incorporated into living memory.

As Kunuk's remarks suggest, the archival research for the film contributed to ensuring that the reconstruction of material culture was historically accurate, which is an essential feature of Isuma's production process. Historical accuracy refers not only to achieving the correct appearance of the period represented, as in the styles and designs of the costumes, but also to the ways in which the props, sets, and costumes are made, by employing the same methods and materials used in the past (hence Kunuk's comment on the stitching of the amauti). The head costume designer, Michelline Ammaq, who has worked with Isuma since 1988, explains that with the early videos "we used cloth for the costumes, but for Atanarjuat we had made traditional clothing from fur and skins. ${ }^{, 231}$ In Journals, the costumes are also fashioned from seal and caribou hide, the hunting implements and children's toys are made of walrus bone, and the qulliq (seal oil lamp) burns seal fat. Sonia Gunderson asserts that Isuma's insistence on "cultural accuracy in every facet of the production" applies not only to the look of the mise-en-scène but also to the process of its construction in order to ensure the continuity of traditional knowledge: "If authenticity is compromised - say, an igloo is built from styrofoam or a qamutiq (sled) is tied wrong or the geography of the set is incorrect - the knowledge is

\footnotetext{
${ }^{230}$ Gunderson, “Zacharias Kunuk," 17.

${ }^{231}$ Michelline Ammaq, "Michelline Ammaq, Costume Designer," Live From the Set: Profiles. April 12, 2005. http://www.sila.nu/live/page?atom_id=michelline_profile\&l=en, accessed October 7, 2009.
} 
lost to future generations." ${ }^{232}$ It is therefore crucial for Isuma that when building Avva's igloo or sewing women's parkas the process of production emulates tradition and adheres to elders' memories. The Greenlandic actors were also outfitted with culturally and historically accurate clothing and props, and practiced the dog wrangling methods that are distinct from those of Canadian Inuit. Whether such details are in the end included in the film or even obvious to viewers matters less than the fact that the participants engage in the activities to learn and perform the skills of their ancestors.

Isuma's filmmaking is a multigenerational community practice that seeks to foster respect and pride in Inuit cultural identity and history, especially on the part of Inuit youth. Each department responsible for props, sets, or costumes involved several Igloolik elders whose memories and experiences of the period being recreated were essential to the construction of traditional objects and passing on the cultural history to the many younger Inuit who worked as assistants. The central role of Igloolik elders in the production is indicated by Jobie Weetaluktuk's comments on Louis Uttak, the art director for Journals:

[Uttak] is an unilingual Inuk in his 60 's. Kunuk gushes that Uttak is "like a professor." His knowledge and judgment are highly regarded. He has seen much of the Igloolik implements, tools, weapons, and artifacts that are now being made into props. They are authentic replicas made by knowledgeable and skilled craftsmen. Men and women who learned at their father's and mother's side. ${ }^{233}$

The film's production creates the conditions in which skills that are no longer part of Inuit daily life are made employable, considered economically viable, and given value

\footnotetext{
${ }^{232}$ Gunderson, 15.

${ }^{233}$ Jobie Weetaluktuk, November 22, 2005, "Preparing for the Big Day," Nasitti: Scanning the Landscape Blog, October 15, 2009, http://www.sila.nu/zope/live/page?atom_id=jobieblog\&date=2005-04$03 \& 1=$ en\#1112562283.5.
} 
within a contemporary context. Moreover, as elders' knowledge is transmitted to the younger members of the film crew, the process of transmission is relevant in itself, as a means by which to assuage intergenerational tensions and strengthen social bonds within the community.

The way in which Isuma's filmmaking promotes community cohesion is made apparent on the film's website. Although, unlike Atanarjuat, Journals does not include images of its own production, that Isuma equally stresses the relevance of the filmmaking process with their second feature is evident in Journals' companion website, which extensively documents the film's making. In contrast to most making-of-documentaries, which are included in a DVD package once a film is distributed for home viewing, Isuma posted daily accounts of the production of Journals during the filming, including short video clips, audio clips, and still photographs taken on set, along with several weblogs. This material addresses the filming process, including the unique technical challenges of filming in the Arctic and the improvisational approach of certain scenes, and refers to the building of sets, sewing of costumes, and construction of objects. One of the video clips is of a fashion show in which the actors model their costumes in an auditorium filled with Igloolik residents cheering the actors and designers, who are also their friends, neighbours, and family members. The video underscores the production's integration with the community, whose support and involvement is essential to Isuma. The website further contains interviews with the main cast and crew, background information on the film's narrative, a map indicating Rasmussen's expedition in the Baffin Island region, a timeline of Igloolik, and profiles of the characters with archival photographs. The 
attention given to Igloolik as the location of the historical events and their reenactment places emphasis on the actors' and participants' roots in the past being depicted.

While the film and its website prioritize performance practices, oral narration and the making of material culture, both also incorporate ethnographic representations. Journals presents some of the photographs from Rasmussen's expedition during the closing credits. The website also includes these photos along with excerpts from Across Arctic America and Therkel Mathiassen's First Report on the $5^{\text {th }}$ Thule Expedition 192124 , combined with an interactive map of the locations in the Baffin Island region that Rasmussen and his crew visited. In Journals and its production, Isuma engages ethnographic materials in multiple ways, at once subverting, appropriating, referencing, mimicking, responding to, and recontextualizing these records from an Inuit point of view. If the film, by its very title, speaks to an ethnographic archive and identifies archival documents as an important source of knowledge on Inuit history, it also decenters this body of knowledge as one voice among others. Indeed, the making of Journals places different ways of knowing alongside each other and demonstrates a dynamic interaction between the categories of the archive and the repertoire. As Rasmussen recorded stories conveyed orally by Inuit, the ethnographer's records become a tool for the activation of oral history and the reenactment of traditional knowledge, which are in turn recorded by Isuma on video. The production process is thus a site where the archive is performed as performance is archived. 


\section{CHAPTER FIVE}

\section{Ethical Imperatives: \\ Reenacting Trauma in Shake Hands with the Devil}

There is rarely anything resembling a 'full recovery' for genocide survivors. Visions of people slaughtered by machete, their bodies left strewn over church pews, don't just disappear. Such bloodshed stains people-and nations-for lifetimes.

Eric Page, Helping Rwanda to Weep ${ }^{234}$

[T] here were some moments when I foresaw where we were going with the story, knew I'd seen enough, and walked away. Some of the Rwandans told me that they did the same. Overall, though, we were very careful. We had doctors, nurses, and trauma counselors on-set every day, in case people lapsed back into memories...It wasn't a normal film set.

David Belton, on the making of Shooting $\operatorname{Dogs}^{235}$

[The Rwandan Government Minister] told us, 'We're very glad you're making a film in Rwanda, but you're not telling our story. You'll get it all wrong. But that's of no concern to us. We're just happy you're telling a story,'

Peter Meyboom, supervising producer on Shake Hands With the Devil ${ }^{236}$

In April 1994, Hutu extremists, the Rwandan army, and the Interahamwe militia led Rwanda's Hutu population in a mass extermination of its Tutsi minority. The organizers

\footnotetext{
${ }^{234}$ Eric Page, "Helping Rwanda Weep," Newsweek, April 14, 2006, http://www.newsweek.com/id/46531/page/1, accessed May 4, 2009.

${ }^{235}$ David Belton quoted in Page, "Helping Rwanda Weep."

${ }^{236}$ Peter Meyboom quoted in Etan Vlessing, "The devil and Mr. Dupuis," The Globe and Mail, August 5, 2006, Toronto edition, R1.
} 
enlisted popular participation in a slaughter that involved ordinary people killing their neighbours, co-workers, and family members. Roadblocks were put in place to prevent escape, people were hunted down in their homes, and piles of butchered corpses were transported to mass graves while hundreds of others were left to rot in churches or schools. The sites of these massacres now serve as memorials to the estimated 800,000 killed in the genocide that lasted one hundred days. During this period, the international community not only refused to intervene (except to rescue expatriates who were in minimal danger) but also reduced the United Nations' presence and resources in the country. The genocide was brought to an end with the victory of the Rwandan Patriotic Front (RPF), a rebel army of Tutsi exiles, over the Hutu Power regime in a concurrent civil war, which drove the perpetrators and much of the Hutu population into refugee camps in neighbouring Zaire. Having spent much time in Rwanda in recent years, observing how ordinary people are dealing with their memories and losses, the changed population (with the return of many Tutsi exiles), and the fraught efforts at reconciliation and justice, Philip Gourevitch remarks that "after a genocide, true justice is impossible, and the question for Rwanda's survivors is not so much how to remember but how to live with the unforgettable., 237

As survivors learn to cope with the painful memories of the violence they endured or witnessed and the loss of their family and friends, these memories are collected, commemorated, and manifested with the production of several feature films on Rwanda, most of which began release in 2004, after the tenth anniversary of the genocide: 100

\footnotetext{
${ }^{237}$ Philip Gourevitch, "Among the Dead" in Disturbing Remains: Memory, History, and Crisis in the Twentieth Century, eds. Michael S. Roth, and Charles G. Salas (Los Angeles: Getty Research Institute, $2001), 72$.
} 
Days (2001), Hotel Rwanda (2004), Shooting Dogs (2005), Sometimes in April (2005), Sunday in Kigali (2006), and Shake Hands with the Devil (2007). The films seek to inform an international public largely ignorant of this recent event, which was severely underreported while it occurred and with which Western powers are heavily implicated. With the exception of Hotel Rwanda (which was filmed in South Africa), these primarily American, Canadian, and British productions were filmed in Rwanda with Rwandans as extras in the interests of authenticity and to have the subjects of the films participate in the reconstruction of their own history. In each case, the filmmakers demonstrate an awareness of and sensitivity to the hazards of having genocide survivors reenact their collective trauma since every production included a number of psychologists and counselors on set throughout the filming.

While the performers in the previous case studies included descendants representing their own remote past or representative individuals depicting a typical occurrence, this chapter concentrates on the use made of survivors of mass violence in the reconstruction of a recent national trauma. It specifically considers the kinds of ethical questions and concerns that emerge when the survivors of atrocity are employed in the recreation of the horrific and painful events they previously lived through. Whether fictional narratives or docudramas, films about the Rwandan genocide involve reenactment to the extent that the production has participants stage and relive their collective experience (though not necessarily specific occurrences) in conditions that recreate the material circumstances of the original event, often with filming taking place in the actual locations of devastating atrocities. As both emotionally charged processes 
of filmmaking and cross-cultural production contexts, these films raise questions regarding the value of inciting painful memories through reenactment and the stakes in who gets to represent the past for whom. Thus the production process is a site of ethical implications that bear on the non-professional performers' investment in and ownership of the representation of their national and traumatic history.

This chapter concentrates on Shake Hands with the Devil (Roger Spottiswoode, Canada). Released in 2007, Shake Hands is the most recent in the handful of feature films on the Rwandan genocide. It is based on the memoir of the Canadian General Roméo Dallaire who led the UN peacekeeping mission in Rwanda, UNAMIR (United Nations Assistance Mission to Rwanda), throughout the bloodshed and has since been struggling with post-traumatic stress disorder. The film is of interest for the way in which traumatized subjectivity is a central theme not only in the narrative but also in the discourse on the film's production, which attends to how its makers and performers have been emotionally affected by their participation in the film's making. In particular, a "behind-the-scenes" news report by the Canadian Broadcasting Corporation (CBC) and the making-of-documentary included on the DVD both foreground the reenactment as an event, as a staging in the present with formative and transformative consequences for the participants. In contrast to the previous chapters, which examined marginal cinematic practices, the focus on the production information on Shake Hands with the Devil locates the processes of reenactment within a more mainstream or conventional production context. This work demonstrates how the notion of filmmaking as a transformative event, an intervention in the lives of the performers, and an emotional investment for the 
participants enters a popular discourse of promotion and publicity. In the promotional material, emphasis is placed on the entire production as a humanitarian project that simultaneously mimics the original event (Dallaire's mission), with its traumatizing effects, and corrects the individual and collective failures of the past (the West's neglect of Rwanda). Within this interpretative frame the ethical dilemmas of reenacting historical trauma with survivors are subsumed within a moral imperative to tell the story, as a responsibility on the part of the filmmakers specifically and Western nations generally.

\section{The Requirement to Represent: Ethics in Docudrama and Trauma Cinema}

In her investigation of the ethics of representation in films on the Holocaust, Libby Saxton asserts that "[f]ilm studies, in the Anglo-American tradition at least, has only recently started to bring ethical thought to bear on cinema. Film scholars have often privileged questions of ontology and epistemology over ethical concerns."238 While this is true, it is with respect to the documentary genre that ethical issues have received some attention and theorization, addressing the ways in which documentary aesthetics inscribe ethical positions, ${ }^{239}$ the unequal power relations between filmmakers and subjects, ${ }^{240}$ and

\footnotetext{
${ }^{238}$ Libby Saxton, Haunted Images: Film, Ethics, Testimony, and the Holocaust (London and New York: Wallflower Pres, 2008) 16.

${ }^{239}$ See Bill Nichols, Representing Reality: Issues and Concepts in Documentary (Bloomington: Indiana University Press, 1991) and Vivian Sobchack, "Inscribing Ethical Space: Ten Propositions on Death, Representation, and Documentary," Quarterly Review of Film Studies 9 (1984): 283-300.

${ }^{240}$ See Linda Williams, "The Ethics of Intervention: Dennis O'rourke's the Good Woman of Bangkok," in Collecting Visible Evidence, eds. Jane M. Gaines, and Michael Renov (Minneapolis and London: University of Minnesota Press, 1999) 176-89.
} 
the (moral and legal) consequences of filming private lives for public consumption. ${ }^{241}$ In their introduction to Image Ethics: The Moral Rights of Subjects in Photographs, Film and Television, Jay Ruby, Larry Gross and John Stuart Katz note that fiction films and especially docudramas have not been immune to interrogation on ethical grounds, particularly by critics, viewers, and subjects, though scholarly attention to the ethical concerns raised by dramatic features has remained rather limited. ${ }^{242}$ More recently, trauma studies has marked a turn to a broader consideration of ethics in visual representation: "Trauma studies...offer poststructuralist theory a means to reintroduce a political and ethical stake in the representation of the real without regressing to the very notions of mimetic transparency that it has striven to overturn."243 Theorizations of docudrama and of filmic portrayals of historical, national, or personal trauma tend to locate ethical implications in a film's aesthetic strategies and formal features, along with the spectators' readings of or position towards the material depicted. Of particular concern is how the means of representing historical events entails questions of responsibility - that of the filmmaker towards the viewer and that of the viewer and the film towards the subject matter.

In Real Emotional Logic, a study of how American docudramas of the 1990s persuade viewers of their moral messages, Steven Lipkin provides a short chapter on docudrama ethics by investigating the controversies that have preoccupied audiences

\footnotetext{
${ }^{241}$ See Jay Ruby, "The Ethics of Image Making: Or, "They're Going to Put Me in the Movies. They're Going to Make a Big Star Out of Me..."," in New Challenges for Documentary, eds. Alan Rosenthal, and John Corner (Manchester and New York: Manchester University Press, 2005) 209-19.

${ }^{242}$ Jay Ruby, Larry Gross, and John Stuart Katz, "Introduction: A Moral Pause," in Image Ethics: The Moral Rights of Subjects in Photographs, Film, and Television, eds. Jay Ruby, Larry Gross, and John Stuart Katz (New York: Oxford University Press, 1988) 3-33.

${ }^{243}$ Frances Guerin and Roger Hallas, "Introduction," in The Image and The Witness: Trauma, Memory and Visual Culture, eds. Frances Guerin and Roger Hallas (London and New York: Wallflower Press, 2007) 3.
} 
surrounding certain films. Lipkin attributes ethical concerns to textual practices and identifies three specific operations that result in spectators reading dramatizations of historical events as ethically unsound: "unwarranted creative supplementation, contradiction, and omission of the known are fundamental kinds of ethical problems for docudrama, problems heightened by the ways docudrama re-creates known material within the narrative arc and the terms of reception audiences expect from fiction feature films." 244 At issue are the ways in which actual (or "known") events are shaped into a narrative form. When a filmmaker assumes too much artistic license in constructing the film then the proximity between the representation and its source material is put into question, resulting in the loss of persuasive power of the docudrama and viewers' rejection of the film's depiction as problematic. Proximity refers to how accurately the representation, including actors, settings, and events, resemble known facts, persons, and occurrences. There can be various levels of resemblance but the greater proximity between the film's depiction and viewers' knowledge, where speculation does not appear to outweigh the facts, results in greater believability of the representation. Docudramas seek to effectively convince audiences of a representation's fidelity to the original to avoid charges of misrepresentation and distortion.

According to Lipkin, ethical problems arise when a film appears to violate necessary warrants by failing to adequately answer such questions as to why a story should be told and why it must be told in this particular form. In part, that a story is already public, and therefore established as newsworthy, warrants its telling as a

\footnotetext{
${ }^{244}$ Steven N. Lipkin, Real Emotional Logic: Film and Television Docudrama as Persuasive Practice (Carbondale and Edwardsville: Southern Illinois University Press, 2002) 48.
} 
docudrama. However, when spectators object to a film's representation they fail to accept either of its warrants. Lipkin points to Oliver Stone's JFK (1991) as a docudrama that puts these warrants into question. Rejection of the film's argument by many viewers and critics was based on Stone's focus on Jim Garrison as the central protagonist, a seemingly insignificant figure in the story of Kennedy's assassination, and on the film's mixing of documentary footage with fictional recreation in a way that made known occurrences and Stone's speculations indistinguishable. As a result, "concerns over $J F K$ 's ethics understandably stem from its choice of subject (does Jim Garrison's conspiracy theory deserve to be told?) as well as its methods of re-creation (when does re-creation stop and imaginative speculation begin?). ${ }^{, 45}$ The film was therefore charged with the contentious use of existing material and with constructing a distorted representation of history. The ethics of docudrama here rest on how a story is told, whether its telling is perceived as worthwhile, and therefore warranted, and whether its degree of proximity is persuasive, and therefore believable. A docudrama is perceived as questionable and irresponsible if it seems to distort the material and deceive viewers by deliberately including falsifications, excluding information, or playing with facts.

While Lipkin's analysis presents the presupposed responsibility on the part of the docudrama filmmaker towards the viewer when dramatizing historical material, studies on representations of the Holocaust and trauma in cinema stress the viewer's and the film's responsibility towards the subject by assuming the position of a witness to historical trauma. Limit events like the Holocaust are recognized in trauma studies as demanding representation in order to defy the total erasure of a people and of memory

\footnotetext{
${ }^{245}$ Lipkin, Real Emotional Logic, 50.
} 
that the act of genocide intends. Saxton, for example, refuses the common notion in scholarship on the Holocaust, strongly defended by Claude Lanzmann, that the event is fundamentally unrepresentable:

The reduction of moral debate around Holocaust representation to the binary 'to show or not to show' can become an alibi for neglecting its complex ethical implications for artists, readers, and viewers...[T] the invocation of prohibitions can lead to a disavowal of the ethical relations between filmmaker, viewer and imaged subject and a denial of their responsibilities. ${ }^{246}$

Although events of mass trauma certainly put up resistance to language and posit limitations to understanding, they also require expression and communication. The Holocaust has been identified in trauma studies as "an event without a witness,"247 with the exterminations concealed in camps and those in the vicinity of the camps claiming to have no awareness of what was happening at the time. Saxton therefore sees films depicting the event as taking up the role and responsibility of bearing witness. The challenge for filmmakers then is not whether to represent such trauma but how to represent it adequately, taking into account the ways in which the camera's gaze and the film's form are "charged with ethical meaning."

This position of a witness to historical trauma on the part of the film also extends to the viewers of such films. E. Ann Kaplan argues that of the various ways spectators are invited to engage with cinematic depictions of trauma and suffering, whether by films on the Holocaust or other histories of mass violence, that of a witness is the most political and ethical. Rather than being defined by empathy towards or identification with

\footnotetext{
${ }^{246}$ Saxton, Haunted Images, 11.

${ }^{247}$ See Dori Laub, "An Event without a Witness: Truth, Testimony and Survival," in Testimony: Crises of Witnessing in Literature, Psychoanalysis, and History (New York and London: Routledge, 1992), 75-92.

${ }^{248}$ Saxton, Haunted Images, 17.
} 
subjects, witnessing involves taking responsibility for others' pain and suffering. Kaplan identifies witnessing as an "ethical consciousness" wherein "one feels responsible for injustice in general. Witnessing involves wanting to change the kind of world where injustice, of whatever kind, is common." ${ }^{249}$ Not only does the position of a witness, in Kaplan's terms, prevent trauma from being understood as something safely relegated to the past, it also extends a sense of ethical responsibility beyond the specific events, circumstances, and subjects represented. As witnesses, spectators are made to recognize their own implication in, along with their ability to alter, the political conditions that create suffering and violence.

With films on the Rwandan genocide, whether presenting fictional accounts or recounting actual occurrences, filmmakers often assert the requirement to tell the story and to tell it correctly. The requirement to represent is typically framed in terms of the responsibility to witness on the part of an international, and especially Western, audience. Unlike with the Holocaust, the perpetrators in Rwanda did not conceal their actions and intentions at mass extermination. ${ }^{250}$ The killings were carried out in the open and in front of cameras, with the corpses left rotting in the streets as visible evidence for all to see. However, even with this effort at making the violence visible, powerful and influential nations deliberately chose not to intervene but to turn their backs on the victims and look

\footnotetext{
${ }^{249}$ E. Ann Kaplan, Trauma Culture: The Politics of Terror and Loss in Media and Literature (New Brunswick, New Jersey, and London: Rutgers University Press, 2005) 122.

${ }^{250}$ Nicholas Mirzoeff examines this distinction and critiques the way in which representations of the Rwandan genocide in the West have been shaped by discourses on the Holocaust in "Invisible Again: Rwanda and Representation After Genocide," African Arts 38.3 (2005): 36-9, 86-91, 96.
} 
away from the apparent horror. ${ }^{251}$ The West's complicity in the violence is a central theme in Shake Hands, a film that takes up the responsibility to represent historical trauma for its victims by assuming the role of witness to an event that was initially ignored. These claims to the responsibility of witnessing permeate the discourse on the film's production process and warrant the story's telling. The material on the film's making further warrants the docudrama by establishing the representation's proximity to the original in the resemblance between the lead actor (Roy Dupuis) and Dallaire, the filming taking place in actual locations, and the production generating traumatizing affects for the performers involved. This attention to the film's production and its effects point to additional and largely unexamined implications of representing historical trauma, ones that concern the dynamics of filmmaking and reframe the question of responsibility in terms of that of the filmmaker to the performers, rather than to the spectator or the subject. Rather than concentrating on a film's form or aesthetics, the ethics of reenactment address the emotional stakes of reliving a traumatic event by the participants in the production. Before turning to Shake Hands, then, it is worth first elaborating on the notion of reliving trauma and how this has been theorized in relation to reenactment in cinema.

\footnotetext{
${ }^{251}$ In the United States, the Clinton Administration refused to use the term "genocide" to describe the events in Rwanda during the killings since to acknowledge the genocide as such would have required the American government to intervene.
} 


\section{Reliving Trauma in Reenactment}

Analyses of the reenactment of national trauma, exemplified by Marita Sturken's reading of $J F K$ (see Chapter One) and Aileen Blaney's reading of Bloody Sunday (2002), ${ }^{252}$

demonstrate how reenactment offers viewers a means of catharsis and mourning. These studies examine how national audiences not only "relive the shock and pain of that moment" 253 by viewing the imitation or repetition of original media footage but also how the narrative context enables viewers to come to terms with the event. The primary concern here is the work that reenactment, as a textual practice, performs for spectators. Less attention has been placed on the meaning of staging trauma on the part of nonprofessional performers who experienced the original event and for whom the reenactment, as a kind of reliving of the trauma, can incite strong reactions and painful memories. Trauma theorist Dominick LaCapra addresses this emotional impact in a reading of Claude Lanzmann's Shoah (1985). LaCapra sees Lanzmann's use of

reenactment as promoting an acting out, a return to the past that wallows in the traumatic

\footnotetext{
${ }^{252}$ Much like Sturken's discussion of the reenactment of catastrophic images in docudramas and on television, Blaney presents Bloody Sunday as a film that invites a working through of historical trauma for viewers by imitating the original media images and by giving the event meaning and closure through its narrativization. Bloody Sunday - the actual shooting of protestors by British paratroopers - is an event without closure since Northern Ireland has never received an official apology from the British government. Blaney views Greengrass' film as contributing to a collective mourning, along with the many unofficial commemorative activities that took place surrounding the thirtieth anniversary. She specifically provides a detailed investigation of the film's "mode of address" via the docudrama genre, concentrating on its construction of characters, its proximity to the original, and its use of reenactment. Although Blaney addresses the film's use of members from the Derry community and British paratroopers to stage the massacre, she particularly attends to the ways in which the film refers to the original television footage of the event, both through its aesthetic (grainy with muted colours) and by imitating iconic images (such as the shooting of an elderly man in the middle of the street). Though as a docudrama narrative, she argues, the film does what the original images, and journalistic media generally, cannot do, which is to assist viewers in a working through of the national trauma by interpreting and contextualizing the violence rather than simply repeating it endlessly. As such, the film "performs an ethicopolitical function" not usually found in television journalism. Aileen Blaney, "Remembering Historical Trauma in Paul Greengrass's Bloody Sunday," History \& Memory 19.2 (2007): 119.

${ }^{253}$ Marita Sturken, "Reenactment, Fantasy, and the Paranoia of History: Oliver Stone's Docudramas," History and Theory 36.4 (1997): 74.
} 
affects, as opposed to the processes of mourning. Although not all reenactments of historical trauma can be equated with acting out, LaCapra's critique indicates the affective dimensions and potentially dangerous repercussions of reenactment as a process engaged in by subjects whose own memories and emotional investments are at stake.

In trauma theory acting out is contrasted with working through, as distinct responses to trauma. In reference to how Holocaust survivors deal with their traumatic past, LaCapra characterizes acting out as a compulsive reliving or reenactment of the past. As a symptom of post-traumatic stress disorder (PTSD), acting out involves a repeated return to the trauma on the part of a subject who fails to distinguish the past from the present. The past becomes intensely and uncomfortably present. LaCapra writes:

in post-traumatic acting out...one is haunted or possessed by the past and performatively caught up in the compulsive repetition of traumatic scenes - scenes in which the past returns and the future is blocked or fatalistically caught up in a melancholic feedback loop. In acting out, tenses implode, and it is as if one were back there in the past reliving the traumatic scene. Any duality (or double inscription) of time (past and present or future) is experientially collapsed or productive only of aporias and double binds. In this sense, the aporia and the double bind might be seen as marking a trauma that has not been worked through. ${ }^{254}$

To work through a trauma so that one can engage in mourning is to recognize the distance and the difference between the present and the past - a recognition that opens up new possibilities for the future and a sense of ethical responsibility towards others. LaCapra stresses that acting out and working through are related rather than completely separate processes since to arrive at mourning one may need to engage in acting out

\footnotetext{
${ }^{254}$ Dominick LaCapra, Writing History, Writing Trauma (Baltimore: Johns Hopkins University Press, 2001)

21.
} 
before working through can become an option. Moreover, one never completely heals from violent trauma but, in engaging in one or the other of the two processes, can adopt divergent stances towards one's past and future, either remaining in the past or moving forward.

LaCapra identifies acting out as frequently manifested within Holocaust survivor testimonies, in which "the survivor as witness often relives traumatic events and is possessed by the past." ${ }^{, 255}$ He specifically critiques Shoah on these grounds. Lanzmann's mode of questioning is rather intrusive by persuading subjects to recount their horrific experiences in the most minute detail even when doing so is clearly painful for them. Recall the scene of Abraham Bomba's breakdown discussed in Chapter One. Holocaust survivors are also taken to the locations where concentration camps once stood to trigger their memories. Several subjects are further encouraged to reenact actions they performed at the camps, much like Bomba cutting hair in the barbershop. By having subjects visit the sites of the exterminations and provide meticulous accounts of what took place there, the interview process in Shoah is "an attempt to take the survivor backfiguratively and at times even literally - to the scene of victimization and traumatization...."256 For LaCapra, Lanzmann's approach is an ethically questionable one, as a practice that results in the revictimization of the traumatized subject. Although the filmmaker's intentions may be to communicate the horror of the Holocaust and inspire empathy in viewers, his interviews induce a reliving or acting out of the traumatization for the camera. The film does not show, promote, or assist in a working

\footnotetext{
${ }^{255}$ Ibid., 97.

${ }^{256}$ Ibid.
} 
through of the trauma on the part of survivors, which would be a more ethically responsible undertaking. Instead, LaCapra argues, Shoah is "concerned with victims as victims, not as survivors or agents.

My own notion of reliving the past, which distinguishes the use of survivors in reenactments from descendants or representative individuals, does not fully correspond to LaCapra's use of the term as he equates it with acting out. I do not wish to suggest that all survivors engaged in a reenactment of a historical trauma become absorbed in a melancholic return or that the reenactment necessarily promotes a compulsive desire for such a return. On the contrary, reenactments can entail the kind of social and ritual practices that LaCapra attributes to working through. At the same time, however, we should recognize how the material reconstruction of a past event within reenactment projects concerned with an authentic reproduction of physical details, or feature film productions which through their mise-en-scène, special effects, and return to the actual locations of mass violence, can produce an uncanny atmosphere for survivors-asperformers. This is made apparent in The Battle of Orgreave (2001), which documents the preparation for a reenactment of a violent clash between British riot police and striking miners in 1984 . The reenactment was organized by installation artist Jeremy Deller, with the assistance of a local historical reenactment society, and involved many of the Orgreave miners as performers. The performance took place at the location of the actual strike and, like many historical reenactments, sought an authentic recreation by using historically accurate costumes and props (including riot gear and police horses) as well as by following the precise sequence of events. In the film a number of the ex${ }^{257}$ Ibid. 
miners express the sense of "being back" in the past, which for some was an emotionally overwhelming and even painful experience.

The Battle of Orgreave, Mike Figgis' documentary on Deller's art piece, weaves together multiple interviews with the ex-miners participating in the reenactment (some as strikers, others as police) along with a historian, an ex-police officer, an ex-member of parliament, and others who provide the broader social and political context of the Orgreave mining strike, which marked a transition in Britain's production sector, encapsulated Thatcherism's approach to labour relations, and exemplified a collusion between conservative politics and public media. Deller comments in the film that the project was not "about healing wounds" but was intended to revisit the event and initiate a dialogue on a historical moment that disappeared from public discourse. ${ }^{258}$ Figgis nonetheless draws attention to the wounds that are reopened for a number of the participants. In the interviews with the ex-miners, some reveal the strong emotions and painful memories that re-emerge by their return to the location, especially in encountering old colleagues and rows of riot police. One man, while tearfully recounting losing his home and family during the strike, notes how being at the site "brings it all

\footnotetext{
${ }^{258}$ The reenactment also challenges the media's misrepresentation of the strike at the time by privileging the miners' perspective and position. Robert Blackson therefore sees the work as an example of reenactment being used to reclaim the past by a marginalized community. Robert Blackson, "Once More...With Feeling: Reenactment in Contemporary Art and Culture," Art Journal 66.1 (2007): 28-40. Others have presented more critical perspectives of The Battle of Orgreave. Alice Correia notes that while the project differs from conventional historical reenactments in its clearly political intentions, and by drawing connections between the past and the present, it also exhibits the kind of nostalgia that characterizes the growth of heritage sites and historical reenactment in Britain. Alice Correia, "Interpreting Jeremy Deller's The Battle of Ogreave," Visual Culture in Britain 7:2 (2006): 93-112. Dave Beech argues that by subordinating his authorship to the historical reenactment society Deller subverts his own intentions, as the work becomes a conventional reenactment that celebrates the military tactics of the police and constitutes a monumental form of political art. Dave Beech, " "The Reign of the Workers and Peasants Will Never End': Politics and Politicisation, Art and the Politics of Political Art," Third Text 16. 4 (2002): 387-398.
} 
back." Another angrily complains that some of the ex-miners participating in the reenactment were from other mines and were working at the time of the Orgreave strike. Despite almost twenty years having passed, his anger is still quite raw. During another interview, a group of participants spontaneously and energetically erupts into a chorus of "I'd rather be a picket than a scab." Several of the men mention the ease of being "swept up" in the reenactment and the adrenaline it produces, "like back then." Certainly the events are not the same; the reenactment lacks the immediacy, uncertainty, and danger of the actual strike, which the film indicates by documenting the extensive preparations for the performance. The documentary neither implies an equation of the two events nor an absorption in the past on the part of the performers, who clearly recognize the difference and the distance between the past and the present - a condition for working through. Figgis also shows their playfulness while preparing for the reenactment; as the ex-miners laugh and joke while reminiscing with tales about the strike, one remarks on the "fun and easy-going atmosphere." Within the range of responses, however, the reenactment is certainly a trigger for the various memories and emotions expressed, whether a renewed sense of camaraderie among the strikers, old anger over divisions between the miners, or a new sympathy for either side by the other.

A "reliving of the past" therefore does not suggest a living over as if the second experience were the same as the first. Broadly speaking, it is a return to an (often traumatic) historical event on the part of subjects who lived through the actual incident in conditions that mimic, recount, or recreate the original in some detail, whether through the kind of individual testimonials found in Shoah or the collective performance in The 
Battle of Orgreave. As indicated by both films, such a process is potentially jarring, painful, intense, and overwhelming for the subjects. Without necessarily equating or collapsing the past with the present, a reliving of a prior experience through its reenactment can arouse painful memories and even a sense of "being back" as a result of the return to the actual location, the visual resemblance of the setting to the original event, and/or the performance of gestures associated with the traumatic event, which can be either violent (the police on horseback charging at the miners in The Battle of Orgreave) or rather banal (Bomba cutting hair in a barbershop).

In the case of the feature productions on the Rwandan genocide, the mise-en-scènes of the films recreate in detailed materiality and corporeal immediacy scenes of death and violence, in which Rwandan extras imitate butchered corpses, rape victims, or Interahamwe killers. This necessarily poses some ethical questions for the mostly Canadian, American, and British filmmakers to contend with: To what extent is the recreation of horrific violence desirable and in the interests of the Rwandan performers? What are the consequences and value of having survivors relive their traumatic past? And what right does one have in representing another's history of mass violence? The following discussion of Shake Hands does not seek to provide definitive answers so much as raise these concerns as relevant to the processes of reenactment in the reliving of a traumatic history. 


\section{Shake Hands with the Devil}

Although Shake Hands is a more typical docudrama than the previous case studies, with its use of professional actors and a full script, it also exhibits the pedagogical and commemorative features of reenactments, and employs non-professional Rwandan performers in a depiction of their recent national history. The film's representation of a national trauma, however, is framed by the individual memory and traumatized subjectivity of the central protagonist, the Canadian General Roméo Dallaire. Particular attention is given to the role, responsibility, and trauma of the witness to genocide. This applies not only to Dallaire, as the subject of the film, but also to the film's viewers, especially Western audiences, who are invited to identify with Dallaire's position as a sympathetic outsider and witness to suffering. If for the General the act of witnessing is traumatic, for viewers it is a responsibility. The initial neglect of the Rwandan genocide by Western nations and the long-term psychological impact on Dallaire establish the film's requirement to tell its story, a telling that is warranted by the film's claims to present the "real story" of the genocide, from the experiences of a central figure, and its on-location filming, not only in Rwanda but often in the actual locations where the depicted events took place.

The story Shake Hands tells is based on Dallaire's memoir of the same title, which recounts his daily experiences during the Rwandan genocide as the commander of the UN forces of a failed peacekeeping mission. Like the book, the film shows that despite the evidence that genocide was in preparation, and then taking place, the member nations of the UN chose not to intervene but rather reduced the mission's soldiers and 
prevented those who remained from taking action. The UNAMIR soldiers were effectively made to stand by and watch what Philip Gourevitch has described as "the most efficient mass killing since the atomic bombings of Hiroshima and Nagasaki."259 In one hundred days, hundreds of thousands were butchered by machete in the streets, in their homes, in schools, and in churches, with limbs being chopped off and skulls cut in half. The perpetrators also engaged in the mass rape of Tutsi women and mutilated their bodies. In Kenneth Harrow's words, "Rwanda was a gigantic camp of extermination." He adds: "Never has there been such destruction to civil society. Never so little 'neocolonial' intervention. When the violence began in April of 1994, the expatriates were evacuated, the UN Peacekeepers drawn down and defanged." ${ }^{260}$ Told from Dallaire's point-of-view, Shake Hands depicts the effects of bearing witness to this level of bloodshed - his guilt, his sense of responsibility, and his traumatized psyche.

Unlike the low budgets, small crews, and digital video of In This World, La Commune, and Journals, the production of Shake Hands was of a much larger scale. The

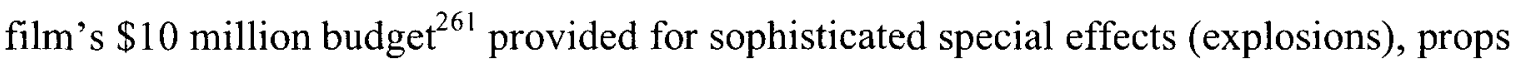
(UN vehicles, firearms, dummies), and make-up (to transform extras into butchered corpses). Professional actors were hired for most of the main roles, along with hundreds of extras, with both the dialogue and the performances determined prior to filming rather than improvised during it. Yet, despite the film's typical production methods, Roger Spottiswoode and screenwriter Michael Donovan stress in interviews that Shake Hands is

\footnotetext{
${ }^{259}$ Philip Gourevitch, We wish to inform you that tomorrow we will be killed with our families (New York: Farrar Straus and Giroux, 1998) 4.

${ }^{260}$ Kenneth W. Harrow, "'Un train peut en cacher un autre': Narrating the Rwandan Genocide and Hotel Rwanda," Research in African Literatures 36.4 (2005): 226.

${ }^{261}$ Etan Vlessing, "The Devil and Mr. Dupuis," The Globe and Mail, August 5, 2006, Toronto edition, R.1.
} 
distinct from Hollywood productions by the focus and structure of its story. ${ }^{262}$ Reviewers certainly agree by pointing to the lack of drama compared to films like Hotel Rwanda and critiquing the narrative as too complex and detailed for a dramatic feature form. ${ }^{263} \mathrm{As}$ one critic put it: "The endless explication ends up feeling school-teacherly and awkward. This kind of dense informational material is probably better handled in the documentary form. ${ }^{264}$ The narrative indeed concentrates on the bureaucratic aspects of Dallaire's mission, recounting his series of meetings with key players, phone calls with or messages from the UN, and briefings with other officers and soldiers, while indicating dates, times, names, and locations along the way. In form and function, then, although certainly conventional and commercial, Shake Hands resembles other reenactments in its didactic attention to process.

Shake Hands is thus a feature film that functions as a kind of document, and as such it distinguishes itself from other docudramas on the Rwandan genocide by claiming an access to the truth from inside the UN mission. Every film on the subject, several of which privilege white protagonists, is critical of the UN's inaction towards and resulting abandonment of Rwanda during the killings. Like Dallaire's memoir, Shake Hands shares in this condemnation of the international community's lack of responsiveness despite their full knowledge of the atrocity. Dallaire's story, however, is also a response to the way he and the UN soldiers in Rwanda have been portrayed in films like Hotel

\footnotetext{
${ }^{262}$ See Johanna Schneller, "Making the movies Hollywood doesn't want," The Globe and Mail, June 7, 2008, Toronto edition, R.3.

${ }^{263}$ See for example Jay Stone, "New look at Rwandan Horror," The Ottawa Citizen, September 28, 2007, Ottawa edition, D.1.

${ }^{264}$ Alison Gilmor, "The Devil is in the confusing details," Winnipeg Free Press, September 28, 2007, Winnipeg edition, D.1.
} 
Rwanda and Sunday in Kigali, as cold or inactive, and as abandoning the victims. ${ }^{265}$ By presenting Dallaire's perspective, as conveyed in his memoir, Shake Hands depicts the General as overwhelmed by the circumstances he was thrown into and frustrated by the lack of institutional support but also fervently dedicated to his mission. ${ }^{266}$ In the film Dallaire rejects the passivity and neutrality required of him by the UN mandate and refuses to comply when ordered to evacuate. He instead does everything he can to protect potential victims with the limited resources the mission was given by transporting 30,000 Tutsis to a stadium patrolled by his soldiers. According to Spottiswoode, by telling "the General's story" the film presents the "real version" of what happened in Rwanda. ${ }^{267}$

Claims to the truth of the representation are grounded in the narrative's basis in personal memory and its filming in actual locations where the depicted events took place, both of which are established during the film's opening sequence. The film begins with title cards that explain the Hutu and Tutsi division as institutionalized by Belgian colonizers, the decades of animosity and violence that followed after independence, the formation and invasion of the RPF, and the peace treaty negotiations that Dallaire was sent to oversee in 1993. From this brief exposition of Rwanda's national history, Shake

\footnotetext{
${ }^{265}$ While these films also show Dallaire and the UN forces to be frustrated and overwhelmed, Nick Nolte's portrayal of Dallaire in Hotel Rwanda presents the General as a rather chaotic, and somewhat bumbling (read by some reviewers as drunk), character rather than the controlled military man in Shake Hands. The very different portrayal in Sunday in Kigali shows Dallaire as quiet and contemplative but also completely inactive and unsympathetic in the way he ignores pleas for assistance.

${ }^{266}$ In his memoir, Dallaire explains that his initial plan for the mission was significantly reduced and his constant requests for additional forces and resources while in Rwanda were consistently denied. Dallaire argues that had he been given what the mission required the genocide could have been prevented or stopped.

${ }^{267}$ See the director's commentary on the DVD. Dallaire accompanies Spottiswoode's commentary by correcting mistakes in the way certain events were represented or confirming their relative accuracy.
} 
Hands immediately shifts to a focus on personal memory, with a close-up of Dallaire (played by Quebec actor Roy Dupuis) seated in a therapist's office, contemplating suicide. The following series of images is a flashback to his initial arrival in the country, consisting of picturesque views of lush landscapes, vast tea fields, and daily life in the streets of the capital Kigali. The beauty of the landscape, with its vibrant colours and serene atmosphere, contrasts sharply with the chaos, brutality and rotting bodies pictured later, while at the same time potentially foreshadowing the violence to come. Images of men and women working in the fields with hoes and machetes allude to - if vaguely and perhaps unconsciously - the way in which the genocide was conceptualized as "communal work," as nationally instituted manual labour, with the machete as the preferred "tool." 268 In addition to their narrative function, these initial images of the country also have a documentary quality that signify the film's on-location filming, its production where the actual events occurred and with the people who experienced those events. The sequence thus simultaneously connotes both past and present, pre- and postgenocide Rwanda, history and its reenactment. The history depicted, however, is limited to Dallaire's memories of and experiences during the genocide, which construct a story that is not only bureaucratic but also intensely personal.

The film's privileging of personal memory is further evident throughout the narrative by what I call the "shock moments" that punctuate the mission-focused trajectory. While the first half of the film progresses quite rapidly through the identification of key figures, significant meetings, and bureaucratic struggles, the pace is

\footnotetext{
${ }^{268}$ See Mirzoeff, "Invisible Again," and Gourevitch, "Among the Dead." Both Mirzoeff and Gourevitch discuss the way in which the Rwandan genocide was understood by the perpetrators as national labour.
} 
occasionally disrupted and gradually altered with the introduction and increasing frequency of moments in which Dallaire encounters horrifying scenes of violence or death, such as uncovering butchered bodies beneath the planks of a bridge or hearing Prime Minister Agathe being killed by machine gun fire over the phone. Since the film, unlike several others, never shows actual killing taking place, emphasis is given to Dallaire personally seeing - his bearing witness to - the growing number of the dead, along with his involuntary paralysis in the face of the immediate and surrounding horror. These shock moments accumulate, leading to Dallaire's ultimate breakdown by the end of the film, which is presented as a hallucination of a pre-genocide paradise where he unites with those killed, then attempts suicide, only to wake up on a park bench back in Canada a psychologically damaged man. The shock moments function both to explain his current post-traumatic stress and to constitute his haunting memories. Additional hallucinations emerge during the many but brief images of Dallaire in therapy sessions that frequently interject the narrative and often have Dallaire speaking with colleagues from the mission who appear as phantoms. With these references to Dallaire being haunted by his past, along with the shock moments and flashback sequences, the film performs what Kaplan calls the "visuality of trauma symptoms," 269 which here intersperse and bookend the narrative in Rwanda.

If the therapy sessions picture Dallaire as stuck in the past, wallowing in his haunted memories and disturbed thoughts, the film as a whole ultimately marks an effort to begin mourning and move forward, whereby the return to a traumatic past takes on a

\footnotetext{
${ }^{269}$ Kaplan, Trauma Culture, 69. See also Maureen Turim, "The trauma of history: flashbacks upon flashbacks," Screen 42:2 (2001): 205-10. Turim specifically discusses the flashback as a formal technique for representing symptoms of PTSD.
} 
social and ethical purpose. In the closing scene of the film, Dallaire orders his therapist to keep him alive, stating, “Everybody wants to forget Rwanda now. I can't let that happen. I haven't finished my mission." The making of Shake Hands, which Dallaire initiated, is part of his continuing "mission," along with the memoir and a 2004 documentary of the same title by Peter Raymont, which together constitute a broader pedagogical project and a process of working through on Dallaire's part. Framed by his struggle with post-traumatic stress, each text performs a return to the traumatic past, either imaginatively through the writing, which Dallaire considers part of his therapy, ${ }^{270}$ or physically in the documentary, which follows Dallaire on a trip back to Rwanda on the tenth anniversary of the genocide. These projects are also an extension of Dallaire's commitment to pedagogical activism through his public lectures on the UN's failure in Rwanda as an example of the West's racism towards Africa. The film and its broader context suggest an intent that is both personal, as a therapeutic working through or catharsis for Dallaire, and pedagogical, a promoting of remembrance on a national and a global level.

In her critique of the body of material that stems from and concentrates on Dallaire's trauma, including several documentaries and news reports, Sherene Razack identifies "a virtual industry [that] has sprung up around General Romeo Dallaire",271 which forms a discourse on the Rwandan genocide by prioritizing peacekeepers as traumatized victims. Razack remarks, "It is their pain and not the Rwandans' that we are

\footnotetext{
${ }^{270}$ Anonymous, “Dallaire haunted: Standing ovation for commander,” Daily Gleaner, April 13, 2000, Fredericton edition, n.p.

${ }^{271}$ Sherene H. Razack, "Stealing the Pain of Others: Reflections on Canadian Humanitarian Responses," The Review of Education, Pedagogy, and Cultural Studies 29 (2007): 381.
} 
invited to listen to....,272 Spectators are invited to identify with the peacekeepers as outside observers who are "compassionate," "uninvolved," and "overwhelmed" by a horror elsewhere. ${ }^{273}$ This is certainly the case in Spottiswoode's feature film by folding the collective history of the Rwandan genocide within a personal narrative of traumatized peacekeeping. As a film limited to Dallaire's perspective of events and the activities of the UN forces, Shake Hands does not examine how ordinary Rwandans experienced or survived the genocide, nor does it investigate the political and economic underpinnings of the killings, their basis in the ideology of Hutu Power and communal labour, other than the reference to the country's history of colonialism in the opening titles. Instead, with the centrality of the shock moments and the therapy sessions, the narrative concentrates on Dallaire navigating the increasing chaos that surrounds him, his response to the atmosphere of death, and the toll it takes on his mental health. This privileging of the outsider witness as traumatized subject further extends to the discourse on the film's production found in interviews, articles, reviews, an extensive CBC report and the film's making-of-documentary, in which the filmmaking, as a reenactment of Dallaire's story, is presented as both a humanitarian effort and a traumatizing event.

\section{Reenacting (An)Other's Suffering}

Prior to the release of Shake Hands, the CBC Sunday night news produced a feature report promoting the film (which was partly funded by the broadcaster). The report reiterates the prevailing descriptions of Shake Hands as a story of a quintessentially

\footnotetext{
272 Ibid., 379.

${ }^{273}$ Ibid., 381.
} 
Canadian hero, stressing the urgency to tell this story and its intensely personal nature. While Dallaire makes a few brief appearances, primary focus is given to Roy Dupuis who provides an extensive interview on the emotional and psychological impact of the film's production. Particular emphasis is placed on the film's making as an emotionally charged process for the performers, with Dupuis' portrayal of Dallaire as an especially painful and transformative experience for the actor. Clips from the film that comprise the shock moments identified earlier are included - from the most dramatic, personal, and affective scenes in which Rwandans depict corpses and Dupuis performs as the witness to the dead - to reinforce the actor's statements and the similarity being drawn between him and Dallaire. Like the film's narrative, personal trauma frames the promotional discourse on the making of Shake Hands. The attention to the production as itself a site of trauma establishes the proximity between the representation and its referent that warrants the telling of the story.

Claims to the fidelity of Shake Hands' depiction centre on the casting of Dupuis in the leading role. During the promotion of the film, Dupuis and Dallaire stressed their resemblance and relationship both on and off the screen. At festivals and in television appearances the two men were frequently interviewed together, demonstrating a similar stature and demeanor despite the age difference. On several occasions, both discuss the immediate bond they formed upon meeting when Dallaire recounted his story to the actor, who not only formed a deep respect and responsibility towards the General but also translated the intimate knowledge he acquired into his performance. In the film Dupuis wears Dallaire's actual uniform from the UN mission in Rwanda, a literal taking on of the 
General's past. At one point in the CBC report, Dallaire states that watching the film is like reliving his past and seeing himself on screen. The emphasis placed on the way in which the actor effectively embodies his counterpart signals an ethical responsibility not only towards viewers, to tell the story with the highest level of accuracy, but also to Dallaire himself.

In the one-on-one interview with Dupuis featured in the $\mathrm{CBC}$ report, the bond and resemblance are further pronounced by concentrating on the actor as traumatized and transformed by his performance. Just as Dallaire's traumatic symptoms frame the story of genocide in the film, Dupuis' vicarious trauma frames the story of its reenactment. The interview begins with him remarking, "I would wake up with that story in my head. I would go to bed with that story in my head." Like the traumatized peacekeeper, Dupuis is equally overwhelmed and haunted by his experience, thereby indicating his intense emotional investment in the role and the performance. At one point during the interview Dupuis begins to cry, visibly overtaken by the memory of performing a scene in which he (as Dallaire) removes dead bodies from a dirt road; his posture and mannerisms, with head bowed in one hand, emulates his performance as Dallaire in the film's therapy sessions. We are told he also emotionally broke down during the filming. Over a clip of the scene, Dupuis speaks of this (shock) moment as especially painful for him, illustrating Razack's observation of how Rwandans' bodies, their “anonymous corporeality, ${ }^{, 274}$ function as vessels for the pain of the white Western witness. Just as "Dallaire is the body who suffers and is transformed by it" and is "the principal story of

${ }^{274}$ Ibid., 381. 
the genocide, ${ }^{275}$ Dupuis' suffering is the central story of the production. That Dupuis playing the role of witness to the Rwandan genocide was an equally (though not identical) transformative experience for him is expressed by Dallaire in one of his few statements in the report: "I think Roy Dupuis is a different Roy Dupuis than before this film."

Dupuis' sincerity, that he was deeply affected by listening to and performing Dallaire's story, and even perhaps traumatized by it, is not in question here, as trauma studies scholars have stressed that a particular feature of trauma is precisely how it is passed on to others, whether the children of survivors, listeners of their testimonies, or viewers of films. ${ }^{276}$ Kaplan, for example, makes a strong case for recognizing vicarious trauma as one of the responses to the suffering of others and cites a number of instances where clinical psychologists experienced PTSD symptoms when working with trauma sufferers. ${ }^{277}$ Others have equally noted that "facing traumatic history" presents "an obligation to accept the demands of... a relation that risks our becoming wounded in the attention to the wounds of others." ${ }^{278}$ If listeners and performers can be wounded by another's traumatic past, a potential LaCapra also recognizes, he warns of the danger of collapsing differences and generalizing trauma through the identification with victims:

\footnotetext{
275 Ibid., 383.

${ }^{276}$ See Cathy Caruth, "Introduction," Trauma: Explorations in Memory, ed. Cathy Caruth (Baltimore and London: The Johns Hopkins University Press, 1995) 3-12, and Dori Laub, "Bearing Witness or the Vicissitudes of Listening" in Testimony: Crises of Witnessing in Literature, Psychoanalysis, and History, eds. Shoshana Felman and Dori Laub (New York and London: Routledge, 1992) 57-74.

${ }^{277}$ Kaplan, Trauma Culture.

${ }^{278}$ Roger I. Simon, Sharon Rosenberg and Claudia Eppert. "The Pedagogical Encounter of Historical Remembrance." Between Hope \& Despair: Pedagogy and the Remembrance of Historical Trauma, eds. Roger I Simon, Sharon Rosenberg, and Claudia Eppert (Lanham, Boulder, New York and Oxford: Rowman \& Littlefield Publishers, Inc, 2000) 1-8.
} 
there is an important sense in which the after effects - the hauntingly possessive ghosts - of traumatic events are not fully owned by anyone and, in various ways, affect everyone. But the indiscriminate generalization of the category of survivor and the overall conflation of history or culture with trauma, as well as the near fixation on enacting or acting out post-traumatic symptoms, have the effect of obscuring crucial historical distinctions; they may, as well, block processes that counteract trauma and its symptomatic after effects but which do not obliterate their force and insistence - notably processes of working through, including those conveyed in institutions and practices that limit excess and mitigate trauma. ${ }^{279}$

The kind of conflation that LaCapra warns against characterizes the CBC's report on Shake Hands in its attention to the film's making as a traumatizing process for both Dupuis and the Rwandan participants, without distinguishing the different kinds of subject positions - that of witness, secondary witness, or survivor - in relation to the historical event and its reenactment.

The hundreds of Rwandan extras employed by the film are given brief mention in the report, but none was interviewed. Instead, a voice-over indicates that the set required psychiatrists on hand since, for the Rwandans, their reliving of the past "brought back terrible memories." We are shown an image of a Rwandan woman crying in the arms of a psychiatrist who attempts to comfort her by explaining "it is just a play," before placing her on the ground so she can pretend to be a dead body for the filming. The voice-over concludes, "Everybody was affected and had to pay a price." Certainly everyone was affected, but not all were affected equally or in the same way and for the same reasons, yet the report neglects to investigate the distinctions. Even if certain differences are implied - for the Rwandans the production was a return to a traumatic past while Dupuis' performance generated a new traumatized subjectivity - the concluding statement performs the kind of generalization that LaCapra warns against by encompassing the ${ }^{279}$ LaCapra, Writing History, Writing Trauma, xi. 
reactions on the part of the Rwandan performers within the overall traumatic experience of production already established by Dupuis. In the end, the report presents a unified and shared experience of the film's making as a trauma. Another concern with the generalization of trauma, and PTSD symptoms specifically, raised by Jody Ranck, is that it fails to recognize different contexts for the victims. Ranck argues that applying PTSD to Rwandan survivors may be inappropriate since it assumes a response to a discrete event in the past (as it is for Dallaire and Dupuis whose time spent in Rwanda was temporary) whereas for Rwandans, although the genocide has ended, the threat of violence remains a constant possibility with the continuing conflicts in the region. ${ }^{280}$ This is not to say that the Rwandan genocide was not a historical trauma for the survivors or that the Rwandan performers in Shake Hands were not emotionally affected by their return to and reliving of an event of concentrated mass violence. On the contrary, as already mentioned, the reliving of a violent past through its reenactment can be an intensely emotional and painful experience for survivors, although not exactly equivalent to the original event. The ways in which the $\mathrm{CBC}$ report, then, pays particular attention to and valorizes the pain and suffering generated by the production process for the performers is ethically suspect. It illustrates the kind of "fixation on enacting or acting out" 281 that LaCapra identifies as problematic in Shoah and which is "concerned

\footnotetext{
${ }^{280}$ Jody Ranck, "Beyond Reconciliation: Memory and Alterity in Post-Genocide Rwanda," in Between Hope \& Despair: Pedagogy and the Remembrance of Historical Trauma, eds. Roger I Simon, Sharon Rosenberg, and Claudia Eppert (Lanham, Boulder, New York and Oxford: Rowman \& Littlefield Publishers, Inc, 2000) 187-211. The current government in Rwanda continues to fight with the Hutu extremists and the genocidaires who have regrouped in the Democratic Republic of Congo. See also Philip Gourevitch, "The Life After: A Startling Exercise in Reconciliation," New Yorker, May 4, 2009, 36-49. ${ }^{281}$ LaCapra, Writing History, Writing Trauma, xi.
} 
with victims as victims, not as survivors or agents. ${ }^{282}$ By also generalizing the traumatic affects of reenactment the report asserts a collective investment and unanimous belief on the part of "everyone" in the necessity to make the film. As the voice-over announces at the report's conclusion, "The film was hard on the people doing it but it was worth it to get the story out." The emotional discomfort of the performers is not simply an unfortunate side effect of the production but is also used to testify to the film's value and importance. Presenting the film's making as a worthwhile traumatic experience serves as a warranting strategy that signals a requirement to tell the story. The value of the film's production and its requirement to tell is cemented by screenwriter Michael Donovan, who was also interviewed in the report and states that despite the financial, pragmatic, and psychological difficulties involved in the production, he could not "be someone else who abandons [the story]." Donovan's comment implies that the making of the film was itself a humanitarian project, much like Dallaire's peacekeeping efforts during the genocide. This also places a requirement on Western audiences to see the film in order not to abandon the victims. But if the pain of the production process warrants the film (and requires its viewing on the part of the West), this raises the question of whether the pain engendered or induced (to use LaCapra's term) by the reenactment and reliving of a violent past on the part of genocide survivors is itself warranted.

\section{The Responsibility to Represent History}

If the $\mathrm{CBC}$ report raises questions concerning the investment of the performers in the process of filmmaking by attending to the emotional stakes of reenactment, the making-

\footnotetext{
${ }^{282}$ Ibid., 97.
} 
of-documentary (MOD) for Shake Hands foregrounds the issue of ownership by asserting the film's making as a responsibility to represent a traumatic national event for its subjects. The documentary attends less to the personal nature of the story and its reenactment than to the collective history being represented, the practicalities of filming in Rwanda, and the meaning of the film's production for the Rwandans involved. Unlike the $\mathrm{CBC}$ report, the $\mathrm{MOD}$ includes interviews with a number of the extras out of the hundred who performed as Interahamwe militia, RPF soldiers, or dead victims. It therefore presents more complex, multiple and conflicting responses on the part of the Rwandan performers, with emphasis placed on their motivations for performing in the film over the performance's traumatic affects. Rather than focusing on (or wallowing in) the past, the MOD concentrates on the requirements for the future, specifically the task of remembrance and commemoration with which the film is engaged as a responsibility adopted on the part of the West towards the genocide victims. As such, the MOD equally stresses the significance of the film, though here by establishing the film as a witness to a traumatic collective past.

In the interviews with Rwandan participants the value of the film's production is discussed both as a historical representation with a pedagogical and a commemorative function and, in a more immediate sense, as providing opportunities for employment in Rwanda. For many of the interviewees, financial need is a central motivation for performing in the film. The MOD includes the same image of the woman crying that figured in the $\mathrm{CBC}$ report but provides a broader context; while she is certainly distressed by her role as a corpse and the scene of dead bodies surrounding her, she also fears losing 
the job and was therefore assigned to a less stressful role. A number of the Rwandans interviewed mention the widespread poverty in the country and the role of the film production in providing work for many. The MOD also reveals the frustrations that result by showing a large crowd of young men waiting for hours to be chosen to play the one hundred rebel soldiers or militia killers needed for the scene that day. One of the men complains about such a long wait time for the equivalent of twenty American dollars. The emotional difficulties associated with the reenactment are also addressed, but as related not only to the return of painful memories but also to the discomfort of playing certain roles. One interviewee, for example, admits his shame at playing the part of a militia member, especially while being watched by friends and neighbours. We assume he accepted the part out of a necessity for employment.

As these tensions are broached, however, they are accompanied or followed by statements (made either by the filmmakers or the Rwandan performers themselves) stressing the importance of the film as a text of remembrance, the urgency to tell the story of the genocide, and its value for educating both current and future audiences in and outside Rwanda on the episode in the country's history. After the young man expresses discomfort at performing the role of a perpetrator, another remarks that the "film will help people understand" what happened during the one hundred days of killing. Donovan then asserts that the story "needs to be told a thousand times" to make the point of "never again." The MOD concludes with one of the extras, dressed as a rebel soldier, putting the previous assertions about financial motivation into question. He remarks to the camera, "We are proud to play our history. This is Rwandan history...We are not here for money. 
We are here...so that everyone may know what was going on in Rwanda, even our children. We wish that our children may know this story, the story of Rwanda, because of this movie." Like the CBC report, the documentary closes on the point of collective commitment to the story with Rwandans participating in a historical representation for future generations. According to both texts, the importance of telling the story outweighs the emotional pain associated with reliving the events or the tensions and frustrations experienced during the production. Indeed, the making of the film as an important and necessary task is evinced precisely by its emotionally charged production process on the one hand, and by its representation of history for Rwandans on the other.

Understood as a mission, a point reiterated in the MOD by Dupuis, the production of Shake Hands is seen as a responsibility to represent Rwanda's history, a responsibility on the part of the West both because it is equipped with the necessary resources, and because of its neglect of Rwanda during the genocide. Not only does the film aim to correct "the West's misperception and mischaracterization of these events" 283 at the time (by failing to acknowledge genocide as taking place), it also seeks to correct the past abandonment of Rwanda through its making. Shake Hands demonstrates what Ivone Margulies identifies as the "moral dynamic" of reenactment, in which a prior event is reenacted in order to create an "improved version" of the original. ${ }^{284}$ Margulies writes: "The attempt to both respect and reinterpret the original event leads to strained attempts to get the occurrence right but also to correct it. And 'getting it right' often involves the

\footnotetext{
${ }^{283}$ Jane Blocker, "A Cemetery of Images: Meditations on the Burial of Photographs," Visual Resources 21.2 (2005): 183.

${ }^{284}$ Margulies, "Exemplary Bodies: Reenactment in Love in the City, Sons, and Close-up," in Rites of Realism: Essays on Corporeal Cinema, ed. Ivone Margulies (Durham: Duke University Press, 2003) 220.
} 
repetition on camera of some mistaken behavior, which it is the film's work to put on trial."${ }^{285}$ This applies here not to the performances specifically, as it does in Margulies' examples, but rather to the narrative focus of the film (by attending to past mistakes) and the entire production (as correcting the mistakes depicted). While Shake Hands concentrates on the UN's failure to intervene and its consequent complicity in the genocide, the film's making is driven by a humanitarian impulse to tell the story in order to rectify the West's previous neglect. This raises the question, in whose interest is the film ultimately made and to whom does the story, along with its telling, belong?

Despite the claims that the making of Shake Hands is for Rwanda, neither the story nor its telling belong to the Rwandans involved. Although the MOD presents the filmmaking as a collective commitment, which includes the Rwandan participants, the interview segments with some of the Rwandan performers certainly challenge such a conclusion, as does the film itself. As extras, most of the Rwandans lack speaking roles or a central place in the film, but rather provide the setting for Dallaire's story, primarily as dead bodies. Unlike my previous case studies, the amateur performers are here not activated by the production as contributors whose own memories inform the interpretation of historical events. Moreover, as already indicated, the process itself was potentially painful and humiliating for some. By contrast, Dupuis' participation in the production was transformative, educational, and ultimately rewarding. The production material for Shake Hands presents both the film and its production as personal for Dallaire and Dupuis; it is Dallaire's ownership of the story and Dupuis' emotional investment in its telling that are privileged. The Rwandan performers are identified more ${ }^{285}$ lbid., 218. 
as victims or labourers rather than as participants or collaborators in the reconstruction of the past and its meaning.

The Rwandan genocide is a historical event that certainly demands attention and representation. Discussions on projects of pedagogical remembrance, to which films on the genocide belong, assert that such practices posit the belief that "in order to avoid repeating the mistakes of the past, we must learn the lessons of history." ${ }^{286}$ Hence, the comments by some of the extras in the MOD and by the Rwandan minister who approved the film's production in Rwanda ("[Y]ou're not telling our story. You'll get it all wrong. But that's of no concern to us. We're just happy you're telling a story.") indicate a desire for a witness. Shake Hands takes up the role of witness to the Rwandan genocide and rightly attends to the West's accountability in the immense loss of lives. However, the claims to an ethical responsibility to represent another's history in the MOD outweigh and displace the ethical implications of the dynamics of the film's production process in terms of the cost to the performers and the hierarchical divisions of power, which are neither challenged nor changed. While triggered by the production process, the memories of the Rwandan survivors/performers do not inform and have no place in the representation that privileges Dallaire's memories as the basis and focus of the narrative. Thus, while the film's production seeks to correct the West's neglect of Rwanda in the past, it may in the end simply repeat it.

Something noticeably absent in both the CBC report and the MOD is an elaboration of Rwanda's current socio-political context that the production is situated within, including the difficult efforts at reconciliation, the tensions of a transformed population,

\footnotetext{
${ }^{286}$ Simon, Rosenberg, and Eppert, "The Pedagogical Encounter of Historical Remembrance," 4.
} 
and the ways in which the conditions of the past continue in the present. If the $\mathrm{CBC}$ report demonstrates how the past remains a source of pain, Ranck argues that such a concentration on PTSD symptoms, which is typical of Western discourses on the Rwandan genocide, amounts to "a depoliticization and medicalization of suffering" by ignoring the "ongoing structural violence" 287 that underpinned the mass killings. In a similar vein, Mirzoeff critiques the construction of memorial sites in Rwanda by and for Westerners by remarking that " $[t]$ he pretense of grief is a failure of representation that attempts to cover up the wider failure to engage with the questions of colonization, decolonization, and globalization that led not only to Rwanda's genocide but to a world newly engaged in old divides but with no new solutions. ${ }^{, 288}$ Mirzoeff points to the way in which the conditions of the Rwandan genocide are not only still present but also rooted in global economic relations and structures. We may therefore ask in what way the film's production is itself implicated in these relations? Or, alternatively, how might filmmaking contribute to local processes of recovery, reconciliation, and unification in a climate of ongoing social divisions ${ }^{289}$ The CBC report and the MOD of course avoid such questions, questions that would shift the ethics of responsibility from the film as a representation of a historical event to the film's making as a historical event.

\footnotetext{
${ }^{287}$ Ranck, "Beyond Reconciliation," 197.

${ }^{288}$ Mirzoeff, "Invisible Again," 91.

${ }^{289}$ In post-genocide Rwanda, numerous theatre projects, both government sponsored and grassroots initiatives, have emerged as a tool to aid in reconciliation and in judicial proceedings. These projects, although not without their problems, attest to the direct social and political impact of performance practices. See Chantal Kalisa, "Theatre and the Rwandan Genocide," Peace Review: A Journal of Social Justice 18.4 (2006): 515-21, and Amanda Breed, "Performing Reconciliation in Rwanda," Peace Review: A Journal of Social Justice 18.4 (2006): 507-14.
} 


\section{Conclusion}

This chapter has attempted to outline ethical problematics specific to the processes of reenactment as a reliving of the past and a representation of national trauma. By attending to the dramatic feature Shake Hands with the Devil as a reenactment, I have sought to show how the dynamics of production in a cross-cultural context are ethically charged with respect to the Rwandan performers' role in the reconstruction of their past and the painful affects such a reconstruction generates. Of particular concern, then, are the Rwandan participants' investments in and ownership of the historical representation and how these are portrayed in the discourse on the film's production in order to warrant the film's making as both a traumatic experience for the performers and as a witness to another's traumatic history. Although theories on trauma and ethics in cinema identify witnessing as an ethical position on the part of films and spectators, such claims by the production material for Shake Hands assert the film's importance and undermine questions of the value and meaning of its production process for the Rwandans - not as an abstract entity to whom the production claims a responsibility but as performers engaged in the immediate, political, and material relations of filmmaking. The ethics of reenactment are thus located not only in a film's form, aesthetic strategies, or mode of address, but also in the particular ways in which the production process engages the amateur performers in the recreation of their own traumatic past. 


\section{CONCLUSION}

In both theoretical and popular discourses, reenactment is frequently characterized as an activity that repeats a prior action or occurrence. This equation of reenactment with repetition is evinced in the frequency with which the familiar phrases "Play it again, Sam" and "Once more, with feeling" reoccur as titles or points of reference in discussions of reenactment in film. Repetition implies that each subsequent action is the same as the first or seeks as close a resemblance as possible. This dissertation has attempted to demonstrate how reenactment, which is a performance based on a model, is nevertheless distinguished from repetition, replication, and duplication of an original. Instead, a performance that reenacts the past has its own singularity and specificity in the present. It certainly imitates, traces, and evokes a historical occurrence, but does not and cannot repeat the referent. Moreover, whereas repetition can suggest an automatic iteration of habitual behaviour, reenactment is a purposeful engagement with history that demands self-awareness of one's actions and an interpretation of what is reenacted. The uses of reenactment in film outlined in the previous chapters identify the past on which the reenactment is based as a lesson, a guide, or an inspiration for present and future action. Thus, throughout this study I have stressed the significance of the process of performance and its commitment to continuity in order to assert the forward driven momentum of reenactment as a practice that recalls the past while looking towards the future.

By positing the notion of reenactment as an event, this dissertation has argued for an understanding of reenactment as a bodily and social activity that is simultaneously 
imitative and inventive. In the films in this study reenactment has facilitated transnational migration, renewed revolutionary values, activated traditional Inuit knowledge, and generated traumatic affects on the part of the participants involved. By renewing past values, emotions, and knowledge in and for contemporary conditions, the performances at once testify to and actively establish the continuity between past and present. This emphasis on continuity is especially manifest in the bodies of the amateur actors, whose positions as descendants of historical figures, as witnesses of the prior events, or as representative individuals of the culture and community depicted marks the performers' investment in their history and its impact on the present. The imitative gestures and actions of the performers yield emotions, convictions, attitudes, and actions that are not equivalent to those of the historical agents to which the films refer but rather evince the reverberations of historical events on contemporary lives and subjectivities. Through the activation of collective memory and the perpetuation of tradition, reenactment is here as much a means of emergence as it is an instrument of recollection.

The present goals and functions of reenactment are made apparent in these films by exposing the material and social apparatus of film production. In the interlinked processes of filmmaking and reenactment history is engaged to address contemporary national problems or mitigate cultural divisions. In La Commune, the performance of the Paris Commune, combined with the actors' historical research and collective discussions, directs the cast towards a consideration of the current gender, class, and race inequalities in France. In addition, the collaborative and democratic method of production invites reflection on the potential for a practical application of the Commune's ideals in the 
current political climate. In the production of The Journals of Knud Rasmussen, the construction of traditional Inuit artefacts, its dependence on local elders' memories and the revival of storytelling, attempt to bridge the generation gap in Igloolik and build community cohesion by restoring ties to cultural history, knowledge, and values. In both cases reenactment and filmmaking constitute an interactive social encounter, with the passing down of Inuit skills in the making of Journals and with the out of character discussions that accompany the performances in La Commune. This social dimension of reenactment is equally demonstrated in In This World and Shake Hands with the Devil, which, like the other two films, are cross-cultural productions that highlight the politically and ethically charged relations of filmmaking within postcolonial conditions by raising questions of the authorship and ownership of historical representations.

To conclude I wish to return now to the wider field of reenactment within which these films are situated. Although throughout this dissertation I have distinguished the features of my case studies from other types of reenactment, these films are also one dimension of a much larger and growing phenomenon in contemporary popular culture that includes live historical reenactment, television programming, documentary films, commercial features, and performance and video art. The uses of reenactment as an engagement with the past have also extended into new media technologies, such as virtual reality, video games, and what Vanessa Agnew observes as "reenactment's most ubiquitous instantiation, social and cyber groups devoted to historical performance."290 Although such activities might be dismissed as a mere hobby or entertainment, Agnew

\footnotetext{
${ }^{290}$ Vanessa Agnew, "History's Affective Turn: Historical Reenactment and Its Work in the Present," Rethinking History 11.3 (2007): 300.
} 
argues that their broad public appeal demands an investigation of the kinds of "cultural and political work" ${ }^{291}$ these practices perform. Indeed, whether as heritage sites, commercial films, television shows, live performances, or interactive games, reenactment is a form of historical pedagogy that is continually drawing an increasing number of participants and spectators.

While historical reenactment belongs to a long tradition that includes pageants, parades, and passion plays (in some cases the reenactment of an event began immediately after the original took place, such as the storming of the Winter Palace during the Bolshevik Revolution and certain battles of the American Civil War), the contemporary attraction to such commemorative performances and the organizations devoted to the practice have been steadily growing since the 1950 s. In an article published in 2003 , Alan Filewood provides the results of an Internet search of reenactment societies that demonstrates, as he puts it, "a vastly diverse and...expanding" culture. In addition to the 120 WWII organizations Filewood mentions ("some of the units have hundreds of members"), ${ }^{292}$ he also lists the following:

In the United Kingdom, the National Association of Re-enactment Societies lists 31 members, some which are umbrella organizations such as the Sealed Knot Society, with 58 regiments performing the British Civil War, and the American Civil War Association, Inc. (UK), with 28 units. In Australia and New Zealand, the Australasian Register of Living History Organizations lists 397 units. In Canada, the Canadian Reenactor website lists 44 units (performing $17^{\text {th }}$ century to WWII); in the United States, Reenactor.net lists 312 Civil War reenactment units... When we expand this field to include classical, medieval and Renaissance groups...we are clearly dealing with thousands of groups. ${ }^{293}$

\footnotetext{
291 Ibid., 302.

${ }^{292}$ Alan Filewood, "People's Theatre, People's Army: Masculinism, Agitprop, Reenactment," XCP: Crosscultural Poetics 13.7 (2003): 14-15.

${ }^{293}$ Ibid., 14.
} 
Even though Filewood's research indicates the international appeal of historical reenactment, which even extends beyond English-speaking nations, the most common military event that is reenacted is the American Civil War. In "Catharsis, Revision, and Re-enactment: Negotiating the Meaning of the American Civil War" Randal Allred describes a community of reenactors fervently devoted to revisiting this national conflict, the meanings and motivations of which remain highly contested and unresolved issues in the United States. Allred attends to the passion reenactors express about what they do, which is indicated in the significance of the practice to their lives, their dedication to the authenticity of details, and their interest in the history outside the reenactment event itself. The passion of the reenactors, and their commitment to the practice, is grounded in the effects or feelings the activity can produce. As reenactors (often tearfully) refer to the outcome as a sense of having stepped back in time, Allred does not dismiss such responses as misinterpretations but sees the performance as generating very powerful and genuine emotions, which evince a profound personal and collective investment in reenactment beyond merely trivial play. Allred identifies the number of Civil War reenactors in the United States as ranging between thirty and forty thousand and notes that these reenactments typically attract an audience of tens of thousands. ${ }^{294}$

A new site of historical reenactment that has also attracted a large number of viewers over the last decade is television programming. Between 2000 and 2006 PBS merged historical reenactment with reality television in the popular Historical Home series, where participants live for several months on a colonial era farm or a London

\footnotetext{
${ }^{294}$ Randal Allred, "Catharsis, Revision, and Re-Enactment: Negotiating the Meaning of the American Civil War," Journal of American Culture 19.4 (1996): 2.
} 
home during the Second World War. The series spanned three continents with programs set in Britain, Australia, and the United States. The programs, including 1900 House (2000), 1940s House (2000), Frontier House (2001), Manor House (2002), and Colonial House (2003), among others, concentrated on the tensions that arose between twenty-first century attitudes and the social hierarchies of a historical era, along with the strenuous material conditions of daily life that participants had to contend with. ${ }^{295}$ A similar format also appeared on German television with a series of programs set in various historical periods. ${ }^{296}$ In a similar vein to the reality TV programs but focusing on a specific historical event, the BBC produced The Ship (2002), a documentary series that follows a six-week journey tracing Captain Cook's voyage through the South Pacific with a number of historians and anthropologists on board a replica of Cook's Endeavor, complete with eighteenth century provisions. ${ }^{297}$ In Canada, the two-part broadcast The Great War (2007) by the CBC also explores the physical and emotional challenges of ordinary people placed in an environment that replicates a particular, and especially traumatic, historical event. In the first part of the program a group of young descendants of Canadian soldiers (including women) participate in a reconstruction of their ancestors' experiences by living in the material conditions of WWI soldiers, receiving military training, and reenacting historical battles. Although such programs may reinforce romanticized notions of an era or a sense of national pride, many also seek to educate

\footnotetext{
${ }^{295}$ For an analysis of the series see Julie Anne Taddeo and Ken Dvorak, "The PBS Historical House Series: Where Historical Reality Succumbs to Reel Reality," Film \& History 37.1 (2007): 18-28.

${ }^{296}$ See Agnew, "History's Affective Turn."

${ }^{297}$ The historian Alexander Cook recounts his experience as one of the participants in "Sailing on the Ship:

Re-Enactment and the Quest for Popular History," History Workshop Journal 57 (2004): 247-55.
} 
both viewers and participants on the hardships of a particular period and to challenge sanitized conceptions of the past.

In a rather different use of reenactment in cinema, a number of current films revisit more recent historical events that are still in living memory in order to provide a broader context to original media representations. The CBC production Air India 182 (2008), about the Air India bombing in 1985, and the theatrical feature Polytechnique (Denis Villeneuve, 2009), on the Montreal Massacre in 1989, commemorate and invite public mourning on contemporary national traumas. In both cases, and like many reenactments, the films depict a step-by-step recounting of the circumstances leading up to the tragedy from the perspective of the victims or their families. A resurgence of reenactment in contemporary feature films is also apparent in the way a number of recently released commercial productions imitate previous documentary or television footage through historical dramatizations. The 2009 film Grey Gardens (Michael Sucsy) reenacts segments from the Maysles brothers' documentary of the same title. Ron Howard's Frost/Nixon (2008) is based on and reenacts parts of David Frost's television interview with Richard Nixon from 1977. And Steven Soderbergh's Che: Part One (2008) includes a reenactment of Che Guevera's 1964 speech to the UN, filmed in a black and white aesthetic that resembles the original television footage. While these films employ familiar actors to depict well-known historical figures, like the examples of historical reenactment on television the films invite viewers to formulate new perspectives on the past, here by recontextualizing prior representations. 
The reenactment of previous performances and representations, or the use of reenactment for a rethinking of media representations, is also found in contemporary art, whether as live performance or video installation. I have already mentioned how Jeremy Deller's The Battle of Orgreave (2001) seeks to correct a prior misrepresentation of the Orgreave miners' strike by retelling the events based on the memories and perspectives of the ex-miners. In Pierre Huyghe's The Third Memory (1999) John Wojtowicz, the subject of Sidney Lumet's Dog Day Afternoon (1975), directs and performs in a reenactment of the famous bank robbery as a critique of the Hollywood depiction. The artist Omer Fast has used reenactment in a number of multi-channel videos to explore the intersection between the production of images - both Hollywood and documentary - and the construction of memory. These are just a few contemporary artists who have taken up reenactment in recent years. The current interest in the practice is evident in several art exhibits that have concentrated on the use of reenactment as a distinct strategy, such as "Life, Once More: Forms of Reenactment in Contemporary Art" (2005) at the Witte de With, Rotterdam, "We Could Have Invited Everyone" (2004) at Reg Vardy Gallery, Sunderland, and "Not Quite How I Remember It" (2008) at the Power Plant Gallery, Toronto.

This cursory glance at reenactment in live performance, on television, in cinema, and in video and performance art, suggests a widespread interest in and application of reenactment across multiple cultural spheres. Although reenactment is here presented in divergent forms and modalities, taken together these works evince a shared impulse towards a reconsideration of the past. Whether as a strategy of critique, a pedagogical 
method, or an illustrative device, the uses of reenactment in this range of practices invites both participants and viewers to rework preconceptions and understandings of historical events or periods. As a single field, these works raise questions for further academic inquiry. While the distinct forms have their own specificity, what are the common threads or points of connection between the various instances of reenactment? Why is there such a preoccupation with the past now and what does this preoccupation tell us about the present? How does such work shape contemporary identities and knowledge? And what insight can the practice of reenactment provide into the production of memory, identity, or community? As reenactment grows in popularity among reenactors, television producers, filmmakers, artists, and audiences, the expanding field provides a rich and diverse area for interdisciplinary scholarly research that is only beginning to be investigated. With developing analyses in historiography, performance studies, theatre, and film, future research needs to take into account not only how reenactment takes place in various distinct spheres but also the way it creates points of contact between these cultural domains and blurs their boundaries. 


\section{FILMOGRAPHY}

24 Hour Party People. DVD. Directed by Michael Winterbottom. Manchester, UK:

Revolution Films, 2002.

9 Songs. DVD. Directed by Michael Winterbottom. London, UK: Revolution Films, 2004.

Air India 182. Broadcast. Directed by Sturla Gunnarsson. Vancouver, BC: 52 Media and Eurasia Motion Pictures, 2008.

Atanarjuat: The Fast Runner. DVD. Directed by Zacharias Kunuk. Igoolik, Nunavut: Igloolik Isuma Productions, 2001.

The Battle of Algiers. DVD. Directed by Gillo Pontecorvo. Algiers, Algeria: Igor Film and Casbah Film, 1966.

The Battle of Orgreave. DVD. Directed by Mike Figgis. Ogreave, South Yorkshire, UK: Artangel Media and Channel 4, 2001.

Bloody Sunday. DVD. Directed by Paul Greengrass. Dublin, Ireland: Granada Television, 2002.

Borinage (Misère au Borinage). DVD. Directed by Joris Ivens and Henri Storck. Borinage, Belgium, 1933.

Cathy Come Home. 16mm. Directed by Ken Loach. London, UK: BBC, 1966.

Che: Part One. DVD. Directed by Steven Soderbergh. Campeche, Mexico: Wild Bunch, 2008. 
Courage of the People (El Coraje del pueblo). VHS. Directed by Jorge Sanjinés. Siglo XX, Bolivia: Group Ukamau and Radiotelevisione Italiana, 1971.

Culloden. VHS. Directed by Peter Watkins. Culloden Moor, Scotland: BBC, 1964.

Far From Poland. VHS. Directed by Jill Godmilow. New York, NY: Film Forum, 1984.

Fires Were Started. DVD. Directed by Humphrey Jennings. London, UK: Crown Film Unit, 1943.

Frost/Nixon. DVD. Directed by Ron Howard. Los Angeles, CA: Universal Pictures, 2008.

Grey Gardens. DVD. Directed by Michael Sucsy. Toronto, ON: HBO Films, 2009.

The Great War. Broadcast. Directed by Brian McKenna. Montreal, QC: Galafilm Productions, 2007.

Hotel Rwanda. DVD. Directed by Terry George. Johannesburg, South Africa: United Artists, 2004.

In The Land of the War Canoes (originally In The Land of the Head Hunters). DVD.

Directed by Edward S. Curtis. Alert Bay, BC: Seattle Film Co., 1914.

In This World. DVD. Directed by Michael Winterbottom. Pakistan, Iran, Turkey, Italy,

France, England: Revolution Films, 2002.

$J F K$. Directed by Oliver Stone. Texas, Louisiana, and Virginia: Warner Borthers, 1991.

The Journals of Knud Rasmussen. DVD. Directed by Zackarias Kunuk. Igloolik,

Nunavut: Igloolik Isuma Productions, 2006.

La Commune (Paris, 1871). DVD. Directed by Peter Watkins. Paris, France: La SeptArte, 13 Productions, and Le Musée d'Orsay, 2000. 
Little Dieter Needs to Fly. DVD. Directed by Werner Herzog. California, US, Laos, .Thailand, and Germany: Werner Herzog Filmproduktion, ZDF, BBC, Arte, and Media Ventures, 1998.

Man of Aran. DVD. Directed by Robert Flaherty. Aran Islands, Ireland: Gainsborough Pictures, 1934.

Mysterious Object at Noon (Dokfa nai meuman). Directed by Apichatpong

Weerasethakul. Thailand: Hubert Bals Fund, 2000.

Nanook of the North. DVD. Directed by Robert Flaherty. Hudson Bay and Ungava

Peninsula, QC: Les Frères Revillon, 1922.

Nanook Revisited. VHS. Directed by Claude Massot, 1990.

Nunavut (Our Land). VHS. Directed by Zacharias Kunuk. Igloolik, Nunavut: Igloolik

Isuma Productions, 1995.

October (Ten Days that Shook the World). VHS. Directed by Sergei Eisenstein. Moscow, Russia: Sovkino, 1928.

Passage. DVD. Directed by John Walker. Canada, Scotland, and England: PTV Productions, 2008.

Platoon. Directed by Oliver Stone. Luzon, Phillipines: Hemdale Film, 1986.

Polytechnique. Directed by Denis Villeneuve. Montreal, QC: Remstar Media Partners, 2009.

Punishment Park. DVD. Directed by Peter Watkins. Mojave Desert, CA: Chartwell and Francoise Films, 1971. 
The Road to Guantanamo. DVD. Directed by Michael Winterbottom. Afghanistan, Pakistan, and Iran: Revolution Films, Film4, and Screen West Midlands, 2006. Shake Hands with the Devil. DVD. Directed by Roger Spottiswoode. Halifax, NS and Kigali, Rwanda: Barna-Alper Productions, Halifax Film Company, Seville Producitons, and Head Gear Films, 2007.

Shoah. DVD. Directed by Claude Lanzmann. Poland: Historia, Les Films Aleph, and Ministère de la Culture de la Republique Française, 1985.

The Silent Enemy. DVD. Directed by H.P. Carver. Temagami Forest Reserve, Ontario: Burden=Chanler Productions, 1930.

Sometimes in April. DVD. Directed by Raoul Peck. Kigali, Rwanda: HBO Films, 2005.

Sunday in Kigali. DVD. Directed by Robert Favreau. Kigali, Rwanda: Equinoxe Productions, 2006.

Ten. DVD. Directed by Abbas Kiarostami. Tehran, Iran: Abbas Kiarostami Productions, Key Lime Productions, and MK2 Productions, 2002.

The Thin Blue Line. DVD. Directed by Errol Morris. Third Floor Productions and Channel 4, 1988.

Tristram Shandy: A Cock and Bull Story. DVD. Directed by Michael Winterbottom.

England, UK: Revolution Films, BBC Films, and East Midlands Media, 2005.

Touching the Void. DVD. Directed by Kevin Macdonald. France, Switzerland, and Peru: FilmFour, UK Film Coucil, and Darlow Smithson Productions, 2003. 
United 93. DVD. Directed by Paul Greengrass. Boston, Mass., New Jersey, England, UK, and Morocco: Universal Pictures, SKE, Working Title Films, and Studio Canal, 2006.

The Wannsee Conference: Hitler's Final Solution (Die Wannseekonferenz). VHS.

Directed by Heinz Schirk. Berlin, Germany: Bavarian Broadcasting Corporation, Infafilm $\mathrm{GmbH}$, and ORF, 1984.

The War Game. DVD. Directed by Peter Watkins. Canterbury, Kent, England, UK: BBC, 1965. 


\section{BIBLIOGRAPHY}

Agnew, Vanessa. "History's Affective Turn: Historical Reenactment and Its Work in the Present." Rethinking History 11, no. 3 (2007): 299-312.

---. "Introduction: What is Reenactment?" Criticism 46, no. 3 (2004): 327-39.

Allred, Randal. "Catharsis, Revision, and Re-Enactment: Negotiating the Meaning of the American Civil War." Journal of American Culture 19, no. 4 (1996): 1-13.

Almereyda, Michael. "In This World: To be and to Have." Film Comment 39, no. 5 (2003): 73 .

Anonymous. "Dallaire haunted: Standing ovation for commander." Daily Gleaner, April 132000 , n.p.

Appadurai, Arjun. Modernity At Large: Cultural Dimensions of Globalization.

Minneapolis and London: University of Minnesota Press, 1996.

Arthur, Paul. "La Commune (Paris 1871)." Film Comment 39, no.4 (2003): 72-73.

--. "Jargons of Authenticity (Three American Moments)." In Theorizing Documentary, edited by Michael Renov, 108-34. New York: Routledge, 1993.

Barsam, Richard Meran. Nonfiction Film: A Critical History. Bloomington: Indiana University Press, 1992.

Beech, Dave. "'The Reign of the Workers and Peasants Will Never End': Politics and Politicisation, Art and the Politics of Political Art.” Third Text 16, no. 4 (2002): $387-98$.

Bentley, Tom. "Please, not again!" Open Democracy. February 11, 2005. Accessed 
March 25, 2011.

http://www.opendemocracy.net/globalization-vision_reflections/article_2339.jsp.

Blackson, Robert. “Once More. With Feeling: Reenactment in Contemporary Art and

Culture." Art Journal 66, no. 1 (2007): 28-40.

Blaney, Aileen. "Remembering Historical Trauma in Paul Greengrass's Bloody Sunday."

History \& Memory 19, no. 2 (2007): 113-38.

Blocker, Jane. "A Cemetery of Images: Meditations on the Burial of Photographs."

Visual Resources 21, no. 2 (2005): 181-91.

Breed, Amanda. "Performing Reconciliation in Rwanda." Peace Review: A Journal of

Social Justice 18, no. 4 (2006): 507-14.

British Broadcasting Corporation. "Short History of Immigration." $B B C$ News. Accessed March 25, 2011.

http://news.bbc.co.uk/hi/english/static/in_depth/uk/2002/race/short_history_of_imm igration.stm.

Burton, Julianne. "The Camera as Gun: Two Decades of Culture and Resistance in Latin America." Latin American Perspectives 5, no. 1 (1978): 49-76.

Caruth, Cathy. "Introduction." In Trauma: Explorations in Memory, edited by Cathy Caruth, 3-12. Baltimore and London: The Johns Hopkins University Press, 1995.

Cash, John. "The Usable Past Reconsidered: An Ethnography of Civil War Reenactors." In Times, Places, Passages: Ethnological Approaches in the New Millenium, edited by Attila Paladi-Kovacs, Gyorgyi H Csukas, and Akademiai Kiado, 246-57. Budapest, Hungary: International Society for Ethnology and Folklore, 2001. 
Caughie, John. "Progressive Television and Documentary Drama." Screen 21, no. 3 (1980): 9-35.

Chapman, James. "The BBC and the Censorship of the War Game (1965)." Journal of Contemporary History 41, no. 1 (2006): 75-94.

Clifford, James. The Predicament of Culture: Twentieth-Century Ethnography, Literature, and Art. Cambridge, Massachusetts and London: Harvard University Press, 1988.

---. "Four Northwest Coast Museums: Travel Reflections." In Exhibiting Cultures: The Poetics and Politics of Museum Display, edited by Ivan Karp, and Steven D.

Lavine, 221-54. Washington and London: Smithsonian Institution Press, 1991. ---. Routes: Travel and Translation in the Late Twentieth Century. Cambridge, Massachusetts and London: Harvard University Press, 1997.

---. "Looking Several Ways: Anthropology and Native Heritage in Alaska." Current Anthropology 45, no. 1 (2004): 5-30.

Cohn, Norman. “The Art of Community-Based Filmmaking.” In Atanarjuat the Fast Runner, 25-27. Toronto: Coach House Books and Isuma Publishing, 2002.

Comolli, Jean-Louis. In Realism and the Cinema: A Reader, edited by Christopher Williams, London and: Routledge and Kegan Paul, 1980.

Cook, Alexander. "Sailing on The Ship: Re-Enactment and the Quest for Popular History." History Workshop Journal 57 (2004): 247-55.

Correia, Alice. "Interpreting Jeremy Deller's The Battle of Ogreave." Visual Culture in Britain 7, no. 2 (2006): 93-112. 
Cousineau, Marie-Hélène, and McGough, Laura. Nunavut: A Dialogue in Locality, Television and Media Art. http://atanarjuat.com/media...centre/presskit.htm (accessed 2002, June 14).

Cull, Nicholas. "Peter Watkins' Culloden and the alternative form in historical filmmaking." Film International 1 (2003): 48-53.

Cunningham, Stuart. “Tense, Address, Tendenz: Questions of the Work of Peter Watkins." Quarterly Review of Film Studies 5, no. 4 (1980): 501-18.

Dapena, Gerard. "The politics of popular memory: Jorge Sanjinés' The Courage of the People." CiberLetras 13 (2005): n.p. Accessed June 15, 2010. http://www.lehman.edu/ciberletras/v13/dapena.htm.

Darke, Chris. "The Underside of Globalization: On Michael Winterbottom's in This World." Open Democracy, April 2, 2003. Accessed December 1, 2008. http://www.opendemocracy.net/arts-Film/article_1120.jsp.

Derrida, Jacques. Archive Fever: A Freudian Impression. Chicago and London: The University of Chicago Press, 1996.

Evans, Michael Robert. "Frozen light and fluid time: The folklore, politics, and performance of Inuit Video.” PhD diss., Indiana University, 1999.

---. Isuma: Inuit Video Art. Montreal and Kingston, London and Ithaca: McGill-Queen's University Press, 2008.

Farquharson, Vanessa. "Identifying with an endless landscape." The National Post, September 292006,6 .

Felperin, Leslie. “The Journals of Knud Rasmussen." Variety, September $102006,73$. 
Fielding, Raymond. The American Newsreel: A Complete History, 1911-1967. 2nd ed. Jefferson, North Carolina, and London: McFarland \& Company, Inc, 2006.

Filewood, Alan. "People's Theatre, People's Army: Masculinism, Agitprop, Reenactment." XCP: Cross-cultural Poetics 13, no. 7 (2003): 7-20.

Friedman, Lester. "The Necessity of Confrontation Cinema - Peter Watkins Interviewed." Literature Film Quarterly 11, no. 4 (1983): 237-48.

Gilmor, Alison. "The Devil is in the confusing details." Winnipeg Free Press, September 282007,1 .

Ginsburg, Faye. "Atanarjuat Off-Screen: From 'Media Reservations' to the World Stage." American Anthropologist 105, no. 4 (2003): 827-31.

--. "The Parallax Effect: The Impact of Indigenous Media on Ethnographic Film." In Collecting Visible Evidence, edited by Jane M. Gaines, and Michael Renov, 156-75. Minneapolis and London: University of Minnesota Press, 1999.

---. "Screen Memories: Resignifying the Traditional in Indigenous Media." In Media Worlds: Anthropology on New Terrain, edited by Faye Ginsburg, Lila Abu-Lughod, and Brian Larkin, 39-57. Berkeley, Los Angeles, and London: University of California Press, 2002.

Gomez, Joseph A. Peter Watkins. Boston: Twayne Publishers, 1979.

Gomez, Joseph A, and Welsh, James M. "Micro-Study 2: Peter Watkins, the Gulf War, and the Media Project (1991)." Film \& History 22, no. 1-2 (1992): 41-46.

Gourevitch, Philip. We Wish to Inform You That Tomorrow We Will be Killed With Our Families: Stories From Rwanda. New York: Farrar Straus and Giroux, 1998. 
---. “Among the Dead." In Disturbing Remains: Memory, History, and Crisis in the Twentieth Century, edited by Michael S. Roth, and Charles G. Salas, 63-73. Los Angeles: Getty Research Institute, 2001.

---. "The Life After: A startling exercise in reconciliation." New Yorker, May 4 2009, 3649.

Greeman, Richard. "The Permanence of the Commune." The Massachusetts Review 12, no. 3 (1971): 388-96.

Griffiths, Alison. 'Shivers down your spine': panoramas and the origins of the cinematic reenactment." Screen 44, no. 1 (2003): 1-37.

Grisoni, Tony. "Journey Into Flight.” The Guardian, March 16, 2-003. Accessed October $11,2010$.

http://www.guardian.co.uk/film/2003/mar/16/berlinfilmfestival2003.festivals.

--.. "In This World." Vertigo 2, no. 4 (2003): 6-7.

Guerin, Frances, and Roger Hallas. "Introduction." In The Image and the Witness:

Trauma, Memory and Visual Culture, edited by Frances Guerin, and Roger Hallas, 1-20. London and New York: Wallflower Press, 2007.

Gunderson, Sonia. "Zacharias Kunuk: Giving Inuit a Voice." Inuit Art Quarterly 21, no. 1 (2006): 12-20.

Hall, Dennis. "Civil War Reenactors and the Postmodern Sense of History." Journal of American Culture 17, no. 3 (1994): 7-11.

Handler, Richard. "Overpowered By Realism: Living History and the Simulation of the Past." The Journal of American Folklore 100 (397), no. 397 (1987): 337-41. 
Handler, Richard, and Eric Gable. The New History in an Old Museum: Creating the Past At Colonial Williamsburg. Durham and London: Duke University Press, 1997.

Hansen, Miriam. Babel \& Babylon: Spectatorship in American Silent Film. Cambridge, Mass. and London: Harvard University Press, 1991.

Hark, Ina Rae. “One Eyewitnessing History: The Compromised Spectator in Peter Watkins's Culloden." The South Atlantic Quarterly 84 (1985): 294-301.

Harrow, Kenneth W. "'Un train peut en cacher un autre': Narrating the Rwandan Genocide and Hotel Rwanda." Research in African Literatures 36, no. 4 (2005): 223-32.

Hearne, Joanna. "Telling and Retelling in the 'Ink of Light': Documentary Cinema, Oral Narratives, and Indigenous Identities.” Screen 47, no. 3 (2006): 307-26.

Heath, Tina, Jeffries, Richard, and Purcell, James. “Asylum Statistics: United Kingdom 2003." Home Office Bulletin. August 24, 2004. Accessed March 25, 2011. http://rds.homeoffice.gov.uk/rds/pdfs04/hosb1 104.pdf.

Hirsch, Joshua. Afterimage: Film, Trauma, and the Holocaust. Philadelphia: Temple University Press, 2004.

Huhndorf, Shari. "Atanarjuat, The Fast Runner: Culture, History, and Politics in Inuit Media." American Anthropologist 105, no. 4 (2003): 822-26.

Ivens, Joris. "Repeated and Organized Scenes in Documentary Films." In Joris Ivens and the Documentary Context, edited by Kees Bakker, 261-72. Amsterdam: Amsterdam University Press, 1999.

James, Caryn. "How to Improvise in Afghanistan? Don't Ask." The New York Times, 
September $212003,13,30$.

Jameson, Fredric. Signatures of the Visible. Routledge, 1.992.

Jones, Kent. "I Walk the Line." Film Comment 41, no. 1 (2005): 30-33.

Kahana, Jonathan. "Introduction: What Now? Presenting Reenactment." Framework 50, no. $1 \& 2$ (2009): 46-60.

Kalisa, Chantal. "Theatre and the Rwandan Genocide." Peace Review: A Journal of Social Justice 18, no. 4 (2006): 515-21.

Kaplan, E. Ann. Trauma Culture: The Politics of Terror and Loss in Media and Literature. New Brunswick, New Jersey, and London: Rutgers University Press, 2005.

Keel, Erich. "From Militant Cinema to Neo-Realism: The Example of Pueblo Chico." Film Quarterly 29, no. 4 (1976): 17-24.

Keuhl, Jerry. "Lies About Real People." In Why Docudrama? Fact-Fiction on Film and Television, edited by Alan Rosenthal, 119-24. Carbondale and Edwardsville: Southern Illinois University Press, 1999.

Kilborn, Richard. “'Drama Over Lockerbie': A New Look At Television DramaDocumentaries." Historical Journal of Film, Radio and Television 14, no. 1 (1994): $59-77$.

Kunuk, Zacharias. "I first heard the story of Atanarjuat from my mother." In Atanarjuat The Fast Runner, 12-15. Toronto: Coach House Books and Isuma Publishing, 2002. ---. "The Public Art of Inuit Storytelling." The 2002 Spry Memorial Lecture, November 25, 2002. Accessed January 30, 2011. http://www.com.umontreal.ca/spry/old/spry- 
kz-lec.html.

LaCapra, Dominick. Writing History, Writing Trauma. Baltimore: Johns Hopkins University Press, 2001.

Lajtha, Terry. "Brechtian Devices in Non-Brechtian Cinema: Culloden." Literature Film Quarterly 9, no. 1 (1981): 9-14.

Laub, Dori. "An Event Without a Witness." In Testimony: Crises of Witnessing in Literature, Psychoanalysis, and History, edited by Shoshana Felman, and Dori Laub, 75-92. New York and London: Routledge, 1992.

---. "Bearing Witness Or the Vicissitudes of Listening." In Testimony: Crises of Witnessing in Literature, Psychoanalysis, and History, edited by Shoshana Felman, and Dori Laub, 57-74. New York and London: Routledge, 1992.

Levy, David. "Re-Constituted Newsreels, Re-Enactments and the American Narrative Film." In Cinema 1900/1906: An Analytical Study, edited by Roger Holman, 24360. Brussels: Féderation Internationale des Archives du Film, 1982.

Lindvall, Daniel. "In This World." Film International 5, no. 5 (2003): 64-65.

Lipkin, Steven N. Real Emotional Logic: Film and Television Docudrama as Persuasive Practice. Carbondale and Edwardsville: Southern Illinois University Press, 2002.

Lipkin, Steven N., Derek Paget, and Jane Roscoe. "Docudrama and Mock-Documentary: Defining Terms, Proposing Canons." In Docufictions: Essays on the Intersection of Documentary and Fictional Filmmaking, edited by Gary D Rhodes, and John Parris Springer, 11-26. Jefferson, North Carolina, and London: McFarland \& Company, Inc, 2005. 
Lütticken, Sven. “An Arena in Which to Reenact.” In Life, Once More: Forms of Reenactment in Contemporary Art, edited by Sven Lütticken, 17-60. Rotterdam: Witte de With, Centre for Contemporary Art, 2005.

MacDonald, Scott. "Filmmaker as Global Circumnavigator: Peter Watkins's the Journey and Media Critique." Quarterly Review of Film and Video 14, no. 4 (1993): 31-54.

MacDougall, David. Transcultural Cinema. Edited by Lucien Taylor. Princeton, N.J.: Princeton University Press, 1988.

Magelssen, Scott. "Living History Museums and the Construction of the Real Through Performance." Theatre Survey 45, no. 1 (2004): 61-74.

Mann, Nyta. "Blair's asylum gamble.” BBC News, February 7, 2003. Accessed March 25, 2011. http://newswww.bbc.net.uk/2/hi/uk_news/politics/2738065.stm.

Manoff, Marlene. "Theories of the Archive From Across the Disciplines." portal: Libraries and the Academy 4, no. 1 (2004): 9-25.

Marcus, George, and James Clifford, (eds.) Writing Culture: The Poetics and Politics of Ethnography. Berkeley, Los Angeles and London: University of California Press, 1986.

Margulies, Ivone. “Bodies Too Much.” In Rites of Realism: Essays on Corporeal Cinema, edited by Ivone Margulies, 1-23. Durham: Duke University Press, 2003.

---. "Exemplary Bodies: Reenactment in Love in the City, Sons, and Close-Up." In Rites of Realism: Essays on Corporeal Cinema, edited by Ivone Margulies, 217-44. Durham: Duke University Press, 2003.

Marks, Laura U. "Inuit Auteurs and Arctic Airwaves: Questions of Southern Reception.” 
Fuse 21, no. 4 (1998): 13-17.

McFarlane, Brian, and Deane Williams. Michael Winterbottom. Manchester, UK and New York: Manchester University Press, 2009.

Meadows, Michael. "Ideas From the Bush: Indigenous Television in Australia and Canada." Canadian Journal of Communication 20 (1995): 197-212.

Mirzoeff, Nicholas. "Invisible Again: Rwanda and Representation After Genocide." African Arts 38, no. 3 (2005): 36-9, 86-91, 96.

Murphy, Patrick. "The War Game - The Controversy." Film International 3, no. 3 (2003): $25-28$.

Musser, Charles. "The Early Cinema of Edwin Porter." In Cinema 1900/1906: An Analytical Study, edited by Roger Holman, 261-80. Brussels: Féderation Internationale des Archives du Film, 1982.

---. Before the Nickelodeon: Edwin S. Porter and the Edison Manufacturing Company. Berkeley: University of California Press, 1991.

Nichols, Bill. Representing Reality: Issues and Concepts in Documentary. Bloomington: Indiana University Press, 1991.

---. "Documentary Reenactment and the Fantasmatic Subject." Critical Inquiry 35 (2008): 72-89.

---. Representing Reality: Issues and Concepts in Documentary. Bloomington: Indiana University Press, 1991.

Paget, Derek. True Stories? Documentary drama on radio, screen, and stage. Manchester and New York: Manchester University Press, 1990. 
---. "Tales of Cultural Tourism." In Why Docudrama? Fact-Fiction on Film and Tv, edited by Alan Rosenthal, 47-63. Carbondale and Edwardsville: Southern Illinois University Press, 1999.

Panchasi, Roxanne. "If the Revolution Had Been Televised: The Productive Anachronisms of Peter Watkins's La Commune (Paris 1871)." Rethinking History 10 , no. $4(2006): 553-71$.

Pape, Eric. 2006. Helping Rwanda to Weep. http://www.newsweek.com/2006/04/13/helping-rwanda-to-weep.html (accessed July 16, 2010).

Petley, Julian. "Fact Plus Ficiton Equals Friction." Media, Culture, and Society 18, no. 11 (1996): 11-25.

Pratt, Mary Louise. Imperial Eyes: Travel Writing and Transculturation. London and New York: Routledge, 1992.

Prime, Rebecca. "Stranger Than Fiction: Genre and Hybridity in the 'Refugee Film'." Post Script 25, no. 2 (2006): 56-66.

Ranck, Jody. "Beyond Reconciliation: Memory and Alterity in Post-Genocide Rwanda." In Beyond Hope \& Despair: Pedagogy and Remembrance of Historical Trauma, edited by Roger I Simon, Sharon Rosenberg, and Claudia Eppert, 187-211. Lanham, Boulder, New York and Oxford: Rowman \& Littlefield Publishers, Inc, 2000.

Rapfogel, Jared. "Cautionary Tales and Alternate Histories: The Films of Peter Watkins." Cineaste 32, no. 2 (2007): 20-25. 
Razack, Sherene. "Stealing the Pain of Others: Reflections on Canadian Humanitarian Responses." The Review of Education, Pedagogy, and Cultural Studies 29 (2007): 375-94.

Rhodes, Gary D., and John Parris Springer, (eds.) Docufictions: Essays on the Intersection of Documentary and Fictional Filmmaking. Jefferson, North Carolina and London: McFarland \& Company, Inc, 2006.

Romney, Jonathan. "The Making of the Unmaking of the Adaptation of the Life and Opinions of Tristram Shandy." Film Comment 42, no. 1 (2006): 32-37.

Rony, Fatimah Tobing. The Third Eye: Race, Cinema, and Ethnographic Spectacle. Durham and London: Duke University Press, 1996.

Rosenthal, Alan. "The War Game: An Interview With Peter Watkins." In New Challenges for Documentary, edited by Alan Rosenthal, and John Corner, 110-20. Manchester and New York: Manchester University Press, 2005.

Ruby, Jay. Picturing Culture: Explorations of Film and Anthropology. Chicago: Chicago University Press, 2000.

---. "Film Reviews." American Anthropologist 96, no. 1 (1994): 221-22.

---. “The Ethics of Image Making: or, 'They're Going to Put Me in the Movies. They're Going to Make a Big Star Out of Me...’” In New Challenges for Documentary, edited by Alan Rosenthal, and John Corner, 209-19. Manchester and New York: Manchester University Press, 2005.

Ruby, Jay, Larry Gross, and John Stuart Katz. "Introduction: A Moral Pause.” In Image Ethics: The Moral Rights of Subjects in Photographs, Film, and Television, edited 
by Jay Ruby, Larry Gross, and John Stuart Katz, 3-33. New York: Oxford University Press, 1988.

Said, S.F. "Everyday White." Sight and Sound 16, no. 9 (2006): 36-39.

---. Igloolik’s Embedded Journalist Blog. http://www.sila.nu/live/page?atom_id=sfsaidblog

Sanjinés, Jorge. "Revolutionary Cinema: The Bolivian Experience." In Cinema and Social Change in Latin America: Conversations With Filmmakers, edited by Julianne Burton, Austin: University of Texas Press, 1986.

Saxton, Libby. Haunted Images: Film, Ethics, Testimony and the Holocaust. London and New York: Wallflower Press, 2008.

Schechner, Richard. Between Theatre and Anthropology. Philadelphia: University of Pennsylvania Press, 1985.

---. Performance Studies: An Introduction. New York: Routledge, 2006.

Schneider, Rebecca. "Performance Remains." Performance Research 6, no. 2 (2001): 100-08.

Schneller, Johanna. "Making the movies Hollywood doesn't want." The Globe and Mail, June $72008,3$.

Schwartzberg, Shlomo. “The Journals of Knud Rasmussen.” Boxoffice, January 2007, 95. Schwarz, Anja. "'Not This Year!' Reenacting Contested Pasts Aboard The Ship." Rethinking History 11, no. 3 (2007): 427-46.

Seguin, Denis. 2005. Hollywood Far Far North. http://www.canadianbusiness.com/after_hours/opinions/article.jsp?content=200508 
29 70181_70181 (accessed January 31, 2011).

Shaw, Tony. "The BBC, the State and Cold War Culture: The Case of Television's 'the War Game' (1965).” The English Historical Review 121 (2006): 1351-84.

Simon, Roger I, Sharon Rosenberg, and Claudia Eppert. "The Pedagogical Encounter of Historical Remembrance." In Between Hope \& Despair: Pedagogy and the Remembrance of Historical Trauma, edited by Roger I Simon, Sharon Rosenberg, and Claudia Eppert, 1-8. Lanham, Boulder, New York and Oxford: Rowman \& Littlefield Publishers, Inc, 2000.

Sobchack, Vivian. "Inscribing Ethical Space: Ten Propositions on Death, Representation, and Documentary." Quarterly Review of Film Studies 9 (1984): 282-300.

Springer, John Parris. "The Newspaper Meets the Dime Novel: Docudrama in Early Cinema." In Docufictions: Essays on the Intersection of Documentary and Fictional Filmmaking, edited by Gary D Rhodes, and John Parris Springer, 27-42. Jefferson, North Carolina, and London: McFarland \& Company, Inc, 2005.

Steedman, Carolyn. Dust: The Archive and Cultural History. New Brunswick, New Jersey: Rutgers University Press, 2002.

Stoler, Ann Laura. "Colonial Archives and the Arts of Governance." Archival Science 2 (2002): 87-109.

Stone, Jay. "New Look At Rwandan Horror." The Ottawa Citizen, September 28 2007, 1. Sturken, Marita. "Reenactment, Fantasy, and the Paranoia of History: Oliver Stone's Docudramas." History and Theory 36, no. 4 (1997): 64-79.

---. "Personal Stories and National Meanings: Memory, Reenactment, and the Image." In 
The Seductions of Biography, edited by Mary Rhiel, and David Suchoff, 31-41. New York and London: Routledge, 1996.

---. Tangled Memories: The Vietnam War, the AIDS Epidemic, and the Politics of Remembering. Berkeley: University of California Press, 1997.

Taddeo, Julie, and Dvorak, Ken. "The PBS Historical House Series: Where Historical Reality Succumbs to Reel Reality." Film \& History 37, no. 1 (2007): 18-28.

Taylor, Diana. The Archive and the Repertoire: Performing Cultural Memory in the Americas. Duke University Press, 2003.

Toulmin, Vanessa. “An Early Crime Film Rediscovered: Mitchell and Kenyon's Arrest of Goudie (1901)." Film History 16, no. 1 (2004): 37-53.

Turim, Maureen. "The trauma of history: flashbacks upon flashbacks." Screen 42, no. 2 (2001): 205-10.

Turner, Victor. The Anthropology of Performance. New York: PAJ, 1986.

Uncredited. "Little boy lost." The Guardian. February 28, 2003. Accessed October 12, 2010. http:/www.guardian.co.uk/culture/2003/feb/28/artsfeatures.immigration. Valaskakis, Gail. “Communication, Culture, and Technology: Satellites and Northern Native Broadcasting in Canada." In Ethnic Minority Media: An International Perspective, edited by Harold Riggins, 63-81. Newbury Park: Sage, 1992. Vlessing, Etan. "The devil and Mr. Dupuis." The Globe and Mail, August 52006. Ward, Paul. "The Future of Documentary? 'Conditional Tense' Documentary and the Historical Record." In Docufictions: Essays on the Intersection of Documentary and Fictional Filmmaking, edited by Gary D Rhodes, and John Parris Springer, 270-82. 
Jefferson, North Carolina, and London: McFarland \& Company, Inc, 2006.

Wayne, Michael. "The Tragedy of History: Peter Watkins's La Commune." Third Text 16, no. 1 (2002): 57-69.

Welsh, James M, and Kramer, Steven Philip. "Film and History Interview - Peter Watkins: Therapeutic Cinema and the Repressive Mind." Film \& History 7, no. 2 (1977): 6-13, 34-42.

Whissel, Kristen. "Placing the Spectator on the Scene of History: The Battle ReEnactment At the Turn of the Century, From Buffalo Bill's Wild West to the Early Cinema." Historical Journal of Film, Radio and Television 22, no. 3 (2002): 22541.

White, Hayden. "The Value of Narrativity in the Representation of Reality." In On Narrative, edited by W.J.T. Mitchell, 1-23. Chicago: University of Chicago Press, 1981.

---. "The modernist event." In The Persistence of History: Cinema, Television and the Modern Event, edited by Vivian Sobchack, 17-38. New York and London: Routledge, 1996.

Williams, Linda. "Mirrors Without Memories: Truth, History, and the New Documentary." Film Quarterly 26, no. 3 (1993): 9-21.

---. "The Ethics of Intervention: Dennis O'rourke's the Good Woman of Bangkok." In Collecting Visible Evidence, edited by Jane M. Gaines, and Michael Renov, 176-89. Minneapolis and London: University of Minnesota Press, 1999.

Williams, Melanie. "9 Songs.” Film Quarterly 59, no. 3 (2006): 59-63. 
Winston, Brian. "'Honest Straightforward Re-Enactment': The Staging of Reality." In Joris Ivens and the Documentary Context, edited by Kees Bakker, 161-70. Amsterdam: Amsterdam University Press, 1999.

---. Lies, Damn Lies and Documentaries. London: bfi Publishing, 2000.

Wood, Frances. The Silk Road: Two Thousand Years in the Heart of Asia. Berkeley: University of California Press, 2002.

Young, Neil. "Dream Factory: 24 Hour Party People." Critical Quarterly 44, no. 3 (2002): 80-87. 